\title{
INFLUÊNCIA DO BALANÇO CÁTION-ANIONICO DA DIETA NO DESEMPENHO DE OVINOS.
}

\section{Gustavo Ribeiro Del Claro}

Dissertação de Mestrado depositada na Seção de Pós-Graduação da Faculdade de Zootecnia e Engenharia de Alimentos da USP , como parte dos requisitos para a obtenção do Título de Mestre em Zootecnia, na área de Concentração: Qualidade e Produtividade Animal.

Orientador: Prof Dr. Marcus Antonio Zanetti 


\section{FICHA CATALOGRÁFICA}

preparada pela

Biblioteca da Faculdade de Zootecnia e Engenharia de Alimentos da Universidade de São Paulo

\section{Del Claro, Gustavo Ribeiro.}

D331i Influência do balanço cátion-aniônico da dieta no desempenho de ovinos / Gustavo Ribeiro Del Claro - Pirassununga, 2003.

$83 \mathrm{p}$.

Dissertação (Mestrado) -- Faculdade de Zootecnia e

Engenharia de Alimentos - Universidade de São Paulo, 2003.

Departamento de Zootecnia.

Área de concentração: Qualidade e Produtividade animal.

Orientador: Prof. Dr. Marcus Antonio Zanetti.

Unitermos: 1. Ovinos, minerais 2. Nutrição animal

3. Ruminantes I. Título. 


\section{SUMARIO}

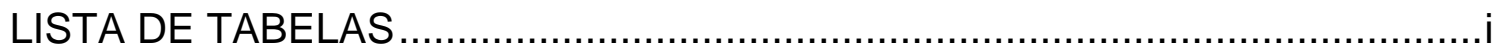

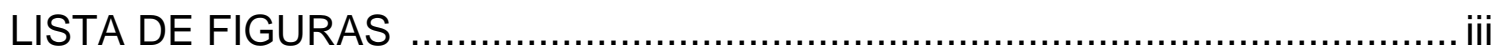

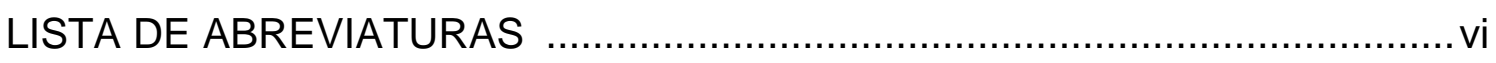

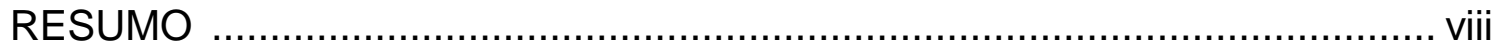

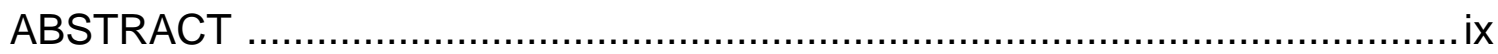

1. INTRODUÇÃO

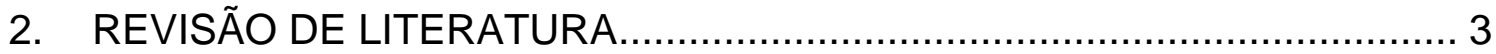

2.1 Balanço cátion-ânion dietético (BCAD) .............................................. 3

2.2 Efeitos do BCAD no equilíbrio ácido-base......................................... 6

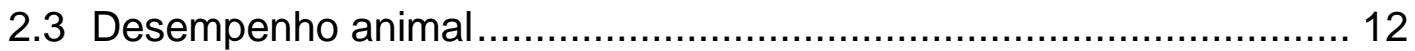

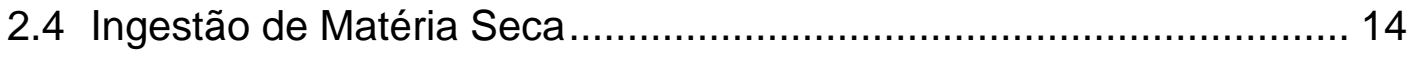

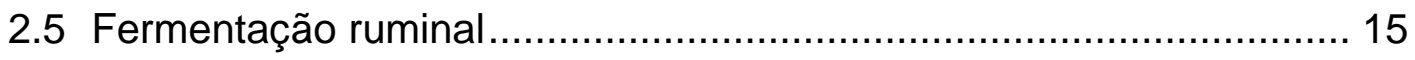

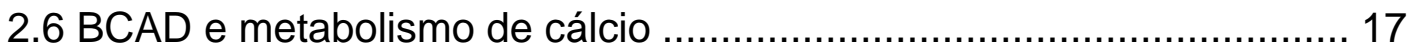

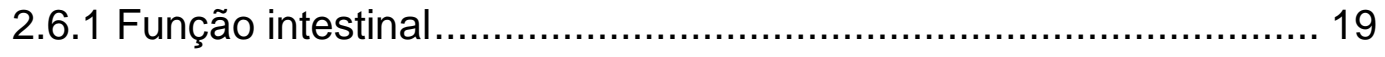

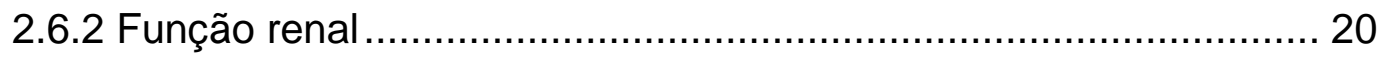

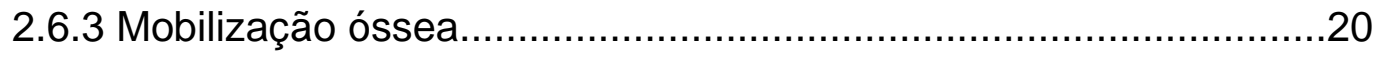

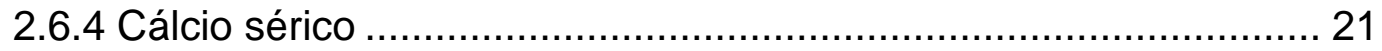

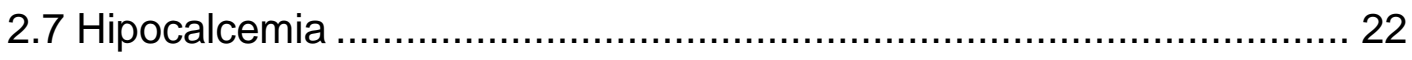

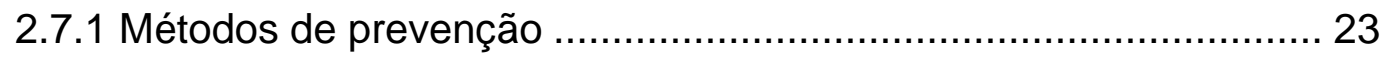

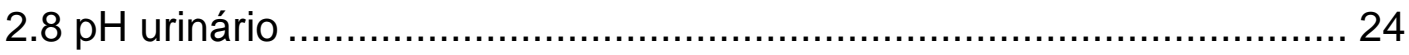

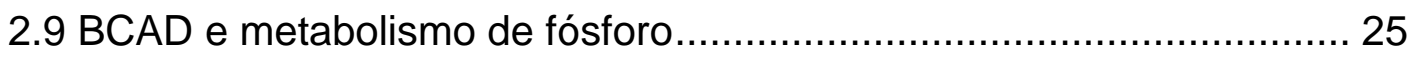

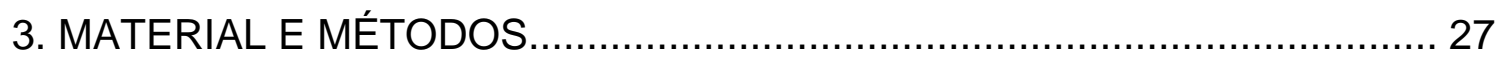

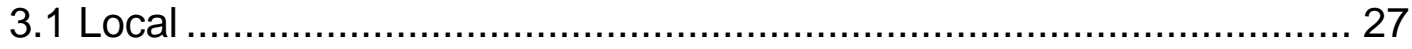

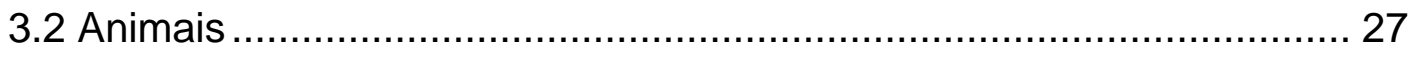

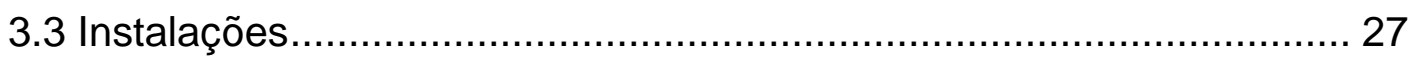

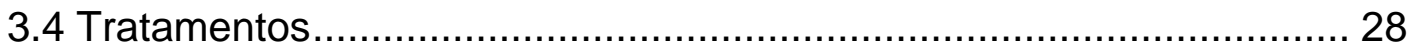

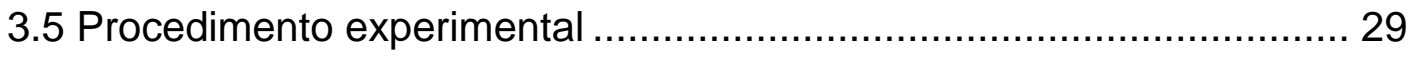

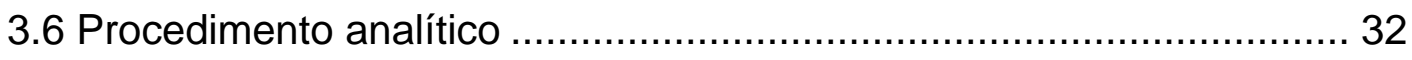




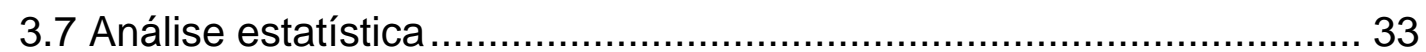

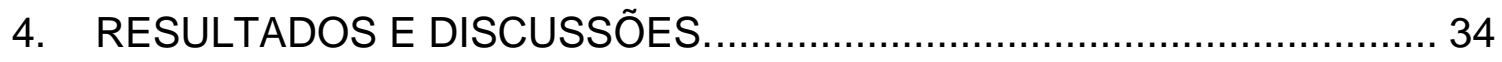

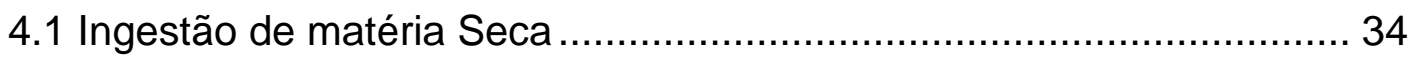

4.2 Ganho de peso e eficiência alimentar ............................................. 39

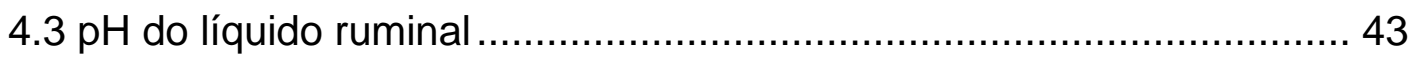

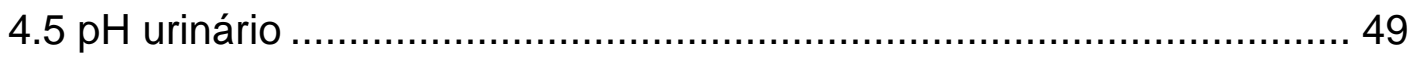

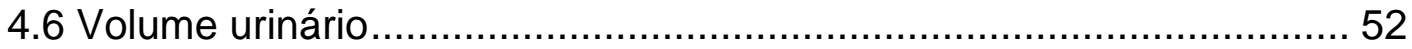

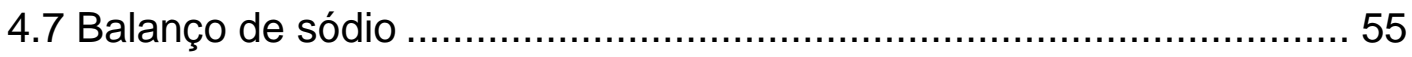

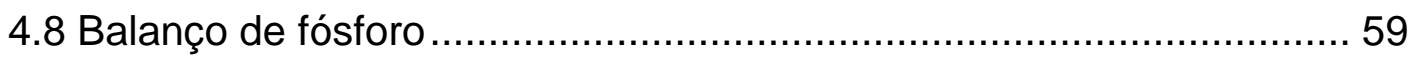

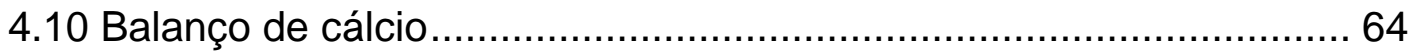

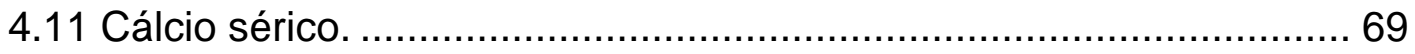

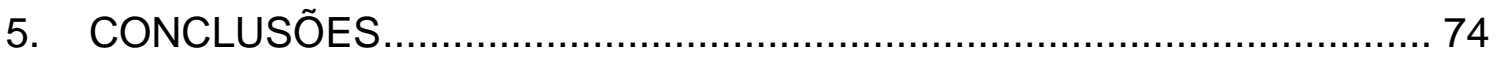

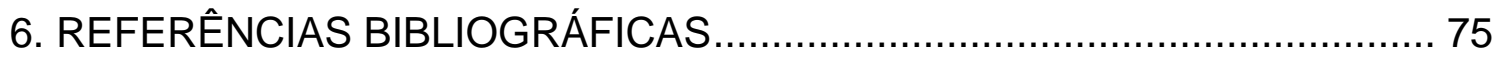




\section{LISTA DE TABELAS.}

TABELA 01. Composição percentual dos ingredientes das dietas em base seca

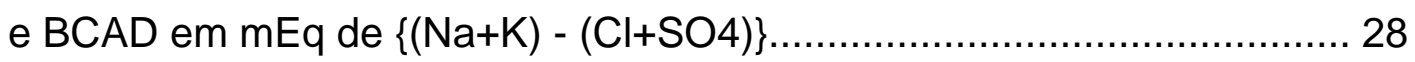

TABELA 02. Composição químico-bromatológica e percentual dos minerais nas dietas experimentais com base na matéria seca e BCAD em mEq de $\{(\mathrm{Na}+\mathrm{K})-(\mathrm{Cl}+\mathrm{SO} 4)\}$.

TABELA 03. Níveis médios de Ingestão de matéria seca em g kg -0,75 em ovinos alimentados com diferentes níveis de BCAD em mEq/kg de MS... 34

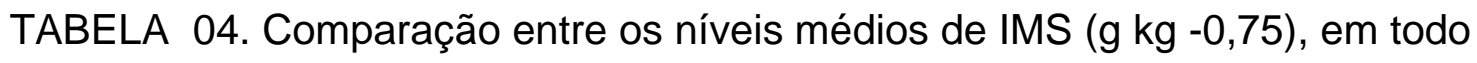
o período experimental, em ovinos alimentados com diferentes níveis de BCAD.

TABELA 05. Valores médios da digestibilidade de matéria seca(\%), ganho de peso diário em kg por dia e eficiência alimentar (ganho/peso), em ovinos alimentados com diferentes níveis de BCAD.

TABELA 06.Valores médios de $\mathrm{pH}$ do líquido ruminal no $30^{\circ}$ e $60^{\circ}$ dia de experimento em ovinos alimentados com diferentes níveis de BCAD

TABELA 07. Concentrações médias de ácidos graxos voláteis em mmol/dL e em percentual do total no $30^{\circ}$ dia, em ovinos alimentados com diferentes níveis de BCAD. 
TABELA 08 Concentrações médias de ácidos graxos voláteis em mmol/dL e em percentual do total no $60^{\circ}$ dia em ovinos alimentados com diferentes níveis de BCAD.

TABELA 09 Níveis médios de pH urinário no $25^{\circ}$ ao $30^{\circ}$ dia e do $55^{\circ}$ ao $60^{\circ}$ dia de experimento em ovinos alimentados com diferentes níveis de BCAD. . 49

TABELA 10. Valores médios de volume de urina em litros por um período de 24 horas em ovinos alimentados com diferentes níveis de BCAD 52

TABELA 11. Comparação entre a média de urina excretada (L/dia), em ovinos alimentados com diferentes níveis de BCAD.

TABELA 12. Balanço de sódio entre o $25^{\circ}-30^{\circ}$ dia de experimento em ovinos, alimentados com diferentes níveis de BCAD......................................... 55

TABELA 13. Balanço de sódio entre o $55^{\circ}-60^{\circ}$ dia de experimento em ovinos, alimentados com diferentes níveis de BCAD........................................ 56

TABELA 14. Balanço de fósforo entre o $25^{\circ}-30^{\circ}$ dia de experimento em ovinos alimentados com diferentes níveis de BCAD........................................59

TABELA 15. Balanço de fósforo entre o $55^{\circ}-60^{\circ}$ dia de experimento em ovinos, alimentados com diferentes níveis de BCAD.........................................6 60

TABELA 16. Balanço de cálcio entre o $25^{\circ}-30^{\circ}$ dia de experimento em ovinos, alimentados com diferentes níveis de BCAD......................................... 64

TABELA 17. Balanço de cálcio entre o $55^{\circ}-60^{\circ}$ dia de experimento em ovinos, alimentados com diferentes níveis de BCAD. 
TABELA 18. Níveis de cálcio total e ionizado $(\mathrm{mg} / \mathrm{dL})$ em ovinos alimentados

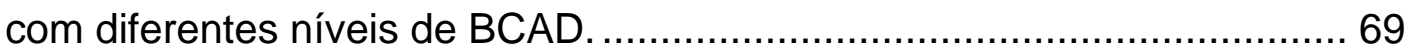




\section{LISTA DE FIGURAS}

FIGURA 01. Galpão experimental.

FIGURA 2. Colheita de líquido ruminal.

FIGURA 03. Colheita de sangue

FIGURA 04. Amostragem de urina.

FIGURA 05. Níveis médios de IMS ( $\mathrm{g} \mathrm{kg}-0,75)$ em ovinos alimentados com diferentes níveis de BCAD, ao longo dos 75 dias de experimento.

FIGURA 06. Níveis médios de ganho de peso diário (GPD) em kg por dia e eficiência alimentar, em ovinos alimentados com diferentes níveis de BCAD em mEq de $(\mathrm{Na}+\mathrm{K})-(\mathrm{Cl}+\mathrm{S})$ por kg de $\mathrm{MS}$, durante os 75 dias de experimento.

FIGURA 07. Gráfico do efeito do BCAD sobre pH urinário no $25^{\circ}$ ao $30^{\circ}$ dia e do $55^{\circ}$ ao $60^{\circ}$ dia de experimento em ovinos alimentados com diferentes níveis de BCAD. 51

FIGURA 08. Cálcio excretado na urina em \% do cálcio ingerido, nos tratamentos de BCAD negativos (-160 e $-40 \mathrm{mEq} / \mathrm{kg}$ de $\mathrm{MS}$ ), controle (140 $\mathrm{mEq} / \mathrm{kg}$ de MS) e positivos (250 e $500 \mathrm{mEq} / \mathrm{kg}$ de MS). 68

FIGURA 09. Efeito do BCAD no cálcio total ( $\mathrm{mg} / \mathrm{dL})$, nos diferentes dias de colheita do experimento. 
FIGURA 10. Efeito do BCAD no cálcio ionizado ( $\mathrm{mg} / \mathrm{dL})$, nos diferentes dias de

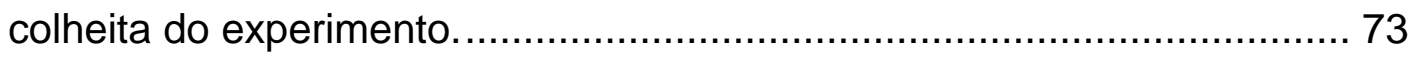




\title{
LISTA DE ABREVIATURAS E SÍMBOLOS
}

\author{
AGV - Ácidos graxos voláteis \\ BCAD - Balanço cátion-aniônico da dieta \\ BE - Balanço eletrolítico \\ BID - Balanço iônico da dieta \\ Ca - Cálcio \\ $\mathrm{CaCl}_{2}$ - Cloreto de cálcio \\ $\mathrm{Cl}^{-}$- Cloreto \\ $\mathrm{Cl}$ - Cloro \\ $\mathrm{Cl}_{2} \mathrm{NH}_{4}$ - Cloreto de amônio \\ CT - Calcitonina \\ EA - Eficiência Alimentar \\ GPD - Ganho de peso diário \\ $\mathrm{H}^{+} \quad$ - íon hidrogênio \\ $\mathrm{H}_{2} \mathrm{PO}_{4}$ - Ácido fosfórico \\ $\mathrm{HCO}_{3}^{-}$- Bicarbonato \\ IMS - Ingestão de matéria seca \\ K - Potássio \\ $\mathrm{KCl}$ - Cloreto de potássio \\ Meq - Miliequivalente \\ Mg - Magnésio \\ $\mathrm{MgSO}_{4}$ - Sulfato de magnésio \\ MS - Matéria Seca \\ $\mathrm{Na}$ - Sódio \\ $\mathrm{NaCl}$ - Cloreto de sódio \\ $\mathrm{NaHCO}_{3}$ - Bicarbonato de sódio \\ $\left(\mathrm{NH}_{4}\right)_{2} \mathrm{SO}_{4}$ - Sulfato de amônio \\ $\mathrm{NH}_{4} \mathrm{Cl}$ - Cloreto de amônio \\ $\mathrm{P}$ - Fósforo
}


$\mathrm{pCO}_{2}$ - pressão de $\mathrm{CO}_{2}$

PTH - Paratormônio

$S$ - Enxofre

$\mathrm{SO}_{4}$ - Sulfato 


\section{RESUMO}

O efeito do balanço cátion-aniônico da dieta (BCAD) no desempenho, balanço macromineral (cálcio, fósforo, sódio e potássio), na fermentação ruminal , pH urinário e na concentração sérica de cálcio, foi estudado utilizandose 25 ovinos machos, da raça Santa Inês, por um período de 75 dias. O delineamento experimental foi em blocos ao acaso, com cinco tratamentos. Para a manipulação do BCAD foram adicionados sulfato de amônio e bicarbonato de sódio, obtendo-se os seguintes tratamentos: -160, -40, 140, 250 e $500 \mathrm{mEq} / \mathrm{kg}$ MS. O aumento do BCAD resultou em aumento da IMS, aumento em ganhos diários e eficiência alimentar $(\mathrm{P}<0,05)$. O pH ruminal, $\mathrm{pH}$ urinário e o volume urinário aumentaram com aumento do BCAD $(P<0,05)$. $O$ perfil de ácidos graxos ruminais não foi afetado pelo BCAD. O BCAD influenciou o metabolismo macromineral principalmente o de cálcio, com a diminução do BCAD o cálcio sérico aumentou. Dietas aniônicas aumentaram a excreção urinária de cálcio, entretanto a retenção não foi afetada.

Palavras-chave: ânion, BCAD, cátion, cálcio, desempenho, fósforo, pH . 


\section{ABSTRACT}

The dietary cation-anion balance (DCAB) effect in performance, macromineral (calcium, phosphorus and sodium) balance, urinary $\mathrm{pH}$ and calcium serum concentration, was studied in 25 males sheeps, from Santa Ines breed, during 75 days. The design used was randomized complete blocks, with five treatments. For DCAB manipulation were added ammonium sulfate and sodium bicarbonate in order to achieve the values: -160, -40, 140, 250 e 500 $\mathrm{meq} / \mathrm{kg} \mathrm{DM}$. Increasing the DCAB resulted in higher DMI, daily gains and feed efficiency $(\mathrm{P}<0,05)$. Rumen $\mathrm{pH}$, urine $\mathrm{pH}$ and urine volume increased as $\mathrm{DCAB}$ increased $(p<0,05)$. Ruminal VFA profile was not affected by DCAB. The DCAB affected the calcium metabolism, decresing the DCAB the serum calcium increased. Dietary anionic increased urinary excretion of calcium, however calcium retention was not effect.

Key words: anion, cation, calcium, DCAB, performance, $\mathrm{pH}$, phosphorus. 


\section{INTRODUÇÃO}

Nos últimos anos muito se tem pesquisado sobre a manipulação do equilíbrio ácido-basico na prevenção de doenças metabólicas. A inter-relação entre o balanceamento de íons dietéticos e a homeostase ácido-base na produção animal iniciou-se na avicultura de corte, entretanto, atualmente é na bovinocultura leiteira que as pesquisas se concentram, principalmente, na prevenção de distúrbios como a hipocalcemia peri-parto.

O balanço cátion-aniônico dietético (BCAD), representa a diferença entre os íons de carga positiva e os de carga negativa presentes na dieta, sendo expresso habitualmente em $\mathrm{mEq}$ de $(\mathrm{Na}+\mathrm{K})-\left(\mathrm{Cl}+\mathrm{SO}_{4}\right)$ por $\mathrm{kg}$ de matéria seca (MS). Dessa forma, a maior concentração de sódio e ou potássio na dieta caracteriza um BCAD positivo ou uma dieta denominada catiônica. A maior concentração de cloro e ou enxofre se refere ao BCAD negativo ou à dieta chamada aniônica.

O uso de dietas altamente catiônicas, com a inclusão de fontes de sódio ou potássio, tem sido preconizado para melhorar o desempenho de vacas em lactação, bovinos de corte e ovinos. A explicação reside na alta taxa metabólica e conseqüente maior produção de ácidos endógenos. O equilíbrio ácido-básico é uma homeostase com prioridade fisiológica a ganho de peso ou produção de leite, por isso a relação direta com desempenho animal.

A maior parte dos alimentos utilizados no arraçoamento animal possuem BCAD positivo. Para o oferecimento de BCAD negativo se faz necessário a adição de fontes de cloro ou enxofre. Essas dietas têm a capacidade de produzir leve acidose metabólica com subseqüente reabsorção de cálcio dos ossos prevenindo a hipocalcemia.

Em se tratando de BCAD, existem controvérsias literárias que necessitam ser esclarecidas. A dieta aniônica não tem sido preconizada por alguns técnicos vinculados à nutrição animal por acreditarem que a utilização 
da mesma acarrete queda da ingestão de matéria seca. Não se encontra fundamentação científica para a relação entre BCAD e IMS. Os efeitos da manipulação do BCAD na absorção aparente e retenção de macrominerais também merece ser investigado, uma vez que existe relação fisiológica entre o equilíbrio ácido-básico e a regulação de eletrólitos. Quanto ao desempenho animal, a carência de informações impossibilita a recomendação de níveis de BCAD ótimos na nutrição de ruminantes em crescimento.

Dessa forma, o presente experimento teve por objetivo verificar os efeitos do BCAD sobre o desempenho, metabolismo ruminal e balanço macromineral em ovinos em crescimento. 


\section{REVISÃO DA LITERATURA}

\subsection{Balanço cátion-ânion dietético (BCAD)}

O balanço cátion-aniônico dietético (BCAD), também conhecido por diferença cátion-aniônica da dieta (DCAD), balanço eletrolítico (BE) ou balanço iônico da dieta (BID), representa a diferença entre os cátions e os ânions fixos totais, presentes na dieta. O conceito de íons fixos refere-se aos biodisponíveis e não metabolizáveis, como o $\mathrm{Na}^{+}$(Sódio), $\mathrm{K}^{+}$(Potássio) e $\mathrm{Cl}^{-}$(Cloreto). Esses são os íons mais atuantes no equilíbrio ácido-base (STEWART citado por BLOCK,1994). Em um dos estudos pioneiros no assunto, MONGIN (1981), propôs a seguinte equação no cálculo do BCAD: BCAD $=(\mathrm{Na}+\mathrm{K}+\mathrm{Ca}+\mathrm{Mg})-$ $\left(\mathrm{Cl}+\mathrm{SO}_{4}+\mathrm{H}_{2} \mathrm{PO}_{4}\right) / 100 \mathrm{~g}$ de MS. Os cátions e ânions considerados na equação, de fato têm influência no equilíbrio ácido base, entretanto, tal equação considera uma taxa de absorção intestinal igual entre eles, o que não condiz com a realidade. As taxas de absorção do $\mathrm{Na}, \mathrm{K}$ e $\mathrm{Cl}$ estão por volta de $90 \%$, enquanto a do $\mathrm{S}$ ao redor de $60 \%$. As taxas de absorção do $\mathrm{Ca}, \mathrm{Mg}$ e $\mathrm{P}$ são respectivamente de 40, 30 e 50\%. Segundo GOFF e HORST (1997), pela baixas taxas de absorção, o $\mathrm{Ca}$ e $\mathrm{Mg}$ só teriam influência no equilíbrio ácido base se incluídos em alta quantidade na dieta. Alguns autores incluem $\mathrm{O} \mathrm{HCO}_{3}{ }^{-}$ na fórmula do BCAD, entretanto, segundo ERDMAN (1993), o uso de $\mathrm{HCO}_{3}{ }^{-}$ não é consistente, uma vez que sua concentração é regulada por outros mecanismos e independe do fornecimento na dieta. Para ruminantes, o BCAD inicialmente era calculado utilizando-se o $\mathrm{Na}$ e K como cátions e apenas o $\mathrm{Cl}$ o ânion, entretanto, atualmente a maior parte dos experimentos calcula o BCAD em mEq de $\left(\mathrm{Na}^{+}+\mathrm{K}^{+}\right)-\left(\mathrm{Cl}^{-}+\mathrm{SO}_{4}{ }^{-}\right)$por $\mathrm{kg}$ ou 100 gramas de Matéria Seca. O enxofre, apesar de não ser um íon fixo, é incluído no cálculo do BCAD para ruminantes, já que segundo TUCKER et al. (1991) os sulfatos acidificam diretamente os fluídos biológicos e dessa maneira alteram o equilíbrio ácidobásico, se incluídos em alta concentração na dieta (COLE e ZLOTKIN citados por BLOCK, 1994). 
Dessa forma o BCAD pode ser calculado com a análise apenas de sódio, potássio e cloro ou com a inclusão do enxofre.

O sódio é o principal cátion do líquido extracelular e um importante componente do esqueleto. Mais de $50 \%$ do total catiônico do plasma sangüíneo é devido ao sódio e a regulação da concentração de sódio é feita mediante um controle da ingestão e excreção do elemento. Animais com deficiência de sódio apresentam comportamento voltado para a ingestão de cloreto de sódio ( $\mathrm{NaCl})$, de maneira a corrigirem o déficit corporal desse cátion. A excreção de Na pelo rim envolve a filtração do $\mathrm{Na}$ do plasma nos glomérulos e então, sua reabsorção. A aldosterona aumenta a capacidade do processo de retenção do $\mathrm{Na}$ pelo corpo, e sua reabsorção requer uma passagem equivalente de $\mathrm{H}^{+} \mathrm{e} \mathrm{K}^{+}$ na direção oposta, sendo importante na manutenção do balanço ácido-base. A diferença de sódio filtrado e o reabsorvido corresponde ao eliminado pela urina (SWENSON, 1984). A absorção desse elemento é feita principalmente no intestino delgado, através de sistemas de bombas e também por sistemas de transporte passivo (McDOWELL 1992). Segundo DOUGLAS (2002b), o sódio pode ser absorvido por transporte ativo, absorção eletrogênica, absorção acoplada com glicose, antitransporte de sódio hidrogênio e também absorção de sódio acoplado ao cloreto. Dessa forma, em função da presença de diferentes mecanismos específicos de transporte pouca quantidade é excretada nas fezes. A absorção do sódio também ocorre no rúmen. Quando o consumo é inadequado, o corpo tem a capacidade de aumentar a retenção, excretando baixas quantidades na urina. Quando o consumo é alto, maiores concentrações serão eliminadas pelos rins e o consumo de água irá aumentar (McDOWELL 1992). DOUGLAS (2002b) afirmou que o sódio também é secretado passivamente no intestino delgado.

O potássio ( $\mathrm{K}$ ) é o terceiro elemento presente em maior quantidade no corpo animal, representa aproximadamente 0,3\% da matéria seca corporal. Ele é o principal cátion do fluido intracelular, sendo aproximadamente $89 \%$ do potássio corporal localizado dentro das células. Sua absorção é feita por 
difusão no intestino delgado. Em ruminantes a absorção ocorre no rúmen, no omaso e também no restante do trato gastrintestinal. Em função da grande quantidade de saliva produzida, uma grande parte do $\mathrm{K}$ do rúmen é proveniente da saliva. A digestibilidade verdadeira desse elemento é alta, cerca de $95 \%$. (McDOWELL 1992). Em ovinos, segundo RAl citado por McDOWELL (1992), $30 \%$ do $\mathrm{K}$ excretado em condições de calor e umidade foi através da pele. Sua deficiência dietética não é comum em ruminantes, uma vez que as forragens contêm níveis adequados de K. Segundo SWENSON (1984), um aumento na concentração de potássio resulta na liberação de aldosterona, que incrementa a excreção de potássio na urina, com uma conseqüente queda do potássio plasmático. Ele é excretado pelo rim através da filtração glomerular e pela secreção tubular, sendo aumentado pela aldosterona. Contudo, a habilidade do rim para conservar K não é tão eficiente como para o Na (WHEELER, 1980). O potássio excretado corresponde ao resultado da secreção, pelos túbulos contornados distais e ductos coletores (SWENSON, 1984). A excreção de sódio e de potássio envolve uma relação recíproca, na qual o potássio é mantido em detrimento do sódio. O excesso, de potássio na dieta em relação ao sódio, pode fazer com que o rim cause uma deficiência de sódio, mesmo que esse esteja em níveis adequados (BLOCK, 1994).

O cloreto é o principal ânion tanto no plasma como no fluído intracelular.Ele é absorvido principalmente no intestino delgado, entretanto, pode também se absorvido no rúmen. $\mathrm{O} \mathrm{Cl}$ é quase totalmente absorvido no trato gastriintestinal, assim como o sódio. $\mathrm{O} \mathrm{Cl}$ é excretado principalmente na urina como sal, com pequenas quantidades perdidas nas fezes e por transpiração (McDOWELL 1992). O metabolismo do Cl é controlado em relação ao sódio. Quando um excesso de sódio é excretado pelos rins, geralmente há um excesso de cloreto também excretado, a fim de manter a eletroneutralidade. Os alimentos geralmente consumidos pelos ruminantes são pobres em cloreto, sendo dessa forma suplementados através do cloreto de sódio (WHEELER, 
1980). Suas principais funções são a manutenção da pressão osmótica e regulação do equilíbrio ácido-base, assim como o $\mathrm{Na}$ e o $\mathrm{K}$.

A manutenção do $\mathrm{pH}$ do fluido corporal é essencial uma vez que muitos processos metabólicos no interior das células são dependentes do $\mathrm{pH}$. Portanto, a concentração nos fluidos corporais do íon $\mathrm{H}^{+}$é um dos mais importantes na função reguladora corporal. Assim, a excreção de íons $\mathrm{H}$ pela substituição do $\mathrm{Na}$ e K na urina é importante para conservação de reservas de cátions e para remover o excesso de íons $\mathrm{H}^{+}$(WHEELER,1980).

Os íons $\mathrm{Na}, \mathrm{K}, \mathrm{Cl}$ e $\mathrm{SO}_{4}$ são escolhidos para o cálculo do BCAD por terem influência no balanço ácido-base, entretanto, podem alterar o balanço osmótico, mecanismos de transporte de membrana, impulsos nervosos, entre outras alterações no metabolismo animal (WHEELER, 1980; BLOCK, 1994).

\subsection{Efeitos do BCAD no equilíbrio ácido-base.}

A principal ação do balanço cátion-ânion dietético (BCAD) é atuar na regulação do equilíbrio ácido-base, apesar de não ser o único efeito no metabolismo animal.

A homeostase ácido-base é um fator de fundamental importância em qualquer espécie animal de interesse zootécnico. Equilíbrio ácido-base diz respeito à regulação da concentração do íon hidrogênio nos líquidos corporais. Para que os processos vitais transcorram normalmente é de grande importância que o $\mathrm{pH}$ dos fluídos corporais seja mantido entre limites estritos. Segundo GUYTON (1988), a concentração de íons hidrogênio nos fluídos corporais é a mais cuidadosa função reguladora do corpo. Pequenas modificações nessa concentração podem causar alterações na velocidade das reações químicas das células. Em função disso é que reside a grande importância de tal homeostasia. A condição habitual que precisa ser corrigida é o acréscimo de ácido, ou íon hidrogênio, aos líquidos corporais pois, com o metabolismo há uma produção constante de ácidos. Em condições normais, há um contínuo 
acréscimo de ácidos ou bases aos líquidos corporais, em função da ingestão ou pelo metabolismo celular (DOUGLAS, 2002a). A quantidade de ácido produzida se altera com a alimentação, nível de exercício, fases do ciclo. Também existem distúrbios na carga básica, entretanto, com menor freqüência. Dessa forma os sistemas destinados à manutenção da homeostasia ácido-básica devem ser capazes de adaptar-se à alterações (CUNNINGHAM,1999).

Uma alimentação rica em carboidrato solúvel, oferecida aos ruminantes, pode induzir uma a acidose aguda ou crônica, afetando o pH sangüíneo, ocasionando laminite, problemas no fígado, entre outras desordens. Os fluídos ruminais são tamponados por bicarbonato e o pH dos fluidos corporais pode ou não diminuir durante a acidose, dependendo da capacidade de tamponamento. O sistema nervoso central pode ser prejudicado pela baixa concentração de bicarbonato se o pH do sangue não for diminuído. Embora os diagnósticos clínicos para acidose necessitem um pH sangüíneo abaixo de 7,35, outros sinais clínicos como pH ruminal, anorexia, ingestão de alimentos, diarréia e letargia são também indicativos de acidose em ruminantes (OWENS et al., 1998).

Para a manutenção da estreita variação do $\mathrm{pH}$ dos fluídos corporais, o organismo animal faz uso de uma combinação de mecanismos compensatórios. Entre eles podemos destacar os efeitos tampão do sangue, o mecanismo realizado pelo sistema respiratório, bem como os mecanismos de excreção e reabsorção feito pelos rins (CUNNINGHAM,1999).

Vários tampões intra e extracelulares titulam o íon hidrogênio, tais tampões incluem a hemoglobina e outras proteínas, carbonato nos ossos, fosfatos e bicarbonatos, esses normalizam rapidamente o pH após alterações agudas na carga ácida, a não ser que a capacidade tamponante seja ultrapassada. Uma proteína como a hemoglobina é um tampão, já que sua molécula contém um grande número de grupos ácidos ou básicos, no ponto isoelétrico as suas cargas positivas são iguais as negativas. Em meio ácido, os íons hidrogênio, reagem, por exemplo, com o grupamento carboxílico da 
proteína evitando uma queda brusca no pH do meio. Na presença de hidroxila, os grupamentos ácidos da proteína cedem seus íons hidrogênio formando água. Grande parte do tamponamento da hemoglobina é devido aos grupamentos imidazol da histina (DAVENPORT ,1973). Um sistema tampão do sangue de fundamental importância é o sistema bicarbonato-ácido carbônico. Quando há entrada de substâncias ácidas no sangue, o bicarbonato recebe um íon hidrogênio e transforma-se em ácido carbônico, um ácido fraco. O ácido carbônico mantém-se em equilíbrio com o $\mathrm{CO}_{2}$ que pode ser eliminado pelos pulmões (GURTLER et al., 1987; DOUGLAS 2002a).

Todas as células do corpo, não só os eritrócitos, contêm tampões. Quando a pressão de $\mathrm{CO}_{2}$ se eleva, íons bicarbonato são o que resulta não no tamponamento global do organismo (DAVENPORT,1973).

Em casos de acidose crônica, os ossos proporcionam um reservatório de tampão que contribui para a manutenção do pH. Nessa condição, o excesso de $\mathrm{H}^{+}$e baixo $\mathrm{HCO}_{3}^{-}$no líquido extracelular, promovem uma dissolução físicoquímica de ossos, mediada por osteoclastos, liberando carbonato, que serve de tampão para o íon hidrogênio (CUNNINGHAM, 1999).

O sistema respiratório também responde rapidamente para a manutenção do pH sanguíneo, eliminando uma maior quantidade de dióxido de carbono e reduzindo, dessa forma, o ácido carbônico do sangue. A enzima anidrase carbônica, presente nas hemácias e outras células, catalisa a reação de desidratação do ácido carbônico (CUNNINGHAM, 1999). Segundo MILES e BUTCHER (1993a), os pulmões também poderiam conservar esse ácido volátil durante a alcalose e dessa forma, a taxa respiratória poderia ser alterada, sendo de extrema importância na regulação do $\mathrm{pH}$ dos fluídos corporais. $\mathrm{O}$ aumento do $\mathrm{pH}$ deprime a respiração e reduz a ventilação dos espaços alveolares, aumentando a $\mathrm{pCO}_{2}$ do sangue arterial, o que induz a uma queda de $\mathrm{pH}$, sendo a compensação respiratória para a alcalose metabólica. A compensação respiratória para a acidose metabólica acontece, já que a 
diminuição do pH estimula a respiração e aumenta a ventilação pulmonar, com isso a $\mathrm{pCO}_{2}$ é diminuída (DAVENPORT ,1973).

O rim tem como função global manter a constância do meio interno e através da excreção e regulação de íons, mantém um padrão eletrolítico, funcionando como terceira defesa da homeostase ácido-básica (DAVENPORT,1973). Embora o sistema tampão e o sistema respiratório sejam capazes de estabilizar o pH sanguíneo, é o rim que promove a excreção da maior parte de $\mathrm{H}+$. Enquanto os pulmões removem um ácido volátil, os rins conseguem excretar ácidos não-voláteis, secretando H+. Grandes quantidades podem ser removidas pela secreção tubular, onde o túbulo proximal é o principal responsável pela secreção de ácido e o ducto coletor, pela excreção de ácido e pelo $\mathrm{pH}$ final da urina (CUNNINGHAM, 1999). No caso de uma tendência do equilíbrio ácido-base se deslocar para o lado alcalino, os rins reagem produzindo uma urina alcalina (GURTLER et al., 1987). A excreção ácida tem como responsável um conjunto de enzimas e de transportadores do $\mathrm{H}^{+}$das células epiteliais para os líquidos tubulares, combinados com tampões (amônia, bicarbonato, fosfato) que impedem altas concentrações de $\mathrm{H}^{+}$nesse líquido (CUNNINGHAM, 1999). Quando a urina é ácida, o ácido excretado foi removido do sangue e uma quantidade igual de base foi adicionada ao sangue. Para cada íon $\mathrm{H}^{+}$excretado, uma hidroxila é deixada dentro das células tubulares renais elevando $\mathrm{o} \mathrm{pH}$ interno. Posteriormente os íons hidrogênio formados a partir de $\mathrm{CO}_{2}$ e água se combinam com a hidroxila neutralizando o pH interno. Os íons bicarbonato resultantes vão para o sangue. Dessa forma, para cada mol de ácido secretado na urina, um mol de bicarbonato aparece no sangue. A hidratação do $\mathrm{CO}_{2}$ no rim também é catalisada pela anidrase carbônica. Quando um ácido é secretado, um equilíbrio elétrico deve ser mantido e isso é conseguido pelo sódio, de forma que, para cada íon hidrogênio excretado na urina, um $\mathrm{Na}$ é reabsorvido. Portanto, a excreção de um ácido é acompanhada pela adição de bicarbonato de sódio. Esse processo também acontece com o potássio, onde um aumento na taxa de secreção de $\mathrm{H}^{+}$reduz a 
secreção de potássio. Durante uma deficiência de potássio, a secreção renal é reduzida e a secreção de hidrogênio na urina aumenta. O fosfato é um dos tampões mais importantes da urina. Se um ácido for adicionado à urina, teremos a transformação do ácido fosfórico monobásico em dibásico e, para cada 5 moléculas de fosfato na urina, teremos 4 íons sódio retornados ao sangue. O segundo tampão que permite a conservação do sódio é a amônia formada nas próprias células tubulares, a qual reage com íons hidrogênio formando amônio. A secreção de urina ácida tem duas funções: adicionar bases ao sangue e evitar que o bicarbonato do filtrado glomerular seja excretado. Existe uma relação inversa entre excreção renal de bicarbonato e excreção renal de cloreto. Quando a excreção renal de bicarbonato é baixa, o íon em maior quantidade na urina é o cloro e, quando a excreção de bicarbonato é grande, a quantidade de cloro é reduzida. Portanto, as duas variáveis renais que mais são afetadas durante a alcalose ou acidose são a concentração plasmática de bicarbonato e a quantidade de tampão na urina. $\mathrm{Na}$ alcalose metabólica o pH plasmático e a concentração de bicarbonato estão elevados e, se ocorreu a compensação respiratória, a pressão de $\mathrm{pCO}_{2}$ também está elevada. Dessa forma, tem-se a excreção urinária de bicarbonato e uma urina alcalina é excretada, para manter uma eletroneutralidade. Cátions, principalmente o sódio, são eliminados e a concentração plasmática tende a se reduzir. A taxa de excreção de cloro é reduzida e a sua concentração plasmática tende a aumentar. Esse aumento do cloreto substitui o bicarbonato e, nenhum íon amônio é excretado na urina. No caso de acidose metabólica, o $\mathrm{pH}$, a concentração plasmática de bicarbonato e a pressão de $\mathrm{CO}_{2}$ estão abaixo do normal. Então, a urina excretada é ácida, além de aumento da concentração de bicarbonato plasmático. Com a urina ácida, íons amônio são excretados e sódio é conservado (DAVENPORT,1973).

Como abordado anteriormente, os distúrbios no equilíbrio ácido base são classificados como acidose ou alcalose. O primeiro, representado por um excesso de ácido ou falta de base no fluído corporal. O segundo, 
correspondendo a um excesso de base ou falta de ácido no fluído corporal. Normalmente o corpo conserva ácidos durante esse estado (MILES e BUTCHER, 1993a). Assim, quando o animal está em acidose respiratória, significa que ele está com excesso de ácido carbônico no sangue e, quando está em alcalose respiratória, está com nível baixo de ácido carbônico. A acidose metabólica pode ser entendida como a falta de bicarbonato e, a alcalose metabólica o excesso de bicarbonato. Os fenômenos de acidose e alcalose metabólica estão associados à perdas de eletrólitos. O estresse causado pelo calor pode induzir o animal a uma alcalose metabólica e, até que eles tenham o seu equilíbrio ácido-base recuperado, seus desempenhos ficam comprometidos.

$\mathrm{O}$ pH sanguíneo é mantido dentro de limites muito estritos. Alterações bruscas podem afetar diretamente a atividade enzimática e a estrutura de receptores celulares, reduzindo a produtividade (GOFF citado por CAMPOS, 1998).

Segundo PATIENCE (1991), o balanço ácido-base não é definido apenas pelo $\mathrm{pH}$ do fluido extracelular, mas inclui a $\mathrm{pCO}_{2}, \mathrm{HCO}_{3}$ e excesso de bases. Em combinação, estes parâmetros ajudam a definir não apenas o status ácidobase do animal, mas também alguma derivação do normal. Os parâmetros ácido-base do sangue poderão mudar apenas quando as compensações respiratória e renal forem incapazes de eliminar a carga ácida ou alcalina. Mudanças nos níveis de bicarbonato ou na $\mathrm{pCO}_{2}$ têm efeito direto no $\mathrm{pH}$ sanguíneo.

$\mathrm{O} \mathrm{pH}$ do sangue dos bovinos é mantido entre 7,31 e 7,53 através dos mecanismos de homeostasia ácido-básica. A influência do BCAD sobre o $\mathrm{pH}$ sanguíneo se dá pelos mecanismos fisiológicos do animal para manter a eletroneutralidade e ocorre no trato gastrintestinal, uma vez que a absorção de cátions é acompanhada da secreção de $\mathrm{H}^{+}$e a de ânions acompanhada da absorção de $\mathrm{H}^{+}$ou secreção de $\mathrm{HCO}_{3}$. O íon cloreto, quando está em excesso em relação ao íon sódio (o que acontece em uma dieta aniônica) é absorvido na 
troca com $\mathrm{O}_{\mathrm{HCO}_{3}}$. Dessa forma, ocorre uma drenagem de bicarbonato do sangue para o intestino, o que pode levar à uma condição de acidose, uma vez que o bicarbonato é um importante tampão sanguíneo. Por outro lado, quando existe o predomínio de sódio (em uma dieta catiônica) a absorção desse elemento é acompanhada pela troca de íons $\mathrm{H}^{+}$, os quais vão para o intestino, diminuindo a concentração dos mesmos no sangue, levando à uma condição de alcalose metabólica (BLOCK, 1994). Outra forma de alteração promovida pelo BCAD na homeostase ácido base, diz respeito aos mecanismos de reabsorção promovidos pelo rim.

Outro mecanismo, responsável pela acidose metabólica conferida pela dieta aniônica, é denominado "deslocamento do cloreto". O potássio se combina com a oxihemoglobina eritrocitária, resultando na formação de bicarbonato endógeno, o qual é trocado pelo cloreto ganhando a corrente sangüínea diminuindo as reservas do sistema tampão. Dietas ricas em cloreto, e pobres em potássio inibem a formação extra de bicarbonato, ocasionando um ligeiro estado de acidez orgânica. Paralelo a isso, existe um potencial de troca intestinal do sódio pelos íons $\mathrm{H}^{+}$circulantes do sangue, o que poderia ser uma explicação para a alcalose metabólica observada nessas situações (BLOCK, $1994)$.

A combinação desses mecanismos pode induzir a um estado de alcalose ou acidose, compatível com a vida. Esses estados podem ser manipulados através do BCAD da dieta, interferindo no metabolismo de macrominerais e desempenho animal como será abordado posteriormente.

\subsection{Desempenho animal}

Segundo KRONFELD citado por FAUCHON et al. (1995), a homeostase ácido-base tem prioridade fisiológica ao crescimento, à lactação ou à reprodução. O equilíbrio ácido-base tem influência direta no metabolismo animal e, por isso, uma relação intrínseca com desempenho (MILES e 
BUTCHER, 1993a). Um fator que poderia explicar a relação entre o BCAD e o desempenho é a bomba de $\mathrm{Na}^{+}$e $\mathrm{k}^{+}$. O mecanismo da bomba $\mathrm{Na}-\mathrm{K}$ é responsável pela manutenção de altos níveis de $\mathrm{K}^{+}$e baixo níveis de $\mathrm{Na}^{+}$dentro da célula, usando energia na forma de ATP. Esse processo é responsável pelo consumo de aproximadamente $40 \%$ da energia de manutenção. A bomba de $\mathrm{Na}^{+}-\mathrm{K}^{+}$promove a entrada de glicose para a célula. Sendo a glicose uma fonte de energia celular, uma diminuição no funcionamento da bomba poderá prejudicar as células, especialmente as da glândula mamária, onde altas quantidades de glicose são utilizadas para síntese de lactose. O excesso de um cátion pode causar uma diminuição na velocidade da bomba (conseqüentemente uma menor quantidade de energia) ou um aumento da velocidade (causando uma maior necessidade de manutenção celular) (BLOCK,1994).

O crescimento máximo em frangos tem sido obtido com um balanço entre cátions e aniôns por volta de $250 \mathrm{mEq} / \mathrm{kg}$ de MS (MONGIN, 1981). Para suínos em crescimento, segundo PATIENCE et al. (1987), o melhor desempenho tem sido mostrado com BCAD de 0 até $341 \mathrm{mEq} / \mathrm{kg}$ de $\mathrm{MS}$. $\mathrm{O}$ BCAD pode também interferir no desempenho de ruminantes. Dietas altamente catiônicas para vacas em lactação, têm aumentado a ingestão de matéria seca (IMS) e a produção de leite, minimizando os efeitos do estresse pelo calor. Vacas em lactação devem ter o BCAD altamente positivo, já que esses ruminantes apresentam altas taxas metabólicas e, portanto, há uma tendência para o ambiente celular tornar-se ácido (BLOCK,1994). O BCAD para vacas deveria ser alto no início da lactação e diminuir no seu decorrer, de tal forma a ser negativo, de 3 a 4 semanas antes do parto, a fim de que se evite a paresia puerperal (BYERS ,1994). TUCKER et al. (1988) sugeriram em vacas lactantes, para o máximo desempenho, que o BCAD esteja entre +200 à $+375 \mathrm{mEq} / \mathrm{kg}$ de MS. DEN HARTOG et al. (1990) relataram um desempenho inferior de vitelos com $\mathrm{NaHCO}_{3}$ e $\mathrm{BCAD}$ de $+200 \mathrm{mEq} / \mathrm{kg}$ de $\mathrm{MS}$ em relação ao grupo controle, já o grupo com $\left(\mathrm{NH}_{4}\right) \mathrm{SO}_{4}$ e BCAD de $-100 \mathrm{mEq} / \mathrm{kg}$ de MS apresentaram 
resultados intermediários. Para bovinos de corte, ROSS et al. (1994), trabalhando com novilhos Angus em crescimento, concluíram que o melhor desempenho foi conseguido com um BCAD de 150 à $300 \mathrm{mEq} / \mathrm{kg}$ de $\mathrm{MS}$. ROSS et al. (1994b) concluíram que $150 \mathrm{mEq} / \mathrm{kg}$ de MS proporcionaram o melhor desenvolvimento para bovinos Angus em terminação. FAUCHON et al. (1995) observaram que dietas entre 500 e $700 \mathrm{mEq} / \mathrm{kg}$ de MS foram as que apresentaram um maior desempenho para ovinos em crescimento. JACKSON et al. (2001), em experimento conduzido com bezerros tratados com BCAD de 0 ou $200 \mathrm{mEq}[(\mathrm{Na}+\mathrm{K})-(\mathrm{Cl}+\mathrm{S})] / \mathrm{kg}$ de $\mathrm{MS}$, não observaram diferenças no desempenho entre os dois tratamentos.

Apesar dos resultados apresentados, qualquer recomendação de níveis ótimos de BCAD na nutrição de ruminantes é precipitada, em função da escassez de trabalhos na literatura.

\subsection{Ingestão de Matéria Seca}

Segundo o NRC (1985), a maior parte dos alimentos utilizados no arraçoamento de ovinos possui um BCAD positivo, a se analisar pelos níveis de sódio, potássio, cloro e enxofre. BLOCK (1994) citou valores positivos para o farelo de soja $(+266,37)$, silagem de milho $(+156,40)$, milho em grão $(+18,80)$ e negativos para a farinha de peixe $(-75,60)$, a aveia $(-26,95)$, além da cevada $(-23,40)$. A fim de uma diminuição do BCAD, deve-se, fazer uso de sais aniônicos. Um sal é considerado acidogênico se o ânion for absorvido preferencialmente ao cátion (GOFF et al., 1991). Para o aumento do BCAD, fazse uso de fontes de sódio, como o bicarbonato e o sesquicarbonato de sódio. TUCKER et al. (1994) avaliaram a influência do sesquicarbonato (0 e 1\% na MS), em rações para vacas leiteiras, conferindo 115 e $288 \mathrm{mEq} / \mathrm{kg}$ de MS e concluíram que o tratamento com sesquicarbonato conferiu um maior consumo de matéria seca. JACKSON et al. (1992), alimentando bezerros com dietas com níveis de $0,21,37$ e $52 \mathrm{mEq} / 100 \mathrm{~g} \mathrm{MS}$, concluíram que o consumo de matéria 
seca e o ganho médio diário foram maiores para os bezerros com BCAD de +37 mEq e menores paras as de nível 0 em mEq/100g de MS. RUDE e RANKINS (1997), arraçoando vacas de corte com algumas dietas, sendo uma delas a inclusão do sal aniônico cloreto de amônia $\left(\mathrm{Cl}_{2} \mathrm{NH}_{4}\right)$, não encontraram diferenças no consumo de matéria seca. DEL CLARO et al. (2002), suplementando bovinos machos em crescimento com sulfato de amônia $\left(\left(\mathrm{NH}_{4}\right)_{2} \mathrm{SO}_{4}\right)$ oferecidos na forma de ração total, não encontraram diferenças na ingestão de matéria seca em relação à dieta sem a adição de sais aniônicos. SPANGHERO (2002), em experimento desenvolvido com dietas negativas, não encontrou diminuição na ingestão de matéria seca, entretanto, os animais usados nesse experimento foram submetidos a um consumo limitado em 1,5\% do peso vivo. Em paralelo, a diminuição da ingestão com a adição de sais aniônicos foi bem documentada (HORST et al. 1994; VAGNONI e OETZEL, 1998; MOORE et al. 2000).

Segundo TUCKER et al. (1992), a variação no consumo de matéria seca observada por alguns autores se relacionou com a acidose provocada pelos sais aniônicos, ou mesmo pela palatabilidade. Diversos fatores podem estar influenciando na queda da ingestão de matéria seca em função da diminuição do BCAD, entre eles a forma de utilização dos sais aniônicos, o tipo de sal aniônico e o tempo de utilização, de tal forma que mais estudos devem ser feitos para que se possa tirar conclusões a esse respeito.

\subsection{Fermentação ruminal}

Ácidos graxos de cadeia curta são os principais produtos finais da fermentação microbiana do complexo estomacal dos ruminantes. Os ácidos graxos voláteis, predominates na forma de ácido acético, propiônico e butírico, fornecem cerca de $50-80 \%$ da energia digestível total. Altos valores do $\mathrm{pH}$ do rúmen (maior que 6,0) aumentam a proporção de ácido acético pois, são ótimos para as bactérias degradadoras de celulose. Em paralelo, baixos valores do $\mathrm{pH}$ 
do rúmen (pH 5,4 - 6,0) aumentam a proporção de ácido propiônico, já que são valores ideais para as bactérias degradadoras de amido (KAUFMANN, 1976). Aproximadamente $2 / 3$ do ácido acético produzido é absorvido e subseqüentemente oxidado, o restante é usado em processos metabólicos, como a lipogênese. Metade do ácido propiônico absorvido tem destino gliconeogênico, sendo convertido em glicose. O ácido butírico quase integralmente é convertido a corpos cetônicos no epitélio ruminal (FRANCE et al., 1991). O valor do pH do líquido ruminal é resultado da produção dos ácidos graxos voláteis, do tamponamento por meio da saliva e da presença de tampões ou bases dos alimentos. As dietas ricas em concentrado requerem baixo tempo de ruminação, conseqüentemente reduzindo a secreção salivar, em relação à produção de ácidos graxos voláteis (ORSKOV e RYLE, 1990).

A relação existente entre $B C A D$ e fermentação ruminal é pouco estudada. TUCKER et al. (1988), ao arraçoarem vacas holandesas em lactação, com dietas contendo diferentes níveis de BCAD, concluíram que o pH do líquido ruminal diminuiu com o decréscimo do balanço cátion-anionico, mas não houve alteração na fermentação ruminal. VAGNONI e OETZEL (1998), trabalhando com vacas secas, encontraram um decréscimo no $\mathrm{pH}$ do líquido ruminal quando da utlização de dietas aniônicas. A fermentação ruminal, evidenciada na produção e proporção de AGV, não foi alterada. ROSS et al. (1994a) arraçoando novilhos de corte com os níveis 0; $15 ; 30 ; 45 \mathrm{mEq} / 100 \mathrm{~g}$ de $\mathrm{MS}$, relataram que o $\mathrm{pH}$ ruminal aumentou linearmente com acréscimo do BCAD. Nesse experimento os autores fizeram uso de sonda esofágiana para a coleta do líquido ruminal. $\mathrm{O}$ aumento do $\mathrm{pH}$ ruminal com o uso de dietas com BCAD positivo vem sendo mais estudado, de forma indireta, pelo uso das dietas tamponantes. WEST et al. (1987) relataram maior valor de $\mathrm{pH}$ ruminal para vacas em lactação com tratamento com bicarbonato de sódio, quando comparadas com o tratamento controle. GHORBANI et al. (1989) encontraram maior valor de $\mathrm{pH}$ ruminal para o tratamento com adição de $\mathrm{NaHCO}_{3}$ do que o controle. 


\subsection{BCAD e metabolismo de cálcio}

O elemento mineral cálcio é o mais abundante do corpo animal. Segundo McDOWELL (1992), o percentual varia de 1,0\% à 2,0\%, sendo 99\% encontrado nos ossos e dentes. Nesses reservatórios, o cálcio é encontrado na forma de hidroxiapatita, que contém além do cálcio, fosfato e água. O restante, cerca de 1\%, fica distribuído em vários tecidos do corpo. Nestes tecidos o cálcio tem funções de fundamental importância, tanto que a homeostasia é uma das mais bem controladas pelo organismo. O cálcio é importante para reações intracelulares, incluindo a contração muscular, a atividade celular nervosa, a liberação de hormônios por exocitose e a ativação de certas enzimas. Dentro das funções extracelulares do cálcio, podemos citar a coagulação sangüínea, a manutenção e estabilidade de membranas celulares, bem como a manutenção e integridade estrutural de ossos e dentes (CUNNINGHAM, 1999),

A manutenção da calcemia nos animais envolve processos desde a absorção intestinal até a eliminação renal do cálcio. Nesse processo, inclui-se a participação de hormônios, como o do paratormônio (PTH), a calcitonina (CT), bem como o 1,25 dihidroxicolicalciferol ( $\left.1,25(\mathrm{OH})_{2} \mathrm{D}_{3}\right)$.

Os animais absorvem cálcio no intestino delgado e, a eficiência de absorção pode se alterar com o requerimento desse macromineral. Dessa forma, a absorção do cálcio é diretamente relacionada com produção de leite. A taxa de absorção de Ca decresce com a idade, alta ingestão de cálcio, ou baixo consumo de vitamina $\mathrm{D}$. O cálcio quando combinado com ácido oxalálico, forma oxalato de cálcio, que é insolúvel indisponibilizando o mineral. Em ruminantes ácidos graxos também podem dificultar a absorção de cálcio, por processos de saponificação (McDOWELL, 1992). A absorção intestinal é feita por difusão passiva e por transporte ativo. A difusão se dá pela alta concentração de cálcio, embora não seja um aspecto importante na sua absorção. $O$ transporte ativo envolve um movimento nas células intestinais, ao longo de um gradiente de concentração que é facilitado por proteínas carreadoras localizadas na face 
lumial das células da mucosa. O sistema ativo torna-se mais efetivo quando as concentrações de cálcio na dieta são mais baixas. A vitamina $D$ desempenha um importante papel na absorção instestinal de cálcio. Os rins funcionam como via de excreção para o cálcio. A maior parte do cálcio que passa para os rins é reabsorvido nos túbulos proximais e distais (CUNNINGHAM, 1999).

O hormônio paratireóideo (PTH), induz ao aumento das concentrações de cálcio nos líquidos extracelulares. O PTH tem efeitos diretos sobre os ossos e rins, e indiretos sobre a absorção intestinal. O PTH provoca reabsorção óssea, efeito esse, resultante do aumento da atividade dos osteoclastos e, inibição da atividade dos osteoblastos, resultando em uma liberação de cálcio. O PTH age também nos túbulos contorcidos distais para aumentar a reabsorção de cálcio e diminuir a de fosfato renal, por meio de um efeito nos túbulos proximais. O PTH está envolvido na ativação da vitamina D nos rins, participando indiretamente da absorção intestinal de cálcio. A secreção deste hormônio é controlada pelas concentrações de cálcio livre (ionizado) no sangue. O aumento inibe, enquanto uma diminuição estimula a produção de PTH.

A calcitonina (CT) é outro hormônio envolvido na homeostase do cálcio. É produzida pelas glândulas tireóides e age em "feedback" negativo com o PTH. O efeito da CT se dá principalmente no osso, diminuindo a reabsorção óssea através de um efeito inibitório sobre os osteoclastos. A CT aumenta a excreção renal de cálcio e fosfato. O controle também é feito pelo cálcio livre, sendo que um aumento eleva a síntese de CT.

A vitamina $D$ é uma molécula sintetizada à partir do acetato, pelas células epiteliais cutâneas. A exposição da pele aos raios ultravioleta resulta na separação das ligações C-9 e C-10 do 7-deshidrocolesterol, resultando na formação da vitamina D. Essa molécula ainda deve ser biologicamente ativada pelo fígado e pelo rim. O fígado hidroxila a molécula em C-25 e posteriormente o rim hidroxila a molécula em $\mathrm{C}$-1, dessa maneira, produzindo o composto ativo 1,25-dihidroxi vitamina $D\left(1,25(\mathrm{OH})_{2} \mathrm{D}_{3}\right)$. A atividade de hidroxilação do rim é feita pela ação do PTH. O estímulo na produção do PTH favorece a ativação da 
vitamina $\mathrm{D}$, consequentemente, maior absorção intestinal de cálcio. A vitamina D ativada estimula a produção de proteínas nas células das mucosas, o que facilita a absorção de cálcio intestinal. A vitamina $D$ também estimula a absorção passiva de cálcio, além de ter efeitos sobre os ossos, promovendo um aumento na reabsorção óssea, bem como um aumento dos efeitos do PTH. O controle da síntese de $1,25(\mathrm{OH})_{2} \mathrm{D}_{3}$ é feito por PTH e fosfato. Existem algumas evidências que, hormônios como o GH e a prolactina, aumentem a produção de $1,25(\mathrm{OH})_{2} \mathrm{D}_{3}$ por aumentar a hidroxilação C-1(CUNNINGHAM, 1999).

O cálcio está presente no plasma, basicamente sob três formas. O ionizado, o complexado e o ligado a proteína (WANG e BEEDE, 1992). Em bovinos tem-se usado a concentração de cálcio total no soro para se avaliar o metabolismo e homeostasia do cálcio, entretanto, em vacas leiteiras, por exemplo, nas quais uma concentração anormal de cálcio foi detectada, a concentração de cálcio iônico foi claramente relacionada ao metabolismo do cálcio. Isso se deve basicamente ao fato dos bovinos apresentarem níveis de albumina, bicarbonato, citrato, fosfato e lactato constantes (LINCOLN e LANE,1990 ).

\subsubsection{Função intestinal}

O balanço entre cátions e aniôns da dieta pode ter interferência no metabolismo de alguns minerais. A influência do BCAD no metabolismo do cálcio é a mais conhecida, em função das implicações na prevenção da paresia puerperal. O aumento do cálcio sanguíneo, oriundo de uma diminuição do BCAD da dieta pode ocorrer em função de alterações na absorção intestinal do cálcio, na função renal, bem como por uma maior mobilização óssea, o que poderia interferir significativamente no balanço de cálcio, tanto na absorção aparente quanto na retenção desse macromineral.

A absorção intestinal de cálcio pode ser aumentada em função da diminuição do BCAD. LOMBA et al. (1978) demonstraram um aumento da absorção devido a natureza acidogênica dos íons no intestino. Quando o cloro 
está presente em maior quantidade que o sódio no intestino, este é trocado por $\mathrm{HCO}_{3}{ }^{-}$presente no sangue, ocasionando uma acidose metabólica. Entretanto, LECLERC e BLOCK (1989) não encontraram um aumento na absorção aparente de cálcio com o uso de uma dieta aniônica. Segundo BLOCK (1994), o BCAD negativo pode inibir a absorção ativa de cálcio no intestino, estimulando com isso a produção de $1,25(\mathrm{OH})_{2} \mathrm{D}_{3}$, o que estimularia o PTH a fazer mobilização óssea direta.

\subsubsection{Função renal}

Com relação à alteração do BCAD negativo na função renal, TAKAGI e BLOCK (1991a), utilizando-se de ovinos, demonstraram que dietas acidogênicas aumentam a excreção urinária de cálcio, então, a retenção diminui, o que causa a formação de 1,25(OH)2D3 e liberação de PTH para estimular a mobilização óssea. FREDEEN et al. (1988a), trabalhando com vacas em lactação e no pré-parto, relataram um acréscimo significativo na excreção urinária de cálcio, no tratamento com dieta aniônica em relação à dieta controle e a catiônica. TUCKER et al. (1991) relataram um aumento linear na excreção urinária de cálcio, com a inclusão do sal aniônico $\mathrm{CaCl}_{2}$. Para os autores, esse resultado é devido a um aumento da absorção de cálcio, a uma mobilização óssea, ou a uma redução da reabsorção renal de cálcio, acompanhados da baixa do BCAD.

\subsubsection{Mobilização óssea}

Além dos mecanismos indiretos do aumento da mobilização óssea em função de um BCAD negativo, podemos citar alguns mecanismos específicos também em função de uma acidose metabólica. A reabsorção óssea é mediada pelo PTH e $1,25(\mathrm{OH})_{2} \mathrm{D}_{3}$. BLOCK (1984) mostrou aumento da mobilização óssea, coincidindo com o aumento de PTH e 1,25(OH $)_{2} \mathrm{D}_{3}$. A reabsorção óssea de cálcio exige pelo menos 48 horas de estimulação pelo PTH. GOFF et al. 
(1991) afirmaram que, vacas alimentadas com dietas altamente catiônicas são menos receptivas ao PTH do que as alimentadas com dieta altamente aniônica. Nesse mesmo experimento, os autores concluíram que a secreção do PTH foi similar nos dois tratamentos (dieta catiônica e aniônica). HORST et al. (1994) afirmaram que a paresia puerperal não resulta da produção inadequada dos hormônios calcitrópicos, mas do número insuficiente ou disfunção dos receptores para esses hormônios nas células alvo.

A acidose metabólica resultante do oferecimento de dietas aniônicas, estimula a transformação de $25(\mathrm{OH})$ colicalciferol em $1,25(\mathrm{OH})_{2} \mathrm{D}_{3}$ o qual aumenta a reabsorção óssea, liberando cálcio para a corrente sangüínea (HORST et al, 1994). Esse efeito é creditado a uma maior modulação da enzima 1 alfa hidroxilase que transforma a 25(OH) em 1,25(OH)2D3.

\subsubsection{Cálcio sérico}

TAURIAINEN et al. (1998b), trabalhando com vacas Ayrshire e Holandesas, concluíram que a redução do BCAD da dieta aumenta a habilidade da vaca em manter a concentração de cálcio no sangue. WANG et al. (1991) fizeram uso de dois lotes de vacas, as quais eram alimentadas com BCAD de +50 mEq/ kg e 9,2 g de Ca / kg de MS nos animais controle e BCAD de -247 $\mathrm{mEq} / \mathrm{kg}$ e $18 \mathrm{~g}$ de cálcio $\mathrm{kg}$ de MS, por 25 dias antes da data prevista para o parto, nos animais do tratamento experimental. As vacas arraçoadas com o tratamento experimental apresentaram-se com maior concentração sérica de Cai (cálcio ionizado), 4,31 mg/dl contra 3,80 mg/dl do tratamento controle. Para BYERS (1994), uma alimentação com dieta aniônica deveria ser utilizada, entre três à cinco semanas antes do parto. Entretanto, OLSON (1993) relatou que o uso de sais aniônicos por 7 dias é suficiente para alteração no metabolismo do cálcio. DEL CLARO et al. (2002) observaram que bovinos em crescimento submetidos a um BCAD de $-150 \mathrm{mEq} / \mathrm{kg}$ de MS, tiveram aumentos dos níveis séricos de cálcio total, 19 dias após o início da suplementação com sais aniônicos. 


\subsection{Hipocalcemia}

Em ruminantes, o tipo mais comum de distúrbio na homeostase do cálcio diz respeito à hipocalcemia associada ao parto. A hipocalcemia também é conhecida por febre do leite ou febre vitular, entretanto, os animais não apresentam hipertermia, mas sim hipotermia. Dessa forma, sendo melhor referenciada como paresia puerperal, paresia do parto ou mesmo paresia parturiente. É uma doença caracterizada pela falta de habilidade de certas vacas, no início da lactação em suprir subitamente altas demandas de cálcio, acarretando hipocalcemia e conseqüente incoordenação neuromuscular, colápso circulatório e depressão. Em países europeus tal doença afeta de 5 a 10\% do rebanho leiteiro (TANOR, 1998).

No início da lactação a elevada demanda de cálcio pela secreção de colostro e leite, pode causar a paresia puerperal em animais que não conseguiram se adaptar, reabsorvendo cálcio dos ossos (AROEIRA, 1993). Com a falha dos mecanismos de manutenção da homeostasia, o animal retira cálcio da fração ionizável do sangue. A forma aguda dessa doença afeta diretamente a saúde da vaca. A hipocalcemia pode não acarretar em paresia puerperal. Dessa forma, o animal ficaria em um estado sub-clínico. A forma sub-clínica da hipocalcemia reduz a ingestão de matéria seca e produção de leite (SPANGHERO, 2002) e pode estar relacionada segundo TANOR (1998), com cetose, deslocamento de abomaso, mastite, retenção de placenta.

Nos dias que antecedem o parto, segundo RAMBERG et al. (1984), os mecanismos de estimulação da mobilização óssea tornam-se inativos e as vacas tornam-se hipocalcêmicas até que o intestino e os ossos se ajustem à lactação. A falta de $\mathrm{PTH}$ e de $1,25(\mathrm{OH})_{2} \mathrm{D}_{3}$ poderia explicar a paresia puerperal, entretanto, tanto o PTH, como $01,25(\mathrm{OH})_{2} \mathrm{D}_{3}$ foram encontrados em concentrações mais elevadas que animais normais (GOFF et al. 1986). 


\subsubsection{Métodos de prevenção}

A prevenção é a forma mais desejável de reduzir as perdas econômicas oriundas da febre do leite. Dentre os vários métodos, THILSING HANSEN et al. (2002) destacam a administração de oral de cálcio no período próximo ao parto. Outra forma de prevenção é a administração de metabólitos da vitamina $D$ no pré-parto. Os metabólitos estimulam principalmente a absorção de cálcio no intestino, fazendo com que a vaca fique mais dependente do cálcio absorvido para manter a homeostase em níveis normais. Segundo FULLMER (1992), a $1,25(\mathrm{OH})_{2} \mathrm{D}_{3}$ tem como ação proporcionar o aumento das taxas de entrada de cálcio. GOFF et al. (1988), tratando vacas com $150 \mu \mathrm{g}$, do sintético análogo 24$\mathrm{F} 1,25$ Dihidroxivitamina $\mathrm{D}_{3}$ e da 1,25 Dihidroxivitamina $\mathrm{D}_{3}$, reduziu a incidência de paresia do parto. Esse método apresenta limitações, eventualmente ocasionando problemas de toxicidade, em função de tratamentos repetitivos por uma falta de exatidão na data do parto (LITTLEDIKE e HORST, 1982). THILSING HANSEN et al. (2002) afirmaram que o uso de grandes doses de 1,25 Dihidroxivitamina $\mathrm{D}_{3}$ na prevenção da paresia puerperal é controvérsio, devido a problemas de toxicidade.

Dietas contendo baixas concentrações de cálcio e fósforo para vacas no pré-parto também previnem a paresia puerperal (BLOCK, 1994). Essas dietas estimulam os metabólitos ativos de Vitamina $D$, além do PTH, e consequentemente a absorção ativa de cálcio no intestino, além do mecanismo de reabsorção óssea. Em algumas situações essa estratégia pode não funcionar. Segundo SETTI (1996), dietas no pré-parto com baixa concentração de cálcio, muitas vezes não funcionam, além de serem difíceis de formular.

Outra forma de prevenção, diz respeito a manipulação do já explanado balanço cátion-aniônico da dieta. Segundo THILSING HANSEN et al. (2002), calculando-se o risco relativo do desenvolvimento da paresia puerperal encontrou o valor de 19 , contra $35 \%$ das dietas com BCAD negativo quando comparadas com BCAD positivo. Alguns estudos mostram que uma dieta com 
maior proporção de ânions em relação aos cátions produz acidose metabólica, com redução do pH sangüíneo e urinário e conseqüente redução da incidência da hipocalcemia. Segundo SANCHEZ (1995), o BCAD para que seja prevenida de forma eficiente a paresia do parto, vai de -100 à $-200 \mathrm{mEq} / \mathrm{kg}$ de MS. TANOR (1998) preconiza um BCAD por volta de -200 à $-300 \mathrm{mEq} / \mathrm{kg}$ de MS, durante o período seco, para prevenir o risco de paresia puerperal. DISHINGTON citado por BLOCK (1994), preveniu a febre do leite em 92\% dos casos quando vacas foram arraçoadas com BCAD negativo, e contendo alta concentração de cálcio, evidenciando a melhor resposta desse método com altos níveis de cálcio. OETZEL et al. (1988) também demonstraram uma redução da paresia puerperal, quando vacas eram alimentadas com o BCAD de $-75 \mathrm{mEq} / \mathrm{Kg}$ de MS, comparado com BCAD de $+189 \mathrm{mEq} / \mathrm{Kg}$ de MS. KIM et al. (1997b) relataram que a incidência de febre do leite em vacas suplementadas com dieta aniônica foi praticamente nula. A gravidade da hipocalcemia subclínica foi diminuída significativamente em cerca de $10 \%$.

O mecanismo de ação não está muito claro, mas está baseado nos receptores de $\mathrm{PTH}$, os quais ficam mais realçados em tecidos alvo como o osso e os rins. E também pelo aumento da síntese do $1,25(\mathrm{OH})_{2} \mathrm{D}_{3}$ (HORST et al. 1997).

\section{8 pH urinário}

O monitoramento da eficiência da dieta aniônica pode ser feito através das análises de sódio, potássio, cloro e enxofre, presentes na dieta. Isso nem sempre é viável além das diferentes taxas de absorção dos minerais. Dessa maneira, outra proposta é a do controle do pH urinário, que deve se tornar mais ácido, evidenciando a acidose metabólica, resultante da ingestão de uma dieta aniônica. Os rins fazem parte da regulação da homeostase ácido-base através da síntese de bicarbonato, controle da reabsorção e por meio de secreção de ácido. $\mathrm{O}$ pH da urina varia, dependendo das necessidades dos fluídos corporais 
para ácidos e bases (MILES e BUTCHER, $1993 \mathrm{ab}$ ). Para TAURIAINEN et al. (1998a), a utilização de sais aniônicos diminuindo o BCAD de +340 para +31 $\mathrm{mEq} / \mathrm{kg}$ foi suficiente para baixar o $\mathrm{pH}$ da urina. PEHRSON et al. (1999), trabalhando com vacas verificaram um decréscimo no $\mathrm{pH}$ urinário com uso de dietas negativas. VAGNONI \& OETZEL (1998) afirmaram que a mensuração do $\mathrm{pH}$ urinário pode ser usada como ferramenta para diagnosticar a acidose metabólica em vacas alimentadas com dietas aniônicas. FREDEEN et al. (1988a), trabalhando com três tratamentos (controle, catiônico e aniônico), para vacas em lactação e no pré-parto, concluíram que o tratamento aniônico baixou o pH. TUCKER et al. (1988) relataram em experimento conduzido com 12 vacas holandesas em lactação, que o pH urinário aumentou linearmente e quadraticamente com o aumento do BCAD, no caso de -100 para +20 $\mathrm{mEq} /(\mathrm{Na}+\mathrm{K})-\mathrm{Cl} / 100 \mathrm{~g}$ de MS. WALKER et al. (1998), trabalhando com dois níveis de BCAD (0 e +25 mEq/kg de $\mathrm{MS})$, na forma de pellets, concluíram que o menor $\mathrm{BCAD}$ diminuiu o $\mathrm{pH}$ urinário. No trabalho desenvolvido por $\mathrm{KIM}$ et al. (1997a), onde novilhas foram submetidas a três níveis de BCAD $(+5,+15,+30$ $\mathrm{mEq} / \mathrm{kg}$ ), foi concluído que o $\mathrm{pH}$ urinário aumentou conforme o acréscimo do BCAD. DEL CLARO et al. (2002) encontraram queda no pH urinário, de 8,17 quando novilhos foram alimentados com dieta basal, para 5,56 quando alimentados com dieta aniônica. WILSON et al. (1998) trabalhando com carneiros em crescimento, alimentados com dois níveis de BCAD (+250 mEq/kg MS ; -100 mEq/kg MS ) concluíram que o menor BCAD diminuiu o pH urinário.

\subsection{BCAD e metabolismo de fósforo}

O fósforo tem seu metabolismo muito relacionado com o cálcio. Juntos perfazem $70 \%$ do conteúdo mineral do corpo. Aproximadamente $80-85 \%$ encontra-se nos ossos e dentes. A absorção de $P$ não depende do requerimento do animal, entretanto, estudos realizados com ovinos revelaram que através de uma absorção ativa a taxa de absorção aumenta com o 
aumento da demanda (BRAITHWAITE citados por McDOWELL 1992). A absorção de fósforo é influenciada pela fonte, $\mathrm{pH}$ intestinal, idade do animal, e pelo consumo de outros minerais como cálcio, ferro, alumínio e magnésio (McDOWELL, 1992). A vitamina D, assim como para o cálcio, estimula a absorção intestinal de P. Pouco se sabe sobre o mecanismo real de absorção de $\mathrm{P}$, entretanto, ele é transportado com uma troca com o sódio. Segundo SCOTT e McLEAN citado por McDOWELL (1992), ovinos alimentados com forragens excretam pouco $P$ na urina. Para ruminantes, a saliva é uma fonte adicional de $P$. Até recentemente a secreção de $P$ na saliva era vista apenas como um tamponante, entretanto, hoje considera-se o $\mathrm{P}$ da saliva com uma importante função na homeostase do fósforo, controlando a quantidade secretada no intestino. A principal via de excreção de $\mathrm{P}$ em herbívoros são as fezes, mas a urina é a principal forma de excreção em carnívoros. Entretanto, a quantidade de $\mathrm{P}$ na urina aumenta muito com o consumo de dieta concentrada. As perdas endógenas são expressivas na excreção fecal de P (McDOWELL 1992). Ovinos utilizam eficientemente o fósforo, em parte pela considerável quantidade reciclada na parótida e pela secreção de saliva (NRC, 1985).

BEIGHLE et al. (1995) utilizaram como tratamentos BCAD de -11,1; $+16,5$ e +25,6 $\mu \mathrm{mol} / 100 \mathrm{~g}$ MS e verificaram que as concentrações de $P$ fecal e no sangue foram maiores para as dietas aniônicas comparadas ao controle e à catiônica. CAMPOS (1998), avaliando o balanço dietético cátion-aniônico na alimentação de vacas leiteiras no pré-parto observaram que a dieta aniônica reduziu a absorção aparente de fósforo. DEL CLARO et al. (2002) em experimento conduzido com bovinos em crescimento, não encontraram alteração na absorção aparente e retenção de fósforo, com o uso de uma dieta aniônica. JACKSON et al. (2001) verificaram que diferentes relações entre cátions e anions não alteraram a excreção urinária de fósforo. 


\section{MATERIAL E MÉTODOS.}

\subsection{Local}

O estudo foi conduzido nas dependências da Faculdade de Zootecnia e Engenharia de Alimentos da Universidade de São Paulo, no Campus de Pirassununga.

\subsection{Animais}

Foram utilizados vinte e cinco ovinos machos da raça Santa Inês, com idade e peso próximos, oriundos da mesma propriedade.

\subsection{Instalações}

Para a colheita de dados, os animais foram alocados em gaiolas de estudo de metabolismo, equipadas com bebedouro automático, cocho e coletor de urina. Foram instaladas em galpão experimental, fornecendo proteção contra intempéries e ventilação inadequada.

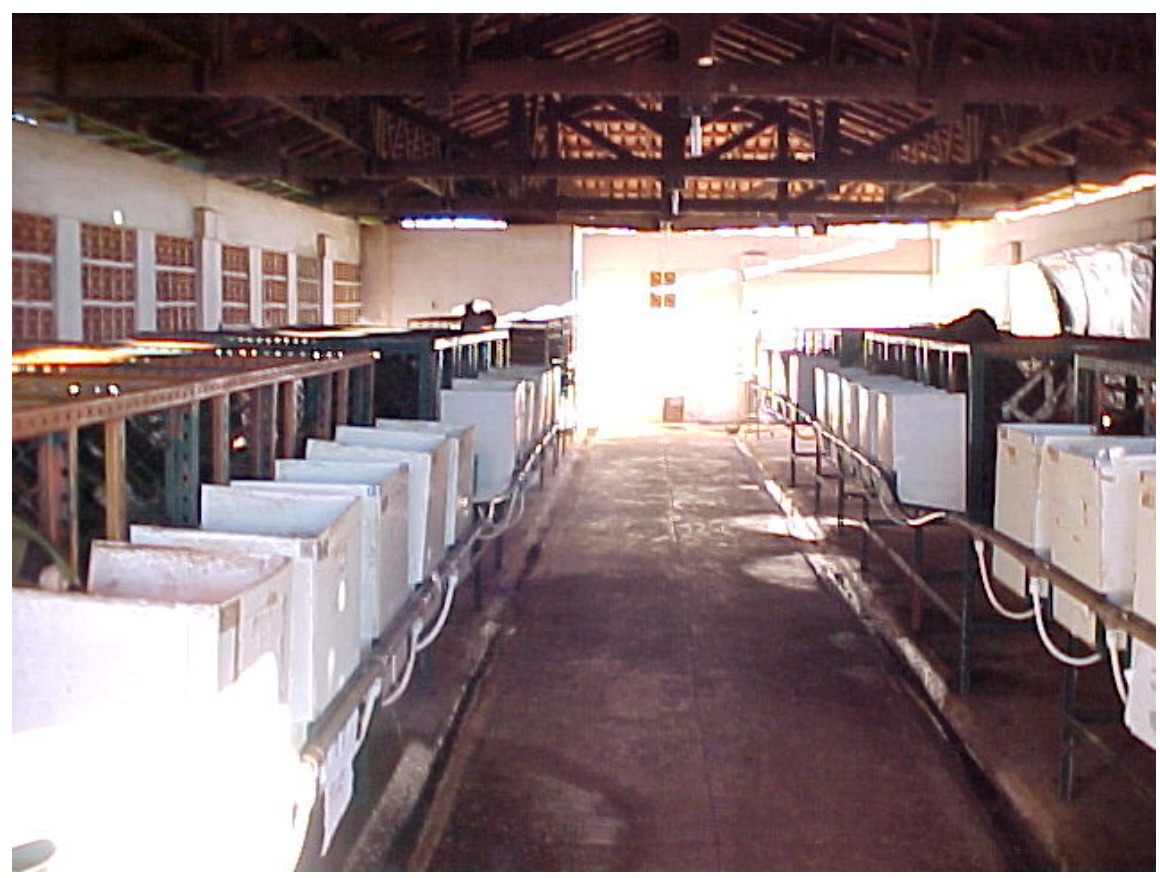

FIGURA 01. Galpão experimental. 


\subsection{Tratamentos}

Os animais foram alimentados com dieta calculada para suprir suas necessidades, segundo o NRC (1985). Foram oferecidos cinco tratamentos, diferindo nas concentrações de bicarbonato de sódio, sulfato de amônio e caulim. Dessa forma, os animais receberam cinco diferentes níveis de BCAD (-160;-40;140;260; $500 \mathrm{mEq} / \mathrm{kg}$ de MS). O tratamento com $140 \mathrm{mEq} / \mathrm{kg}$ de MS foi considerado o controle, uma vez que apresentou os níveis de $\mathrm{Na} ; \mathrm{K} ; \mathrm{Cl}$ e $\mathrm{S}$ preconizados pelo NRC (1985) para ovinos. A Tabela 1 apresenta a proporção dos ingredientes nas dietas experimentais.

TABELA 01. Composição percentual dos ingredientes das dietas em base seca e BCAD em mEq de $\{(\mathrm{Na}+\mathrm{K})-(\mathrm{Cl}+\mathrm{SO} 4)\}$.

\begin{tabular}{|c|c|c|c|c|c|}
\hline Ingredientes & N1 & N2 & C & $\mathbf{P 1}$ & $\mathbf{P 2}$ \\
\hline Casca de algodão & 30,00 & 30,00 & 30,00 & 30,00 & 30,00 \\
\hline Milho & 43,43 & 43,43 & 43,43 & 43,43 & 43,43 \\
\hline Soja extrusada & 20,72 & 20,72 & 20,72 & 20,72 & 20,72 \\
\hline Calcário & 1,35 & 1,35 & 1,35 & 1,35 & 1,35 \\
\hline Suplemento mineral* & 0,50 & 0,50 & 0,50 & 0,50 & 0,50 \\
\hline Caulim & 2,00 & 2,40 & 3,07 & 2,07 & - \\
\hline $\mathrm{NaHCO}_{3}$ & - & - & - & 1,00 & 3,07 \\
\hline $\mathrm{NH}_{3} \mathrm{SO}_{4}$ & 2,00 & 1,20 & - & - & - \\
\hline Uréia & 0,00 & 0,40 & 0,93 & 0,93 & 0,93 \\
\hline BCAD & -160 & -40 & 140 & 250 & 500 \\
\hline
\end{tabular}

(*) $500 \mathrm{~g}$ de suplemento mineral contém: $418,0 \mathrm{~g}$ de cloreto de sódio; $14,3 \mathrm{~g}$ de sulfato de ferro II; $11,5 \mathrm{~g}$ de sulfato de manganês II; 5,6 g de óxido de zinco; $0,32 \mathrm{~g}$ de iodato de sódio; $6,4 \mathrm{~g}$ de sulfato de cobre II e 0,2 $\mathrm{g}$ de sulfato de cobalto; $0,08 \mathrm{~g}$ de selenito de sódio; $40 \mathrm{~g}$ de Flor de enxofre; 0,09 $\mathrm{g}$ Selenito de sódio. 3,34g de complexo vitamínico com vitamina $\mathrm{A}$ (palmitato), vitamina $\mathrm{D}_{3}$ e tocoferol (acetato). 
TABELA 02. Composição químico-bromatológica e percentual dos minerais nas dietas experimentais com base na matéria seca e BCAD em mEq de $\left\{(\mathrm{Na}+\mathrm{K})-\left(\mathrm{Cl}+\mathrm{SO}_{4}\right)\right\}$.

\begin{tabular}{cccccc}
\hline & N1 & N2 & C & P1 & P2 \\
\hline Proteína Bruta (\%) & 19,15 & 20,47 & 18,63 & 20,98 & 19,37 \\
Fibra Bruta (\%) & 9,46 & 8,56 & 8,63 & 8,16 & 9,11 \\
Extrato Etéreo (\%) & 7,24 & 6,70 & 6,38 & 6,70 & 6,70 \\
Matéria Mineral (\%) & 8,52 & 9,10 & 10,99 & 9,73 & 9,64 \\
Cálcio (\%) & 1,11 & 1,11 & 1,10 & 1,12 & 1,13 \\
Fósforo (\%) & 0,55 & 0,55 & 0,55 & 0,55 & 0,55 \\
Sódio (\%) & 0,35 & 0,35 & 0,35 & 0,65 & 0,85 \\
Potássio (\%) & 1,25 & 1,25 & 1,28 & 1,18 & 1,20 \\
Enxofre (\%) & 0,80 & 0,60 & 0,35 & 0,37 & 0,36 \\
Cloro (\%) & 0,46 & 0,43 & 0,44 & 0,40 & 0,40 \\
BCAD & $\mathbf{- 1 5 9 , 8 8}$ & $\mathbf{- 4 0 , 5 4}$ & $\mathbf{1 3 8 , 7 9}$ & $\mathbf{2 5 1 , 0 1}$ & $\mathbf{5 0 0 , 4 9}$ \\
\hline
\end{tabular}

\subsection{Procedimento experimental}

O experimento teve duração de 90 dias, sendo os 15 primeiros constando de uma adaptação à ração total. Inicialmente os animais foram pesados, desverminados e distribuídos nas gaiolas de estudo metabólico. A água foi fornecida ad libitum através do sistema de abastecimento contínuo.

Os tratamentos foram sorteados e, os animais alimentados, às 8 horas e às 14 horas, em 4,4\% em MS do peso vivo. A cada quinzena os animais foram pesados. A colheita de sangue foi realizada no $15^{\circ} ; 30^{\circ} ; 45^{\circ}$ e $60^{\circ}$ dias do experimento.

Para a realização da digestibilidade e do balanço mineral (Ca,P,Na), foram feitas colheitas de fezes e da dieta na proporção de $10 \%$. A urina foi amostrada na proporção de 5\%. O período de colheita teve duração de 5 dias e foi realizado duas vezes. O primeiro realizado do $25^{\circ}$ ao $30^{\circ}$ dia e o segundo entre o $55^{\circ}$ e o $60^{\circ}$ dia. No $30^{\circ}$ e no $60^{\circ}$ dias foram retiradas amostras de fluido 
ruminal através de sonda esofagiana, com análise imediata de $\mathrm{pH}$ e retirada de sub-amostras diluídas em proporção de $25 \%$ com ácido fórmico P.A para posteriores análises de AGV. O pH urinário foi mensurado do $25^{\circ}$ ao $30^{\circ}$ dia do experimento e também do $55^{\circ}$ ao $60^{\circ}$ dia.

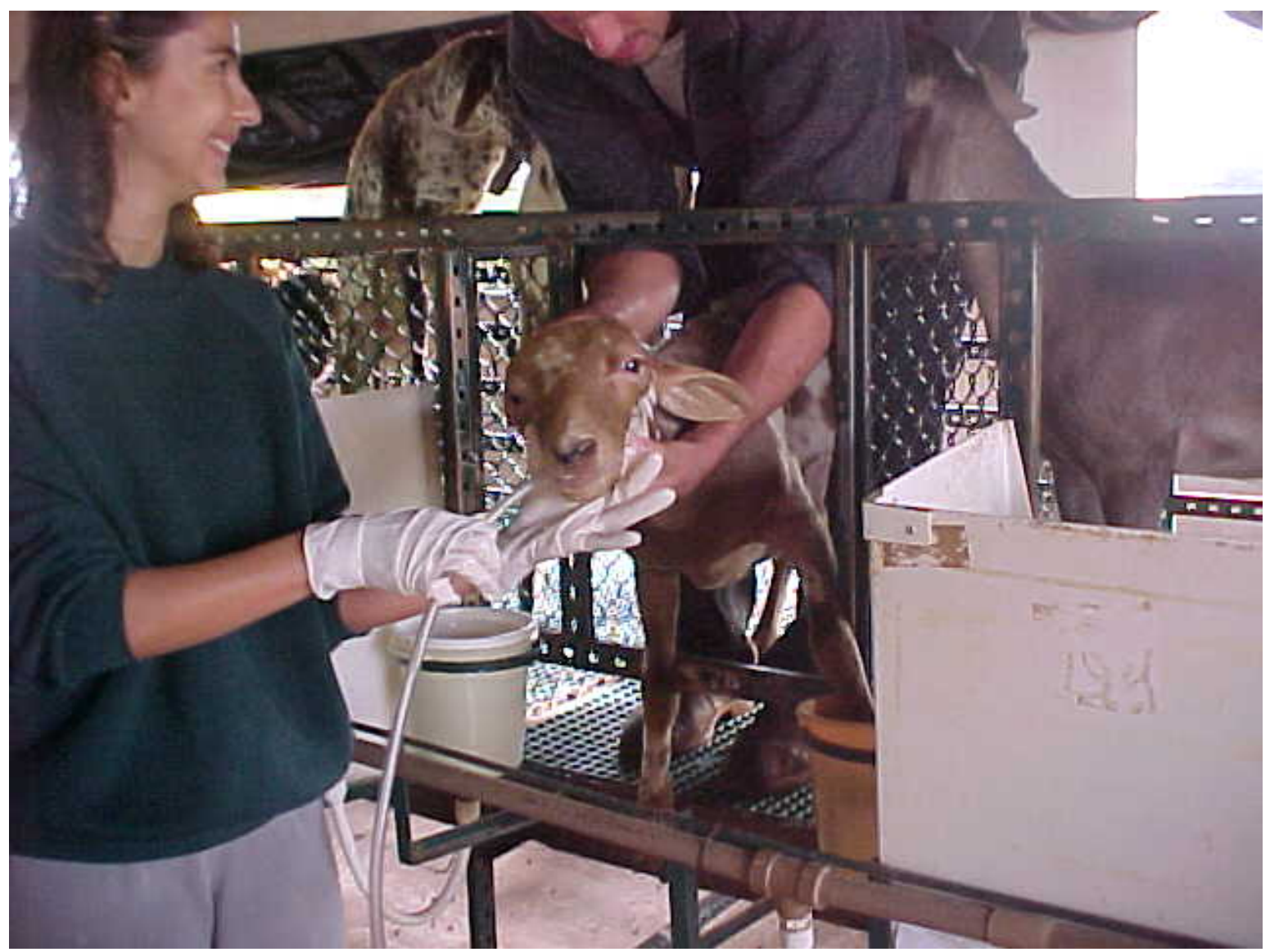

FIGURA 2. Colheita de líquido ruminal. 


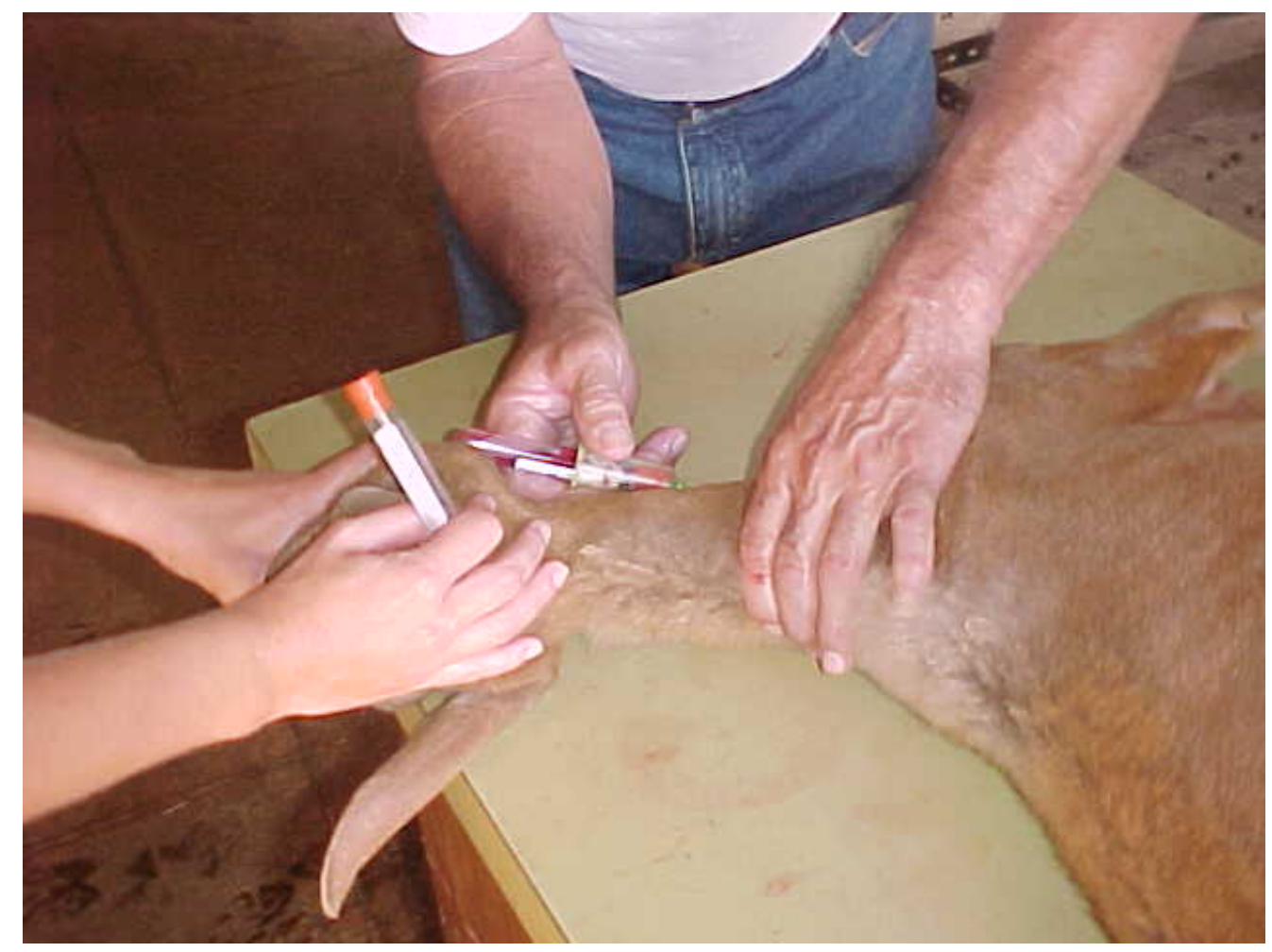

FIGURA 03. Colheita de sangue.

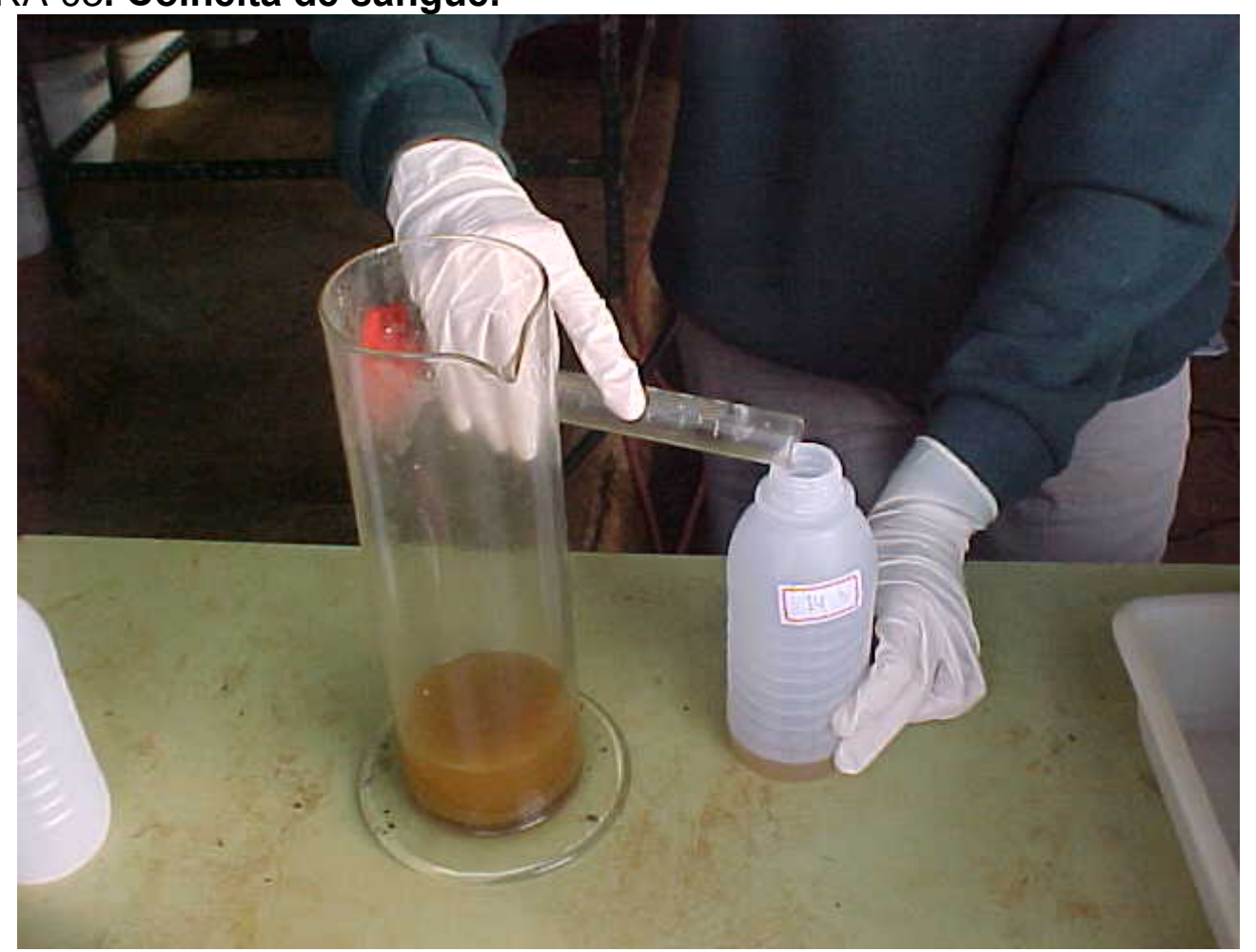

FIGURA 04. Amostragem de urina. 


\subsection{Procedimento analítico}

As determinações de matéria seca e matéria mineral para fezes e rações obedeceram às recomendações da AOAC (1990). As fezes, que foram armazenadas individualmente por dia de colheita e por animal, após serem descongeladas, foram homogeneizadas e colocadas em bandejas, as quais foram pesadas e colocadas em estufa à $65^{\circ} \mathrm{C}$ com ventilação forçada de ar por 72 horas. Essas amostras foram então moídas e alocadas em estufa a $100^{\circ} \mathrm{C}$ por 4 horas para a determinação da matéria seca total, através do resultado das duas pesagens. As amostras de fezes e rações foram solubilizadas com solução de ácido clorídrico $10 \mathrm{~N}$. As amostras foram diluídas primeiramente em balão volumétrico de $50 \mathrm{~mL}$ e posteriormente foram feitas novas diluições de acordo com cada análise feita. O cálcio foi determinado por espectrofotometria de absorção atômica (equipamento Perkin Elmer), através de diluições e adição de $1 \%$ de Lantânio (10N). O sódio foi determinado através de fotômetro de chama. O enxofre nas dietas experimentais foi determinado por turbidimetria em sistema "Flow Injection Analysis". O cloro foi determinado através de titulometria com nitrato de prata. O fósforo foi analisado colorimetricamente, seguindo a metodologia proposta por FISKE e SUBBAROW (1925).

As urinas, armazenadas individualmente, foram homogeneizadas, alocadas em garrafas plásticas e posteriormente acidificadas até atingirem pH entre 1 e 2. As análises de cálcio e sódio seguiram as metodologias apresentadas anteriormente para as rações e fezes. O fósforo na urina foi determinado através de Kit da marca LABTEST.

O cálcio total e ionizado no soro foram analisados através de Kit's da marca LABORLAB. Para a análise do cálcio ionizado, foram utilizados 3 tipos de "kit" , o primeiro para a determinação da quantidade de albumina presente no soro, o segundo para a determinação da proteína total e o terceiro para a determinação do cálcio total. Esses valores foram equacionados para a determinação do cálcio ionizado. 
$\mathrm{O} \mathrm{pH}$ ruminal foi mensurado imediatamente após a colheita, mediante uso de medidor de $\mathrm{pH}$ digital portátil (marca Hanna instruments modelo $\mathrm{HI}$ 8314), previamente calibrado com soluções padrões de $\mathrm{pH}$ 4,0 e 7,0. As subamostras, contendo $4 \mathrm{~mL}$ de líquido ruminal e $1 \mathrm{~mL}$ de ácido fórmico, foram degeladas, centrifugadas a $10^{\circ} \mathrm{C}$ por 20 minutos a uma rotação de $20.000 \mathrm{G}$. As determinações de AGV foram feitas por meio de cromatografia líquida, segundo metodologia proposta por ERWIN et al. (1961).

\subsection{Análise estatística}

O delineamento experimental foi em blocos casualizados, através do peso inicial dos animais. Foram utilizados 25 animais com cinco repetições por tratamento e cinco tratamentos. Os dados obtidos foram analisados por meio do programa computacional SAS (SAS Institute Inc., 1985). As variáveis foram analisadas no PROC GLM por regressão com os níveis do BCAD (-160, -40 140, 250 e $500 \mathrm{mEq} / \mathrm{kg}$ de MS). As variáveis também foram analisadas através de contrastes ortogonais por meio do PROC GLM, entre os tratamentos N1(-160 mEq/kg de MS), N2 (-40 mEq/kg de MS), C (140 mEq/kg de MS), P1(+250 mEq/kg de MS) e P2(+500 mEq/kg de MS), e também entre os tratamentos negativos (N1 e N2), o controle (C) e os positivos (P1 e P2). Foi adotado o nível de significância de 5\% para todos os dados analisados. 


\section{RESULTADOS E DISCUSSÕES.}

\subsection{Ingestão de matéria Seca}

O dados referentes à ingestão de matéria seca (IMS) durante todo o experimento estão apresentados na Tabela 3, onde se verifica uma relação linear entre o balanço cátion-aniônico da dieta (BCAD) e a IMS. Com a exceção dos primeiros 15 dias experimentais, em todas as outras fases observou-se um aumento da IMS com o aumento do BCAD. Em geral, observando os valores médios totais do experimento, a IMS aumentou a partir do BCAD de 140 até o de $500 \mathrm{mEq} / \mathrm{kg}$ de $\mathrm{MS}$.

TABELA 03. Níveis médios de Ingestão de matéria seca em $\mathrm{g} \mathrm{kg}^{-0,75}$, no período, em ovinos alimentados com diferentes níveis de BCAD em $\mathrm{mEq} / \mathrm{kg}$ de MS.

\begin{tabular}{cccccccccc}
\hline Período & \multicolumn{4}{c}{ Tratamentos. } & \multicolumn{4}{c}{ Análise de variância } \\
experimental & $\mathbf{- 1 6 0}$ & $\mathbf{- 4 0}$ & $\mathbf{1 4 0}$ & $\mathbf{2 5 0}$ & $\mathbf{5 0 0}$ & $\mathbf{C V}^{1}$ & $\mathbf{L}$ & $\mathbf{Q}$ & $\mathbf{C}$ \\
\hline $0-15$ & 74,31 & 76,52 & 71,83 & 75,19 & 77,02 & 3,31 & 0,04 & 0,04 & 0,37 \\
$15-30$ & 75,80 & 81,863 & 75,43 & 81,37 & 83,04 & 4,17 & $<0,01$ & 0,37 & 0,97 \\
$30-45$ & 83,20 & 88,560 & 84,29 & 90,61 & 92,89 & 5,55 & $<0,01$ & 0,57 & 0,59 \\
$45-60$ & 93,58 & 98,587 & 93,78 & 102,37 & 102,97 & 5,40 & $<0,01$ & 0,67 & 0,29 \\
$60-75$ & 103,32 & 107,04 & 104,33 & 113,33 & 112,98 & 5,93 & $<0,01$ & 0,89 & 0,15 \\
Total & 86,04 & 90,516 & 85,93 & 92,57 & 93,78 & 4,67 & $<0,01$ & 0,50 & 0,34 \\
\hline
\end{tabular}

$\mathrm{CV}^{1}=$ Coeficiente de variação

L - Efeito Linear Q- Efeito Quadrático C- Efeito Cúbico

Os resultados obtidos estão de acordo com os relatados por FAUCHON et al. (1995), os quais, em experimento desenvolvido com cordeiros recebendo BCAD de 100, 300, 500 e $700 \mathrm{mEq}$ de $(\mathrm{Na}+\mathrm{K})-(\mathrm{Cl}) / \mathrm{kg}$ de MS por 42 dias, encontraram efeito linear significativo $(P<0,01)$ na IMS. Os autores calcularam o $\mathrm{BCAD}$ apenas com a inclusão de $\mathrm{Cl}$ como ânion, não fornecendo os valores de $S$ na dieta. Dessa forma, para efeito de comparação com o presente trabalho, 
utilizando-se o NRC (1985) foi calculado o novo BCAD, resultando nos seguintes valores: 4, 175, 390 e $580 \mathrm{mEq}(\mathrm{Na}+\mathrm{K})-(\mathrm{Cl}+\mathrm{S}) / \mathrm{kg}$ de $\mathrm{MS}$. A IMS aumentou de 4 até $390 \mathrm{mEq} / \mathrm{kg}$ de MS e não se alterou de 390 a $580 \mathrm{mEq} / \mathrm{kg}$ de MS. WEST et al. (1992), em experimento com vacas em lactação sob estresse térmico, também encontraram aumento linear na IMS com o BCAD aumentando de 100 para $464 \mathrm{mEq}(\mathrm{Na}+\mathrm{K})-(\mathrm{Cl}+\mathrm{S}) / \mathrm{kg}$ de MS. ROSS et al. (1994a), em experimento desenvolvido com novilhos em crescimento, alimentados com dieta a base de volumoso (90\%), encontraram efeito linear positivo do BCAD com a IMS até o $84^{\circ}$ dia de experimento. Assim como no experimento citado anteriormente, os autores não forneceram os valores de $\mathrm{S}$ nas dietas experimentais, então, o mesmo procedimento foi adotado chegando aos seguintes valores: $-50,85,200$ e $395 \mathrm{mEq}(\mathrm{Na}+\mathrm{K})-(\mathrm{Cl}+\mathrm{S}) / \mathrm{kg} \mathrm{MS}$, com a ingestão máxima observada no BCAD de $395 \mathrm{mEq} / \mathrm{kg}$ de MS. Em contraste com esses resultados, ROSS et al. (1994b), em experimento conduzido com bovinos em terminação, alimentados com dieta concentrada (80\%), encontraram efeito linear significativo $(P<0,01)$ nos primeiros 28 dias e de efeito quadrático até o $84^{\circ}$ dia de experimento, sendo o maior consumo observado no tratamento de $150 \mathrm{mEq} / \mathrm{kg}$ de MS. Em bezerros, JACKSON et al. (1992) encontraram respostas quadráticas da IMS com BCAD de 0, 210, 370 e 529 $\mathrm{mEq}(\mathrm{Na}+\mathrm{K})-(\mathrm{Cl}+\mathrm{S}) / \mathrm{kg}$ de MS. Nesse experimento, a IMS aumentou até o tratamento de $370 \mathrm{mEq}(\mathrm{Na}+\mathrm{K})-(\mathrm{Cl}+\mathrm{S}) / \mathrm{kg}$ de $\mathrm{MS}$.

LEEK e HARDING citados por FORBES (1995) demonstraram a existência de quimioreceptores, localizados no rúmen e retículo com atividade dependente do $\mathrm{pH}$, sugerindo que a IMS diminui com a queda do $\mathrm{pH}$ ruminal. Os autores relataramm que com a queda do $\mathrm{pH}$ para valores próximos de 5 , ocorre hipofagia. BHATTACHARYA e WARNER, também citados por FORBES (1995) fizeram infusão de vários ácidos no rúmen, mantendo o pH ruminal por volta de 6 observaram redução na IMS com a diminuição do pH. A explicação reside no efeito do $\mathrm{pH}$ na motilidade ruminal. Dessa forma, uma explicação da linearidade entre BCAD e IMS é a relação existente entre o BCAD e o pH 
ruminal, principalmente em níveis positivos. Outra razão do aumento da IMS com o aumento do BCAD seria um possível aumento do consumo de água, o que é esperado pelo aumento de sódio dietético. Segundo WINCHESTER e MORRIS citados por FORBES (1995), o aumento da ingestão de água resulta em proporcional aumento de IMS para vacas. O comportamento quadrático e conseqüente diminuição da IMS em altos níveis de BCAD, encontrada por alguns autores, pode ter ocorrido por uma possível alteração da osmolaridade do líquido ruminal. Segundo DOUGLAS (2002a) a osmolaridade mede a concentração de moléculas por volume. A osmolaridade do rúmen é cerca de $260 \mathrm{mOsmol} / \mathrm{L}$, FORBES (1995) cita queda de IMS com valores superiores a $400 \mathrm{mOsmol} / \mathrm{L}$, o que poderia explicar essa resposta. Segundo MOSELEY e JONES citados por FORBES (1995) a adição de $30 \mathrm{~g}$ de sódio por kg em dietas com níveis adequados de sódio diminuí a ingestão sem afetar os níveis plasmáticos em ovinos.

A Tabela 4 apresenta as comparações entre os cinco tratamentos propostos no experimento. Pode-se observar que os tratamentos de BCAD negativo (N1 e N2) não apresentaram diferenças entre si, e também não foram diferentes do tratamento controle, porém, tiveram IMS menor que os tratamentos positivos (P1 e P2). A Figura 5 ilustra a IMS das dietas negativas positivas e controle, durante os 75 dias de experimento. 
TABELA 04. Comparação entre os níveis médios de IMS $\left(\mathrm{g} \mathrm{kg}^{-0,75}\right)$, em todo o período experimental, em ovinos alimentados com diferentes níveis de BCAD.

\begin{tabular}{cccccccc}
\hline Variável & \multicolumn{7}{c}{ Tratamentos } \\
& N1 & N2 & C & P1 & P2 & N & P \\
\hline N1 & - & NS & NS & S & S & - & S \\
N2 & N2 & - & NS & S & S & - & S \\
C & NS & NS & - & S & S & NS & S \\
P1 & S & S & S & - & NS & S & - \\
P2 & S & S & S & NS & - & S & - \\
N & - & - & NS & S & S & - & S \\
P & S & S & S & - & - & S & \\
\hline
\end{tabular}

$\mathrm{C}=140 \mathrm{mEq} / \mathrm{kg}$ de $\mathrm{MS}$

$\mathrm{N} 1=-160 \mathrm{mEq} / \mathrm{kg}$ de MS N2 $=-40 \mathrm{mEq} / \mathrm{kg}$ de MS.

$\mathrm{P} 1=250 \mathrm{mEq} / \mathrm{kg}$ de MS P2= $500 \mathrm{mEq} / \mathrm{kg}$ de MS.

$\mathrm{N}=$ Dietas com adição de $\left(\mathrm{NH}_{4}\right)_{2} \mathrm{SO}_{4}$ ( $\left.\mathrm{N} 1 \mathrm{e} \mathrm{N} 2\right)$.

$\mathrm{P}=$ Dietas com adição de $\mathrm{Na}\left(\mathrm{HCO}_{3}\right)$ ( $\mathrm{P} 1$ e P2).

$\mathrm{S}=$ Significativo $\mathrm{P}<0,05$. NS= Não significativo $P>0,10$.

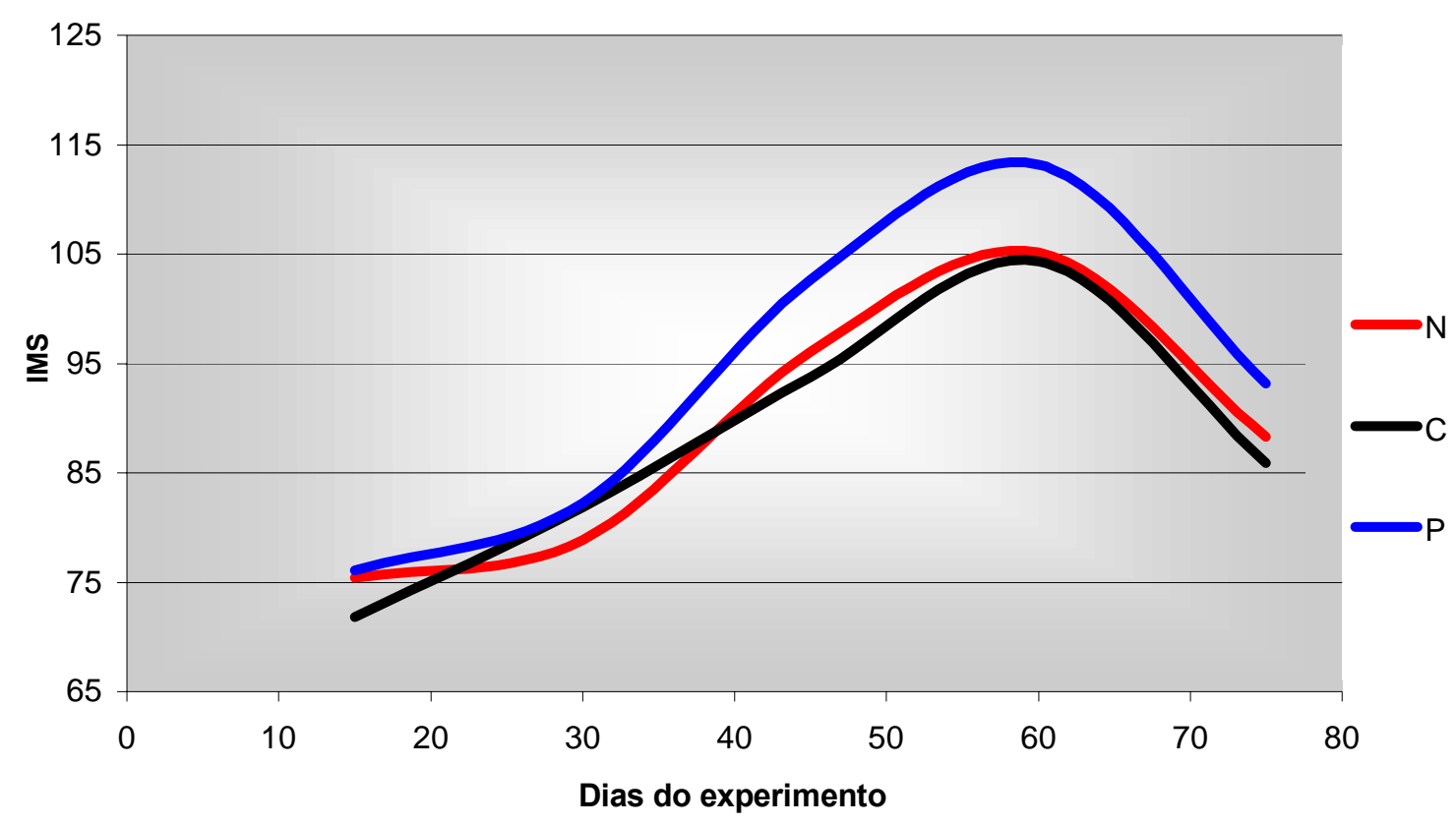

FIGURA 05. Níveis médios de IMS ( $\left.\mathrm{g} \mathrm{kg}^{-0,75}\right)$ em ovinos alimentados com diferentes níveis de BCAD, ao longo dos 75 dias de experimento. 
OETZEL e BARMORE (1993) concluíram que a inclusão de sais aniônicos $\left(\mathrm{NH}_{4} \mathrm{Cl} ; \quad \mathrm{MgSO}_{4} .7 \mathrm{H}_{2} \mathrm{O} ; \quad \mathrm{CaCl}_{2} \cdot 2 \mathrm{H}_{2} \mathrm{O} ; \quad\left(\mathrm{NH}_{4}\right)_{2} \mathrm{SO}_{4}\right)$ diminuíram significativamente o consumo de matéria seca. Entretanto, o volumoso constituído por feno de alfafa e o concentrado com os sais aniônicos foram oferecidos separadamente. MOORE et al. (2000), VAGNONI e OETZEL (1998) também encontraram efeitos negativos na IMS com adição de sais aniônicos.

OETZEL et al. (1988) não encontraram diminuição no consumo de matéria seca quando suplementaram $\mathrm{NH}_{4} \mathrm{Cl}$ ou $\left(\mathrm{NH}_{4}\right)_{2} \mathrm{SO}_{4}$. Nesse experimento, os autores fizeram uso da mistura completa do volumoso com o concentrado. TAKAGI e BLOCK (1991a) em experimento com cordeiros, não encontraram diferenças significativas na IMS em função do uso de BCAD negativo. Tais autores arraçoaram os animais experimentais com ração completa. JACKSON e HEMKEN (1994) fornecendo dietas de -180 e $+130 \mathrm{mEq} / \mathrm{kg}$ de MS na forma de ração total a bezerros não encontraram diferenças na IMS. JACKSON et al. (2001), fazendo uso de ração completa em experimento desenvolvido com bezerros e BCAD de 0 e $200 \mathrm{mEq}$ de $(\mathrm{Na}+\mathrm{K})-(\mathrm{Cl}+\mathrm{S}) / \mathrm{kg}$ de $\mathrm{MS}$ não encontraram diferenças na IMS. DEL CLARO et al. (2002), suplementando novilhos em crescimento com sulfato de amônio $\left(\left(\mathrm{NH}_{4}\right)_{2} \mathrm{SO}_{4}\right)$ e BCAD de -150 $\mathrm{mEq}$ de $(\mathrm{Na}+\mathrm{K})-(\mathrm{Cl}+\mathrm{S}) / \mathrm{kg}$ de $\mathrm{MS}$,oferecidos na forma de ração total, não encontraram diferenças na IMS em relação a dieta basal (+ $70 \mathrm{mEq}$ de (Na+K)$(\mathrm{Cl}+\mathrm{S}) / \mathrm{kg}$ de $\mathrm{MS})$.

A razão pela qual não foi encontrada diferença entre a IMS da dieta considerada controle e das dietas negativas (N1 e N2) se dá, primeiramente, pelos ingredientes utilizados no experimento (soja extrusada e milho), que são veículos altamente palatáveis. Outro fator que favoreceu a estabilização do consumo, diz respeito ao fornecimento da dieta na forma de ração completa, o que diminui os efeitos da baixa palatabilidade dos sais aniônicos. 


\subsection{Ganho de peso e eficiência alimentar}

A Tabela 5 apresenta dados referentes a média de ganho de peso diário, a eficiência alimentar e a digestibilidade de matéria seca, de ovinos alimentados com diferentes relações entre cátions e ânions.

TABELA 05. Valores médios da digestibilidade de matéria seca(\%), ganho de peso diário em $\mathrm{kg}$ por dia e eficiência alimentar ( $\mathrm{kg}$ de ganho/ kg de MS ingerido), em ovinos alimentados com diferentes níveis de BCAD.

\begin{tabular}{|c|c|c|c|c|c|c|c|c|c|}
\hline \multirow[t]{2}{*}{ Variáveis } & \multicolumn{5}{|c|}{ Tratamentos } & \multicolumn{4}{|c|}{ Análise de variância } \\
\hline & -160 & -40 & 140 & 250 & 500 & $C V^{1} \%$ & $\mathbf{L}$ & $\mathbf{Q}$ & C \\
\hline DA & 71,060 & 70,830 & 70,230 & 72,250 & 72,760 & 2,88 & 0,12 & 0,38 & 0,52 \\
\hline \multicolumn{10}{|l|}{ GPD (kg) } \\
\hline Dias 0-15 & 0,026 & 0,095 & 0,062 & 0,110 & 0,107 & 46,67 & $<0,01$ & 0,30 & 0,32 \\
\hline Dias $15-30$ & 0,134 & 0,121 & 0,159 & 0,169 & 0,181 & 33,99 & 0,05 & 0,97 & 0,34 \\
\hline Dias $30-45$ & 0,190 & 0,188 & 0,176 & 0,223 & 0,197 & 17,15 & 0,36 & 0,76 & 0,08 \\
\hline Dias $45-60$ & 0,186 & 0,164 & 0,204 & 0,217 & 0,197 & 20,73 & 0,16 & 0,46 & 0,07 \\
\hline Dias $60-75$ & 0,218 & 0,196 & 0,174 & 0,191 & 0,197 & 24,01 & 0,48 & 0,281 & 0,61 \\
\hline Total & 0,151 & 0,153 & 0,155 & 0,182 & 0,174 & 14,14 & 0,02 & 0,80 & 0,14 \\
\hline \multicolumn{10}{|l|}{$\overline{E A}$} \\
\hline Dias 0-15 & 0,044 & 0,157 & 0,115 & 0,190 & 0,180 & 48,03 & 0,01 & 0,21 & 0,31 \\
\hline Dias $15-30$ & 0,210 & 0,185 & 0,264 & 0,254 & 0,272 & 36,63 & 0,14 & 0,77 & 0,56 \\
\hline Dias $30-45$ & 0,293 & 0,255 & 0,255 & 0,293 & 0,245 & 19,99 & 0,43 & 0,93 & 0,12 \\
\hline Dias $45-60$ & 0,236 & 0,190 & 0,250 & 0,241 & 0,221 & 20,02 & 0,70 & 0,56 & 0,10 \\
\hline Dias 60-75 & 0,245 & 0,213 & 0,195 & 0,195 & 0,193 & 24,00 & 0,05 & 0,34 & 0,94 \\
\hline Total & 0,200 & 0,206 & 0,216 & 0,234 & 0,222 & 10,71 & 0,05 & 0,42 & 0,21 \\
\hline
\end{tabular}

$C V^{1}$-Coeficiente de variação.

L - Efeito Linear Q- Efeito Quadrático C- Efeito Cúbico

$\mathrm{DA}=$ Digestibilidade Aparente da matéria seca.

EA= Eficiência Alimentar (ganho/lngestão) 
A digestibilidade aparente da matéria seca não foi alterada pelo BCAD. $O$ ganho de peso médio e a eficiência alimentar, durante os 75 dias de experimento aumentaram de forma linear sendo que o maior valor, tanto de GPD como de EA foi conseguido com BCAD de $250 \mathrm{mEq} / \mathrm{kg}$ de $\mathrm{MS}$, não se alterando com $500 \mathrm{mEq}[(\mathrm{Na}+\mathrm{K})-(\mathrm{Cl}+\mathrm{S}) / \mathrm{kg}$ de $\mathrm{MS}$.

Os resultados obtidos são semelhantes aos apresentados por FAUCHON et al. (1995), os quais objetivando estudar a relação entre BCAD e desempenho em cordeiros, trabalharam com a inclusão de bicarbonato e BCAD de 4, 175, 390 e $580 \mathrm{mEq}[(\mathrm{Na}+\mathrm{K})-(\mathrm{Cl}+\mathrm{S})] / \mathrm{kg}$ de $\mathrm{MS}$. Os autores não encontraram diferenças na digestibilidade de matéria seca.O aumento do BCAD resultou em aumento linear no GPD. Apesar da linearidade positiva entre BCAD e GPD encontrada nos dois experimentos, FAUCHON et al. (1995), encontraram o maior GPD no BCAD de $+580 \mathrm{mEq} / \mathrm{kg}$ MS . A explicação para essa diferença pode residir no tempo de execução do experimento e no peso inicial dos ovinos, uma vez que esse foi realizado em apenas 42 dias e animais de peso inicial superior (31,4 kg contra $15 \mathrm{~kg}$ em média). A eficiência alimentar não foi alterada no experimento de FAUCHON et al. (1995), entretanto houve uma tendência de aumentar com o aumento do BCAD do $21^{\circ}$ ao $42^{\circ}$ dia de experimento. $A$ máxima eficiência encontrada pelos autores foi de 0,170 diferente do presente experimento $(0,234)$, o que pode ser reflexo da diferença de peso dos animais experimentais. A digestibilidade de matéria seca também não se modificou em função dos diferentes níveis de BCAD (5 a $580 \mathrm{mEq} / \mathrm{kg}$ de MS), assim como o presente experimento. Esses autores consideraram o BCAD entre 390 e 580 $[(\mathrm{Na}+\mathrm{K})-(\mathrm{Cl}+\mathrm{S}) / \mathrm{kg}$ de $\mathrm{MS}$ os de melhor resultado no desempenho de cordeiros, dentro do nível de BCAD preconizado no presente experimento.

ROSS et al. (1994a) avaliaram a influência do BCAD no desempenho de novilhos em crescimento, alimentados com silagem de milho, usando o $\mathrm{NaHCO}_{3}{ }^{-}$como tamponante e $\mathrm{NH}_{4} \mathrm{Cl}$ com sal aniônico, com tratamentos de BCAD 0, 150, 300 e $450 \mathrm{mEq}(\mathrm{Na}+\mathrm{K})-(\mathrm{Cl})] / \mathrm{kg} \mathrm{MS}$, ou -50; 85; 200 e 395 $\mathrm{mEq}(\mathrm{Na}+\mathrm{K})-(\mathrm{Cl}+\mathrm{S})] / \mathrm{kg} \mathrm{MS}$. A média de ganho de peso mostrou um 
aumento linear com o aumento da BCAD nos primeiros 28 dias e uma resposta quadrática para o restante do experimento, com valor máximo obtido no BCAD de +150 e +300 mEq Na + K) - (Cl) ] /kg de MS, ou 200 e $395 \mathrm{mEq}$ de $(\mathrm{Na}+\mathrm{K})$ - $(\mathrm{Cl}+\mathrm{S}) / \mathrm{kg}$ de MS. O mesmo comportamento foi reportado para a eficiência alimentar, sendo esses os níveis de BCAD recomendados pelos autores para novilhos em crescimento com alimentação a base de silagem de milho, ou seja, dentro da faixa observada pelo presente experimento para cordeiros em crescimento. No experimento em que se utilizaram altos níveis de concentrado ROSS et al. (1994b) encontraram um aumento quadrático no GPD e valor máximo em $150 \mathrm{mEq}$ de $(\mathrm{Na}+\mathrm{K})-(\mathrm{Cl})] / \mathrm{kg}$ de $\mathrm{MS}$, enquanto a EA não foi influenciada pelo BCAD.

JACKSON et al. (2001), em experimento conduzido com bezerros tratados com 0 ou $200 \mathrm{mEq}[(\mathrm{Na}+\mathrm{K})-(\mathrm{Cl}+\mathrm{S})] / \mathrm{kg}$ de $\mathrm{MS}$, ou seja, fora da faixa de BCAD encontrada no presente experimento para 0 melhor desempenho em cordeiros em crescimento, não observaram diferenças no GPD médio. Entretanto, JACKSON et al. (1992) estudando os efeitos do BCAD no desempenho de bezerros, utilizando $-179,45,225$ e $383 \mathrm{mEq}[(\mathrm{Na}+\mathrm{K})-$ $(\mathrm{Cl}+\mathrm{S})]$ / $\mathrm{kg}$ de $\mathrm{MS}$, encontraram melhores resultados no tratamento $+225 \mathrm{mEq}$ $[(\mathrm{Na}+\mathrm{K})-\mathrm{Cl}] / \mathrm{kg}$ de $\mathrm{MS}$, resultado próximo do obtido no presente experimento.

O maior desempenho observado para dietas com adição de $\mathrm{NaHCO}_{3}(\mathrm{P} 1$ e P2) são explicados por um aumento na IMS e na EA. BLOCK (1994) sugeriu que a bomba de sódio e potássio, mecanismo que opera juntamente com a entrada de glicose nas células, pode se alterar por um desbalanço entre esses dois minerais, sendo esse um dos motivos da influência do BCAD no desempenho animal.

A análise de contrastes revelou que os tratamentos de BCAD negativo (N1 e N2) e o tratamento controle apresentaram média de GPD inferior às positivas (P1 e P2). Dietas com BCAD negativo podem causar uma 
hipopotassemia devida acidose metabólica, desbalanceando a bomba de sódio e potássio, resultando em menores concentrações de glicose intracelular. $\mathrm{O}$ metabolismo de forma sistêmica gera ácidos endógenos, que também poderiam acarretar em hipopotassemia (se a capacidade de tamponamento for ultrapassada), o que pode explicar o maior desempenho das dietas positivas em relação a controle.

A Figura 6 ilustra o ganho de peso diário e a eficiência alimentar, durante os 75 dias do experimento. Os resultados do presente estudo, juntamente com a literatura consultada, sugerem que para ruminantes em crescimento o BCAD para maximização do desempenho, está entre 250 e $500 \mathrm{mEq}[(\mathrm{Na}+\mathrm{K})-(\mathrm{Cl}$ $+\mathrm{S})]$ / kg de MS.

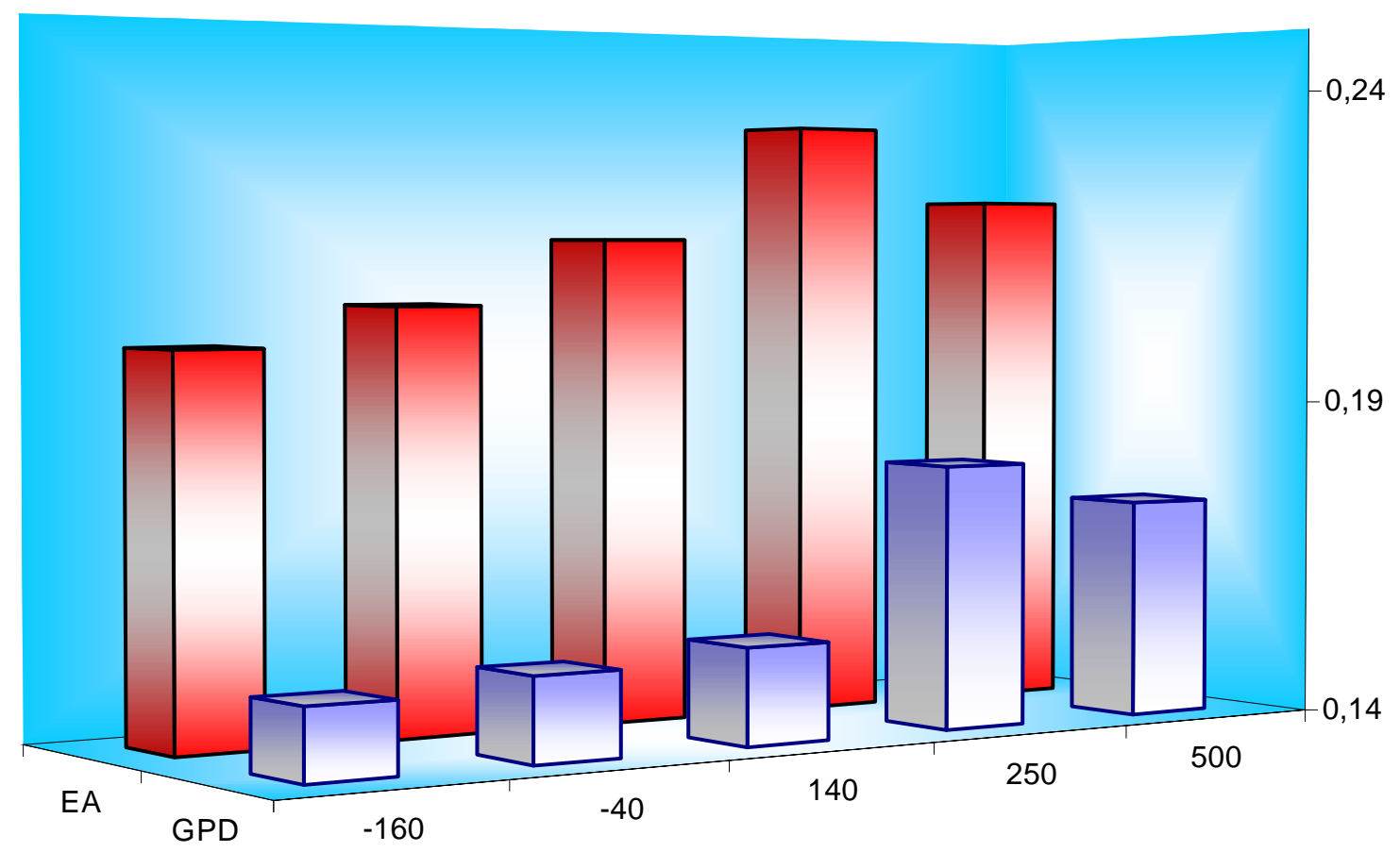

FIGURA 06. Níveis médios de ganho de peso diário (GPD) em $\mathrm{kg}$ por dia e eficiência alimentar, em ovinos alimentados com diferentes níveis de BCAD em mEq de $(\mathrm{Na}+\mathrm{K})-(\mathrm{Cl}+\mathrm{S})$ por $\mathrm{Kg}$ de $\mathrm{MS}$, durante os 75 dias de experimento. 


\section{$4.3 \mathrm{pH}$ do líquido ruminal}

A Tabela 6 apresenta os valores de $\mathrm{pH}$ do líquido ruminal, referentes ao $30^{\circ}$ e $60^{\circ}$ dias, em função de diferentes níveis de BCAD, onde se observa efeito linear e quadrático significativo, respectivamente. $\mathrm{O}$ aumento do BCAD aumentou o pH ruminal. Todos os valores são considerados normais para ruminantes recebendo altos níveis de concentrado e fibra curta, como é o caso da casca de algodão.

TABELA 06.Valores médios de $\mathrm{pH}$ do líquido ruminal no $30^{\circ}$ e $60^{\circ}$ dia de experimento em cordeiros alimentados com diferentes níveis de BCAD.

\begin{tabular}{cccccccccc}
\hline & \multicolumn{4}{c}{ Tratamentos } & \multicolumn{4}{c}{ Análise de variância } \\
Período & $\mathbf{- 1 6 0}$ & $\mathbf{- 4 0}$ & $\mathbf{1 4 0}$ & $\mathbf{2 5 0}$ & $\mathbf{5 0 0}$ & $\mathbf{C V}^{1} \%$ & $\mathbf{L}$ & $\mathbf{Q}$ & $\mathbf{C}$ \\
\hline $30^{\circ}$ dia. & 6,20 & 6,49 & 6,47 & 6,56 & 6,57 & 2,81 & 0,01 & 0,14 & 0,24 \\
$60^{\circ}$ dia. & 5,79 & 6,07 & 6,27 & 6,23 & 6,29 & 2,31 & $<0,01$ & 0,01 & 0,47 \\
Média & 6,00 & 6,24 & 6,37 & 6,42 & 6,40 & 1,89 & $<0,01$ & $<0,01$ & 0,25 \\
\hline
\end{tabular}

CV -Coeficiente de variação.

L - Efeito Linear Q- Efeito Quadrático C- Efeito Cúbico

$\mathrm{O}$ pH do líquido ruminal reflete o balanço entre as taxas de produção e absorção ruminal dos ácidos graxos voláteis, o tamponamento por meio da saliva e a presença de tampões ou bases dos alimentos (VAN SOEST, 1994). Dietas ricas em concentrado requerem baixo tempo de ruminação, conseqüentemente reduzindo a secreção salivar em relação à produção de ácidos graxos voláteis (ORSKOV e RYLE, 1990). O presente experimento fez uso de uma dieta concentrada, utilizando $30 \%$ de casca de algodão como fonte volumosa, ou seja, fibra não efetiva, o que explica os valores de $\mathrm{pH}$ ruminal encontrados em todos os tratamentos. O líquido ruminal foi colhido por sonda esofagiana o que também pode ter influência no $\mathrm{pH}$, já que a contaminação de saliva pode existir. Os resultados do presente experimento concordam com TUCKER et al. (1988), que relataram aumento 
do $\mathrm{pH}$ do fluído ruminal de forma linear com o aumento nos níveis de BCAD em vacas leiteiras. Os tratamentos de $-100,0,100$ ou $200 \mathrm{mEq}(\mathrm{Na}+\mathrm{K})-$ $(\mathrm{Cl}+\mathrm{S}) / \mathrm{kg}$ de MS e os valores encontrados foram de 6,5; 6,63; 6,73 e 6,76 respectivamente. Menores valores de $\mathrm{pH}$ do líquido ruminal para tratamentos com BCAD negativo também foram observados por VAGNONI e OETZEL (1998), os quais trabalharam com vacas secas e diferentes sais aniônicos com BCAD de 203;-51;-40 e -63 mEq(Na+K) - (Cl+S)/ Kg de MS e encontraram queda de 0,12 unidades de $\mathrm{pH}$ quando as vacas eram alimentadas com sais aniônicos em relação ao período com alimentação basal $(203 \mathrm{mEq}(\mathrm{Na}+\mathrm{K})-(\mathrm{Cl}+\mathrm{S}) / \mathrm{kg})$. Os resultados do presente estudo também concordam com os relatados por ROSS et al. (1994a), em experimento desenvolvido com novilhos em crescimento com tratamentos de BCAD -50, 85, 200 e $395 \mathrm{mEq}(\mathrm{Na}+\mathrm{K})-(\mathrm{Cl}+\mathrm{S})] / \mathrm{kg} \mathrm{MS}$, onde com coleta de fluído ruminal por sonda esofagiana encontrou-se efeito linear no $28^{\circ}$ dia de experimento. $\mathrm{O}$ pH aumentou de 6,66 no BCAD de -50 até 6,93 no BCAD de 200, permanecendo inalterado até o BCAD de $395 \mathrm{mEq}(\mathrm{Na}+\mathrm{K})-$ $(\mathrm{Cl}+\mathrm{S})] / \mathrm{kg} \mathrm{MS}$.

Os menores valores encontrados para as dietas negativas, provavelmente são resultados de um aumento do SID (strong íon difference), no fluído ruminal. STEWART (1983) afirmou que a concentração do íon de hidrogênio dependente da diferença entre as concentrações de cátions fortes e de ânions fortes em uma solução (SID). Conseqüentemente, uma mudança em $\mathrm{pH}$ indica que deve haver uma mudança em uma destas variáveis independentes.O SID é definido pela concentração de $(\mathrm{Na}+\mathrm{K})-\left(\mathrm{Cl}+\mathrm{SO}_{4}\right) . \mathrm{O}$ $\left(\mathrm{NH}_{4}\right)_{2} \mathrm{SO}_{4}$ encontrado nos tratamentos de -160 e $-40 \mathrm{mEq} / \mathrm{kg}$ de $\mathrm{MS}$ diminui o SID no rúmen, pela alta concentração de $\mathrm{SO}_{4}$, provavelmente diminuindo $\mathrm{o}$ $\mathrm{pH}$ desse fluído sendo a mesma explicação válida para o maior $\mathrm{pH}$ com a inclusão de $\mathrm{NaHCO}_{3}$ (+250 e $500 \mathrm{meq} / \mathrm{kg}$ de MS).Os tratamentos com adição de $\mathrm{NaHCO}_{3}$ ainda aumentam os valores do $\mathrm{pH}$, por um tamponamento do bicarbonato, um aumento da ingestão de água, diluição do líquido ruminal e 
conseqüente aumento de fluxo (RUSSEL e CHOW, 1993). Dessa forma, a relação positiva encontrada entre $\mathrm{pH}$ ruminal e $\mathrm{BCAD}$, provavelmente foi em conseqüência de uma alteração no SID no rúmen e também por um tamponamento do ácido produzido, nos tratamentos com a inclusão de $\mathrm{NaHCO}_{3}$. 


\section{4 Ácidos graxos voláteis}

Os resultados de fermentação ruminal, analisada pelo perfil de ácidos graxos voláteis estão apresentados nas Tabelas 7 e 8 . Foram realizadas colheitas nos dias 30 e 60 do período experimental, através de sonda esofagiana.

TABELA 07. Concentrações médias de ácidos graxos voláteis em mmol/dL e em percentual do total no $30^{\circ}$ dia, em ovinos alimentados com diferentes níveis de BCAD.

\begin{tabular}{|c|c|c|c|c|c|c|c|c|c|}
\hline \multirow[b]{2}{*}{ Variáveis } & \multicolumn{5}{|c|}{ Tratamentos } & \multicolumn{4}{|c|}{ Análise de variância } \\
\hline & -160 & -40 & 140 & 250 & 500 & $\mathrm{CV}^{1} \%$ & $\mathbf{L}$ & $\mathbf{Q}$ & C \\
\hline Á. acético & 19,01 & 22,75 & 31,75 & 26,79 & 22,83 & 23,94 & 0,21 & $<0,01$ & 0,93 \\
\hline Á. Acético $(\%)^{2}$ & 71,22 & 65,76 & 72,31 & 60,44 & 68,24 & 8,57 & 0,35 & 0,25 & 0,55 \\
\hline A.propiônico & 5,65 & 9,59 & 9,68 & 16,10 & 9,01 & 59,56 & 0,23 & 0,06 & 0,48 \\
\hline A Propiônico (\%) ${ }^{2}$ & 21,64 & 27,30 & 21,63 & 34,54 & 25,86 & 21,40 & 0,21 & 0,27 & 0,74 \\
\hline A. Butírico & 1,92 & 2,45 & 2,72 & 3,71 & 1,96 & 45,64 & 0,63 & 0,03 & 0,33 \\
\hline A. Butírico $(\%)^{2}$ & 7,130 & 6,93 & 6,052 & 7,71 & 5,89 & 22,95 & 0,33 & 0,63 & 0,29 \\
\hline$A / P^{*}$ & 3,36 & 2,56 & 3,44 & 2,02 & 2,79 & 26,28 & 0,25 & 0,35 & 0,83 \\
\hline Total. & 26,59 & 34,79 & 44,17 & 46,61 & 38,81 & 32,22 & 0,21 & 0,01 & 0,68 \\
\hline $\begin{array}{l}C V^{1} \text { Coe } \\
\text { L - Efeitc } \\
\text { Q - Efeit } \\
\text { C - Efeit } \\
{ }^{\star} A / P-A C\end{array}$ & cão & & & & & & & & \\
\hline
\end{tabular}


TABELA 08. Concentrações médias de ácidos graxos voláteis em $\mathrm{mmol} / \mathrm{dL}$ e em percentual do total no $60^{\circ}$ dia, em ovinos alimentados com diferentes níveis de BCAD.

\begin{tabular}{|c|c|c|c|c|c|c|c|c|c|}
\hline \multirow[b]{2}{*}{ Variáveis } & \multicolumn{5}{|c|}{ Tratamentos } & \multicolumn{4}{|c|}{ Análise de variância } \\
\hline & -160 & -40 & 140 & 250 & 500 & $\mathrm{CV}^{1} \%$ & $\mathbf{L}$ & $\mathbf{Q}$ & C \\
\hline Á. Acético & 27,67 & 30,91 & 26,76 & 22,95 & 31,08 & 26,28 & 0,92 & 0,37 & 0,20 \\
\hline Á. Acético $(\%)^{2}$ & 66,09 & 62,63 & 64,60 & 61,99 & 63,41 & 11,43 & 0,70 & 0,63 & 0,57 \\
\hline A.propiônico & 10,93 & 16,00 & 11,67 & 12,92 & 15,97 & 47,55 & 0,54 & 0,94 & 0,19 \\
\hline A.Propiônico $(\%)^{2}$ & 26,23 & 31,54 & 29,15 & 30,83 & 30,73 & 27,40 & 0,61 & 0,63 & 0,38 \\
\hline A. Butírico & 3,19 & 2,88 & 2,53 & 2,88 & 2,893 & 41,21 & 0,81 & 0,64 & 0,75 \\
\hline A. Butírico $(\%)^{2}$ & 7,66 & 5,83 & 6,25 & 7,17 & 5,85 & 29,75 & 0,48 & 0,85 & 0,14 \\
\hline$A / P^{*}$ & 2,71 & 2,120 & 2,31 & 2,17 & 2,554 & 45,43 & 0,89 & 0,31 & 0,52 \\
\hline Total & 41,74 & 49,80 & 40,96 & 38,75 & 49,95 & 28,49 & 0,72 & 0,55 & 0,17 \\
\hline
\end{tabular}

CV Coeficiente de variação.

$L$ - Efeito Linear

Q - Efeito Quadrático

C - Efeito Cúbico

${ }^{*}$ A/P- Acético/Propiônico.

${ }^{2}$ (\%)-em relação ao Total

De maneira geral, tanto no $30^{\circ}$ quanto no $60^{\circ}$ dia de experimento o BCAD não apresentou grande influência sobre o perfil de ácidos graxos voláteis no rúmen. Apenas no $30^{\circ}$ dia de experimento a produção de ácido acético, em mmol por dL apresentou comportamento quadrático, aumentando até o BCAD de 140 e diminuindo posteriormente até o BCAD de $500 \mathrm{mEq} / \mathrm{kg}$ de MS.Também no $30^{\circ}$ dia a concentração de ácido butírico e a concentração total de ácidos graxos voláteis também apresentaram comportamento quadrático, crescendo até o BCAD de 250 e diminuindo no de $500 \mathrm{mEq} / \mathrm{kg}$ de $\mathrm{MS}$, podendo ser reflexo de uma diluição ruminal em função de um maior consumo de água.

Esses resultados concordam com o experimento desenvolvido por TUCKER et al. (1988), os quais em experimento desenvolvido com vacas lactantes, tratadas com BCAD de -100 até $+200 \mathrm{mEq} / \mathrm{kg}$ de MS, afirmaram que o BCAD não interferiu no perfil de AGVs, embora o total de AGV tendeu a 
diminuir com o aumento do BCAD. ROSS et al. (1994a), também afirmaram que o BCAD tem pouca influência nas proporções molares de AGVs. Os autores encontraram um crescimento linear do ácido butírico e propiônico no $84^{\circ}$ dia de experimento. ROSS et al. (1994b) afirmaram que a fermentação ruminal não foi afetada pelo BCAD. VAGNONI e OETZEL (1998) em experimento comparando sais aniônicos, também não encontraram efeitos do BCAD na proporção individual de AGVs, ou na relação entre acético e propiônico e sugeriram que esses sais exerceriam um modesto efeito na fermentação ruminal.

Os resultados do presente estudo concordam com a literatura consultada, em que o BCAD tem pouca influência no perfil de ácidos graxos voláteis no rúmen. Entretanto grande parte dos autores encontram efeitos diminuição na concentração total de AGVs com aumento do BCAD, resultado apenas encontrado no $30^{\circ}$ dia para $500 \mathrm{meq} / \mathrm{kg}$ de $\mathrm{MS}$, sendo a explicação um balanço entre a maior ingestão de água e a menor absorção de AGVs. 


\section{5 pH urinário}

$\mathrm{Na}$ Tabela 9 estão representados os valores médios de $\mathrm{pH}$ urinário do 25 ao $30^{\circ}$ e do 55 ao $60^{\circ}$ dia de experimento. A Figura 7 ilustra o efeito do BCAD no $\mathrm{pH}$ urinário em ovinos.

TABELA 09. Níveis médios de pH urinário no $25^{\circ}$ ao $30^{\circ}$ dia e do $55^{\circ}$ ao $60^{\circ}$ dia de experimento em ovinos alimentados com diferentes níveis de BCAD.

\begin{tabular}{cccccccccc}
\hline & \multicolumn{4}{c}{ Tratamentos. } & \multicolumn{4}{c}{ Análise de variância } \\
Período & $\mathbf{- 1 6 0}$ & $\mathbf{- 4 0}$ & $\mathbf{1 4 0}$ & $\mathbf{2 5 0}$ & $\mathbf{5 0 0}$ & $\mathbf{C V}^{1} \%$ & $\mathbf{L}$ & $\mathbf{Q}$ & $\mathbf{C}$ \\
\hline $25^{\circ}-30^{\circ}$ & 7,18 & 7,62 & 8,55 & 8,35 & 8,79 & 4,44 & $<0,01$ & 0,02 & 0,65 \\
$55^{\circ}-60^{\circ}$ & 6,57 & 7,49 & 7,92 & 8,23 & 8,34 & 7,49 & $<0,01$ & 0,04 & 0,53 \\
\hline
\end{tabular}

$\mathrm{CV}^{1}$-Coeficiente de variação.

$L$ - Efeito Linear

Q - Efeito Quadrático

C - Efeito Cúbico

A Tabela 9 mostra um efeito quadrático significativo, com o $\mathrm{pH}$ urinário diminuindo com o decréscimo do BCAD. O efeito do BCAD no $\mathrm{pH}$ da urina foi positivo, ou seja o $\mathrm{pH}$ aumentou com o aumento do BCAD e diminuiu com a queda do BCAD. O efeito observado foi quadrático, uma vez que a queda do $\mathrm{pH}$ foi mais acentuada com os tratamentos negativos ( $\mathrm{N} 1$ e N2), como pode ser ilustrado com a Figura 7. A análise de contrastes revelou que os tratamentos com BCAD negativo apresentaram BCAD inferior às das positivas e do controle.

Esses resultados estão em concordância com FREDEEN et al. (1988b), TUCKER et al. (1988), OETZEL et al. (1991), WANG e BEEDE (1992), JACKSON et al. (1992), KIM et al. (1997ab), WILSON et al. (1998), VAGNONI e OETZEL (1998), TAURIAINEN et al. (1998ab), PEHRSON et al. (1999), JACKSON et al. (2001), TAURIAINEN et al. (2001), DEL CLARO et al. (2002), SPANGHERO (2002). Todos os autores trabalharam com ruminantes e 
encontraram decréscimo no $\mathrm{pH}$ urinário com o uso de BCAD negativo e ou aumento do $\mathrm{pH}$ com BCAD positivo.

FREDEEN et al. (1988a) diminuíram o BCAD da dieta aniônica para 7 mEq de $(\mathrm{Na}+\mathrm{K})$ - $(\mathrm{Cl})$ por $\mathrm{kg}$ de matéria seca, em relação ao controle que apresentava o BCAD de $90 \mathrm{mEq}$. O tratamento foi oferecido por 6 semanas, tanto para vacas em início de lactação, quanto para vacas secas. Para vacas secas o decréscimo no pH urinário foi de 8,11 para 5,59 com o uso da dieta aniônica. As vacas em lactação tiveram redução de 8,28 para 5,46. JACKSON et al. (1992) trabalhando com o cloreto de cálcio $\left(\mathrm{CaCl}_{2}\right)$, baixando a BCAD para $0 \mathrm{mEq}(\mathrm{Na}+\mathrm{K})-(\mathrm{Cl}) / 100 \mathrm{~g}$ de $\mathrm{MS}$ encontraram um decréscimo do pH urinário para 6,1 . Nesse experimento a urina foi colhida via estimulação da vulva, e o $\mathrm{pH}$ medido imediatamente. $\mathrm{O}$ efeito do BCAD no $\mathrm{pH}$ urinário encontrado no $55^{\circ}$ dia concorda com FAUCHON et al. (1995), os autores encontraram efeito linear com pH urinário variando de 6,82 a 8,60 e BCAD de 4 a $580 \mathrm{mEq}(\mathrm{Na}+\mathrm{K})-(\mathrm{Cl}+\mathrm{S}) / \mathrm{kg}$ de $\mathrm{MS}$, sugerindo uma resposta renal compensatória.KIM et al. (1997a) usando sais de enxofre, como no presente trabalho, e BCAD de $-250 \mathrm{mEq}(\mathrm{Na}+\mathrm{K})-(\mathrm{Cl}+\mathrm{S}) / \mathrm{kg}$ de $\mathrm{MS}$, encontraram valores baixos, quando comparados com a dieta catiônica (+250 mEq/100g de MS), a qual deixou a urina com pH de 8. WILSON et al. (1998) em experimento conduzido com ovinos utilizando-se de um BCAD de $-100 \mathrm{mEq}$ de $/(\mathrm{Na}+\mathrm{K})-(\mathrm{Cl}+\mathrm{S})$ por $\mathrm{kg}$ de $\mathrm{MS}$ encontraram um decréscimo de 8,2 para 6,2 em relação ao tratamento controle. VAGNONI e OETZEL (1998) encontraram redução significativa do pH urinário com adição de sais aniônicos em vacas secas, mesmo com o curto período de exposição as mesmas (7 dias). JACKSON et al. (2001) reportaram que bezerros alimentados com tratamento de $200 \mathrm{mEq}$ tiveram maiores valores de $\mathrm{pH}$ urinário $(8,09)$, quando comparados com animais com $0 \mathrm{mEq}$ de $\mathrm{Na}+\mathrm{K}-\mathrm{Cl}+\mathrm{S}$ por kg de $\mathrm{MS}(6,80)$.

TUCKER et al. (1991) analisando o íon hidrogênio na urina, observaram um aumento linear até a terceira semana, e um decréscimo para níveis normais na quarta semana. Animais alimentados com dietas contendo sulfatos 
(N1 e N2) tem o pH da urina mais ácido do que quando em dietas sem tal suplementação. Quando há uma acidose metabólica, um dos mecanismos de compensação é feito pelos rins, os quais aumentam a excreção de $\mathrm{H}^{+} \mathrm{e}$ reabsorção de bicarbonato, diminuindo o pH urinário, o que explica os resultados obtidos no presente experimento. No caso de uma alcalose metabólica, que pode ter ocorrido nos tratamentos de 250 e $500 \mathrm{mEq} / \mathrm{kg}$ de MS, os rins responderiam diminuindo a excreção de $\mathrm{H}^{+}$, resultando em um maior valor de pH urinário (DOUGLAS, 2002a).

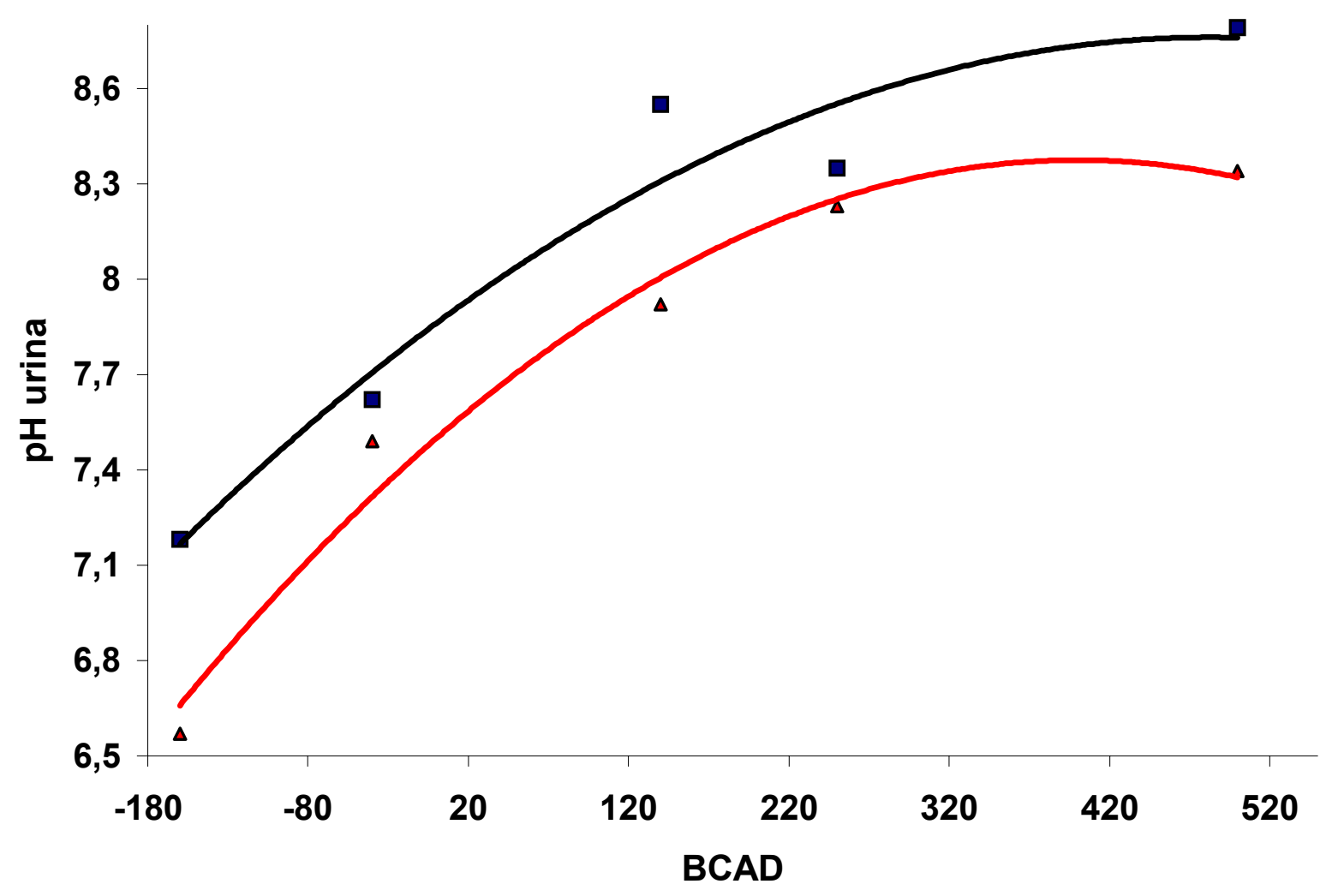
$\triangle 55$ ao 60 dia $R^{2}=0,9405$
$\square 25$ ao 30 dia $R^{2}=0,9775$

FIGURA 07. Gráfico do efeito do BCAD sobre $\mathrm{pH}$ urinário no $25^{\circ}$ ao $30^{\circ}$ dia e do $55^{\circ}$ ao $60^{\circ}$ dia de experimento em ovinos alimentados com diferentes níveis de BCAD. 


\subsection{Volume urinário}

Os valores referentes ao volume médio de urina estão apresentados na Tabela 10. O volume de urina, em litros por dia, nos dias 25 ao 30, apresentou efeito linear significativo $(P<0,05)$, com valor máximo no $B C A D$ de $250 \mathrm{mEq} / \mathrm{kg}$ de MS. Entre os dias 55 e 60, não houve efeito significativo entre BCAD e volume urinário, entretanto, ao analisarmos a média encontramos um efeito linear entre BCAD e volume de urina excretada, com valor máximo obtido no tratamento $\mathrm{P} 1$, comportamento semelhante ao da primeira fase $\left(25-30^{\circ}\right.$ dia). A análise de contrastes, representada na Tabela 11, revelou que os tratamentos com adição de $\mathrm{NaHCO}_{3}$ (P1 e P2) apresentaram maior volume de urina excretada. Os tratamentos com adição de $\mathrm{NH}_{3} \mathrm{SO}_{4}$ (N1 e N2) não apresentaram diferenças quando comparados com o controle (C).

TABELA 10. Valores médios de volume de urina em litros por um período de 24 horas em ovinos alimentados com diferentes níveis de BCAD.

\begin{tabular}{lccccccccc}
\hline Variáveis & \multicolumn{1}{c}{ Tratamentos. } & \multicolumn{4}{c}{ Análise de variância } \\
& $\mathbf{- 1 6 0}$ & $\mathbf{- 4 0}$ & $\mathbf{1 4 0}$ & $\mathbf{2 5 0}$ & $\mathbf{5 0 0}$ & $\mathbf{C V}^{1} \mathbf{\%}$ & $\mathbf{L}$ & $\mathbf{Q}$ & $\mathbf{C}$ \\
\hline $25^{\circ}-30^{\circ}$ dia. & 1,34 & 1,33 & 1,50 & 2,79 & 2,38 & 45,54 & 0,01 & 0,67 & 0,13 \\
$55^{\circ}-60^{\circ}$ dia. & 0,84 & 0,96 & 0,97 & 1,24 & 1,26 & 45,61 & 0,13 & 0,86 & 0,81 \\
$\quad$ Média & 1,09 & 1,27 & 1,23 & 2,02 & 1,82 & 37,11 & 0,01 & 0,66 & 0,33 \\
\hline CV $^{1}$ Coeficiente de variação. & & & & & & & \\
L- Efeito Linear & Q - Efeito Quadrático \\
C - Efeito Cúbico & & & & & & & & \\
\end{tabular}


TABELA 11. Comparação entre a média de urina excretada (L/dia), em ovinos alimentados com diferentes níveis de BCAD.

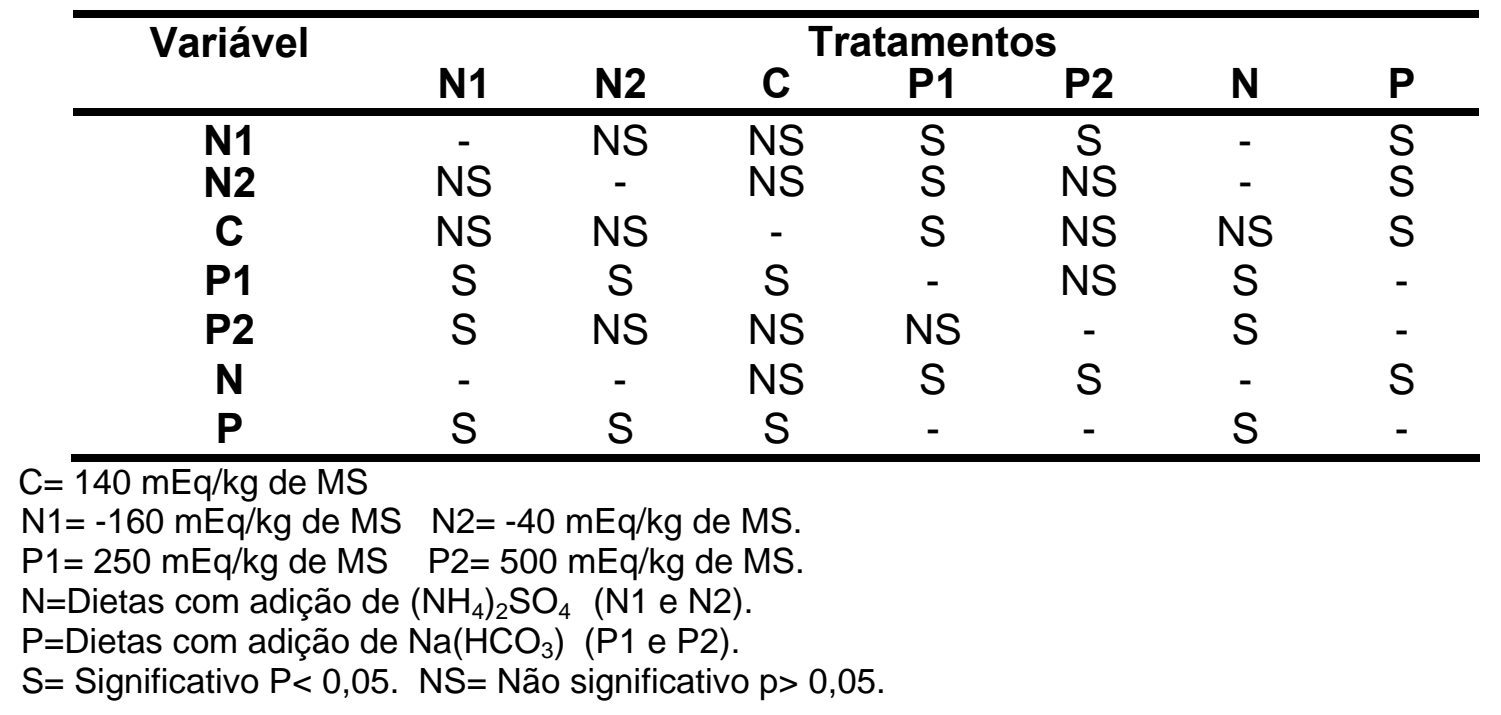

Os resultados obtidos no presente experimento concordam com os relatados por FAUCHON et al. (1995). Os autores encontraram aumento da produção de urina com aumento do BCAD e uso de $\mathrm{NaHCO}_{3}$, assim como o presente experimento, resultado do maior consumo de água. Uma maior produção de urina com a adição de $\mathrm{NaHCO}_{3}$ também foi encontrado em novilhos por ROBY et al. (1987). Os resultados reportados por VAGNONI e OETZEL (1998) discordam dos encontrados no presente experimento, já que os autores encontraram aumento do volume de urina excretada com o a queda do BCAD, entretanto, nesse experimento usou-se $\mathrm{NH}_{4} \mathrm{Cl}$ e $\mathrm{MgSO}_{4}$ como sais aniônicos, sendo esse efeito creditado ao $\mathrm{NH}_{4} \mathrm{Cl}$. Assim, o $\mathrm{NH}_{4} \mathrm{Cl}$ tem um papel na produção de urina que não está relacionado com o BCAD. Os resultados também concordam com TUCKER et al. (1993), os quais encontraram aumento do volume urinário em resposta a infusão de $\mathrm{NaHCO}_{3}$ no rúmen. DELAQUIS e BLOCK (1995), conduzindo experimento com vacas em início, meio e final de lactação, concluíram que o maior BCAD aumentou a excreção diária de urina. 
O volume de água ingerida não foi mensurado no presente trabalho, com o oferecimento ad libitum. Segundo MURPHY citado por FORBES (1995), a ingestão de água é correlacionada com a IMS, o que sugere maior consumo de água nas dietas P1 e P2. Além disso, as dietas P1 e P2 tem a inclusão de bicarbonato de sódio, conseqüentemente um maior consumo de sódio. A osmolaridade dos líquidos extracelulares é determinada principalmente pela relação entre eletrólitos e água. O principal eletrólito extracelular é o sódio, dessa forma o aumento da média de retenção absoluta desse macromineral nas dietas P1 e P2, aumentaria a osmolaridade extra-celular. O aumento da osmolaridade é percebido por osmoreceptores localizados no hipotálamo e vasos sanguíneos, que determinam a sensação de sede e aumentam a ingestão voluntária de água, funcionando como um mecanismo de feed-back negativo para a hiperosmolaridade (DOUGLAS, 2002b). 


\subsection{Balanço de sódio}

As tabelas 12 e 13 apresentam os valores referentes ao balanço de sódio. Os valores estão expressos em valor absoluto em gramas por $\mathrm{kg}^{0,75} \mathrm{e}$ em valor relativo ao consumido.

TABELA 12. Balanço de sódio entre o $25^{\circ}$ e $30^{\circ}$ dia de experimento em ovinos, alimentados com diferentes níveis de BCAD.

\begin{tabular}{|c|c|c|c|c|c|c|c|c|c|}
\hline \multirow[t]{2}{*}{ Variáveis } & \multicolumn{5}{|c|}{ Tratamentos. } & \multicolumn{4}{|c|}{ Análise de variância } \\
\hline & -160 & -40 & 140 & 250 & 500 & CV \% & $\mathbf{L}$ & $\mathbf{Q}$ & C \\
\hline Con & 0,252 & 0,262 & 0,244 & 0,470 & 0,900 & & - & - & - \\
\hline $\mathrm{Fe}$ & 0,019 & 0,028 & 0,030 & 0,017 & 0,038 & 34,37 & 0,03 & 0,29 & 0,01 \\
\hline Fezes (\%) & 7,640 & 10,729 & 12,396 & 3,759 & 4,254 & 31,51 & $<0,01$ & 0,02 & 0,01 \\
\hline Urina $^{2}$ & 0,142 & 0,260 & 0,183 & 0,373 & 0,708 & 20,26 & $<0,01$ & $<0,01$ & 0,12 \\
\hline Urina $(\%)^{*}$ & 56,994 & 99,50 & 74,440 & 79,589 & 78,594 & 19,09 & 0,36 & 0,11 & 0,01 \\
\hline Abs. Aparente ${ }^{2}$ & 0,232 & 0,233 & 0,214 & 0,453 & 0,861 & 5,28 & $<0,01$ & $<0,01$ & 0,01 \\
\hline Abs. Aparente (\%) & 92,359 & 87,271 & 87,603 & 96,24 & 95,54 & 2,60 & $<0,01$ & 0,02 & 0,01 \\
\hline Retenção $^{2}$ & 0,090 & $-0,026$ & 0,031 & 0,079 & 0,153 & 92,01 & 0,01 & 0,01 & 0,05 \\
\hline Retenção (\%) & 35,365 & $-0,232$ & 13,157 & 16,651 & 17,151 & 96,22 & 0,76 & 0,05 & 0,01 \\
\hline
\end{tabular}

$\mathrm{CV}^{1}$ Coeficiente de variação. * Calculados em relação ao consumido.

2 gramas por $\mathrm{kg}^{0,75} / \mathrm{dia}$.

$L$ - Efeito Linear

Q- Efeito Quadrático

C- Efeito Cúbico 
TABELA 13. Balanço de sódio entre o $55^{\circ}-60^{\circ}$ dia de experimento em ovinos, alimentados com diferentes níveis de BCAD.

\begin{tabular}{cccccccccc}
\hline Variáveis & \multicolumn{1}{c}{ Tratamentos. } & \multicolumn{4}{c}{ Análise de variância } \\
& $\mathbf{- 1 6 0}$ & $\mathbf{- 4 0}$ & $\mathbf{1 4 0}$ & $\mathbf{2 5 0}$ & $\mathbf{5 0 0}$ & $\mathbf{C V} \mathbf{\%}$ & $\mathbf{L}$ & $\mathbf{Q}$ & $\mathbf{C}$ \\
\hline Consumo $^{2}$ & 0,266 & 0,278 & 0,264 & 0,509 & 0,985 & - & - & - & - \\
Fezes $^{2}$ & 0,048 & 0,038 & 0,067 & 0,099 & 0,087 & 27,84 & $<0,01$ & 0,21 & 0,01 \\
Fezes (\%) $^{*}$ & 23,601 & 17,752 & 33,278 & 20,478 & 8,614 & 25,23 & 0,02 & 0,01 & 0,41 \\
Urina $^{2}$ & 0,164 & 0,173 & 0,165 & 0,314 & 0,850 & 19,11 & $<0,01$ & $<0,01$ & 0,21 \\
Urina (\%) $^{*}$ & 61,670 & 62,351 & 63,191 & 61,768 & 86,188 & 22,27 & 0,02 & 0,08 & 0,57 \\
Abs. Aparente $^{2}$ & 0,219 & 0,239 & 0,196 & 0,410 & 0,898 & 2,35 & $<0,01$ & $<0,01$ & 0,13 \\
Abs. Aparente (\%) $^{*}$ & 82,417 & 86,025 & 74,782 & 80,539 & 91,169 & 7,26 & 0,09 & 0,01 & 0,11 \\
Retenção $^{2}$ & 0,054 & 0,065 & 0,031 & 0,095 & 0,048 & 99,01 & 0,93 & 0,70 & 0,46 \\
Retenção (\%) $^{*}$ & 20,743 & 23,674 & 11,590 & 18,761 & 4,981 & 91,23 & 0,07 & 0,63 & 0,86 \\
\hline
\end{tabular}

$\mathrm{CV}^{1}$ Coeficiente de variação. ${ }^{*}$ Calculados em relação ao consumido.

2 gramas por $\mathrm{kg}^{0,75} / \mathrm{dia}$.

$\mathrm{L}$ - Efeito Linear

Q- Efeito Quadrático

C- Efeito Cúbico 
No presente experimento foram encontrados diferentes efeitos do BCAD na absorção de sódio em valores absoluto e relativo ao consumido. Entretanto, pela análise de constrastes ortogonais, observamos que os tratamentos com inclusão de $\mathrm{NaHCO}_{3}$ (250 e 500mEq/kg de MS), em média, apresentaram valores superiores de absorção relativa e absoluta que o controle, ou os com a inclusão de $\left(\mathrm{NH}_{4}\right)_{2} \mathrm{SO}_{4}(-160$ e $-40 \mathrm{mEq} / \mathrm{kg}$ de MS. TAKAGI e BLOCK (1991a), em experimento desenvolvido com cordeiros, objetivando avaliar o efeito do BCAD no balanço macromineral, encontraram redução na absorção aparente em valores reais e em relação ao consumido no tratamento com BCAD negativo (-27 mEq/kg de MS), dessa forma, concordando com os resultados do presente experimento. Segundo DOUGLAS (2002b), o sódio pode ser absorvido por diferentes mecanismos específicos de transporte, o que explica a pequena quantidade desse elemento nas fezes encontrada no presente experimento. Uma das formas é a absorção de sódio acoplado ao cloreto DOUGLAS (2002b). Dessa forma, o efeito do BCAD na absorção aparente de sódio parece não estar relacionado ao BCAD propriamente dito e sim aos níveis de sódio e cloro.

A excreção urinária de sódio em valores absolutos também foi maior para os tratamentos com a inclusão do $\mathrm{NaHCO}_{3}$ (250 e $500 \mathrm{mEq} / \mathrm{kg}$ de MS), entretanto em valores relativos a esse comportamento só foi observado no segundo balanço. Os animais do tratamento $-40 \mathrm{mEq} / \mathrm{kg}$ de $\mathrm{MS}$ no primeiro balanço apresentaram comportamento muito diferente dos demais, o que dificulta a análise do efeito do BCAD no balanço de sódio. A retenção na forma relativa no segundo balanço foi maior para as dietas negativas, provavelmente para aumentar as reservas corporais de sódio, em função de uma possível acidose.

Alguns autores, (DELAQUIS e BLOCK, 1995; TAKAGI e BLOCK ,1991a) têm reportado que a redução do BCAD é acompanhada da diminuição na excreção renal de sódio. Resultados semelhantes foram observados no presente estudo, no segundo balanço. Entretanto, nos dois 
trabalhos citados e também no presente trabalho, a redução do BCAD foi acompanhada da redução dos teores de sódio, o que dificulta a interpretação dos resultados. Não se pode afirmar que o BCAD interferiu na retenção de $\mathrm{Na}$, já que essa pode alterar-se com os níveis de sódio consumidos.Segundo TUCKER et al. (1988) e GAYNOR et al. (1989) a excreção urinária de sódio variou com o consumo desse elemento. 


\subsection{Balanço de fósforo}

As tabelas 14 e 15 apresentam os valores do balanço de fósforo, obtidos entre os dias 25 e 30 e os dias 55 ao 60 . Os valores de excreção urinária e fecal, absorção aparente e retenção estão apresentados de forma absoluta em gramas por $\mathrm{kg}^{0,75}$ e relativa ao consumido.

TABELA 14. Balanço de fósforo entre o $25^{\circ}$ e $30^{\circ}$ dia de experimento em ovinos alimentados com diferentes níveis de BCAD.

\begin{tabular}{|c|c|c|c|c|c|c|c|c|c|}
\hline \multirow[t]{2}{*}{ Variáveis } & \multicolumn{5}{|c|}{ Tratamentos. } & \multicolumn{4}{|c|}{ Análise de variância } \\
\hline & -160 & -40 & 140 & 250 & 500 & CV \% & $\mathbf{L}$ & $\mathbf{Q}$ & C \\
\hline Consumo $^{2}$ & 0,395 & $\overline{0,411}$ & 0,384 & 0,398 & 0,396 & - & - & - & - \\
\hline Fezes $^{2}$ & 0,060 & 0,068 & 0,077 & 0,074 & 0,078 & 16,35 & 0,03 & 0,30 & 0,65 \\
\hline Fezes $(\%)^{*}$ & 15,274 & 16,667 & 19,940 & 18,777 & 19,761 & 15,98 & 0,01 & 0,22 & 0,84 \\
\hline Urina $^{2}$ & 0,183 & 0,337 & 0,107 & 0,343 & 0,129 & 34,95 & 0,11 & 0,04 & 0,47 \\
\hline Urina $(\%)^{*}$ & 46,602 & 82,089 & 27,839 & 86,162 & 32,102 & 34,77 & 0,12 & 0,04 & 0,45 \\
\hline Abs. Aparente ${ }^{2}$ & 0,355 & 0,343 & 0,307 & 0,323 & 0,317 & 5,51 & 0,04 & 0,27 & 0,47 \\
\hline Abs. Aparente (\%) ${ }^{\star}$ & 84,725 & 83,332 & 80,059 & 81,222 & 80,238 & 3,54 & 0,01 & 0,22 & 0,84 \\
\hline Retenção ${ }^{2}$ & 0,151 & 0,005 & 0,199 & $-0,019$ & 0,188 & 63,86 & 0,23 & 0,01 & 0,89 \\
\hline Retenção (\%) & 38,122 & 1,242 & 52.220 & -4.939 & 48,135 & 64,24 & 0,22 & 0,02 & 0,27 \\
\hline
\end{tabular}


TABELA 15. Balanço de fósforo entre o $55^{\circ}$ e $60^{\circ}$ dia de experimento em ovinos, alimentados com diferentes níveis de BCAD.

\begin{tabular}{cccccccccc}
\hline Variáveis & \multicolumn{1}{c}{ Tratamentos. } & \multicolumn{4}{c}{ Análise de variância } \\
& $\mathbf{- 1 6 0}$ & $\mathbf{- 4 0}$ & $\mathbf{1 4 0}$ & $\mathbf{2 5 0}$ & $\mathbf{5 0 0}$ & $\mathbf{C V} \%$ & $\mathbf{L}$ & $\mathbf{Q}$ & $\mathbf{C}$ \\
\hline Consumo $^{2}$ & 0,419 & 0,437 & 0,414 & 0,431 & 0,433 & - & - & - & - \\
Fezes $^{2}$ & 0,049 & 0,073 & 0.075 & 0,049 & 0,059 & 24,84 & 0,79 & 0,15 & 0,01 \\
Fezes (\%) $^{*}$ & 11,923 & 16,938 & 18,123 & 11,315 & 13,583 & 23,77 & 0,67 & 0,12 & 0,01 \\
Urina $^{2}$ & 0,356 & 0,251 & 0,307 & 0,170 & 0,096 & 60,46 & 0,01 & 0,74 & 0,66 \\
Urina (\%) $^{*}$ & 84,904 & 57,452 & 75,082 & 34,754 & 22,385 & 62,72 & 0,01 & 0,72 & 0,61 \\
Abs. Aparente $^{2}$ & 0,369 & 0,363 & 0,339 & 0,382 & 0,374 & 4,31 & 0,27 & 0,07 & 0,09 \\
Abs. Aparente (\%) $^{*}$ & 88,076 & 83,061 & 81,876 & 88,684 & 86,416 & 3,95 & 0,67 & 0,12 & 0,01 \\
Retenção $^{2}$ & 0,013 & 0,111 & 0,032 & 0,211 & 0,277 & 104,5 & 0,01 & 0,58 & 0,79 \\
Retenção (\%) $^{*}$ & 3.171 & 25,598 & 6,793 & 48,920 & 64,030 & 111,0 & 0,01 & 0,58 & 0,81 \\
\hline
\end{tabular}

$C V^{1}$ Coeficiente de variação. * Calculados em relação ao consumido.

2 gramas por $\mathrm{kg}^{0,75} / \mathrm{dia}$.

$L$ - Efeito Linear

Q- Efeito Quadrático

C- Efeito Cúbico

No primeiro balanço, foram encontrados efeitos lineares do BCAD na excreção fecal e absorção aparente, tanto nos valores absolutos quanto nos relativos. Entretanto, esse comportamento não se repetiu no segundo balanço, realizado entre os dias 55 e 60. Pela análise de contrastes, observa-se que as dietas negativas (N1 e N2), em média ,apresentaram maior absorção aparente do que as positivas (P1 e P2) e do que o controle, no primeiro balanço. Esse comportamento também não se repetiu no segundo balanço. A absorção de fósforo, assim como a do cálcio, foi estimulada pela vitamina $D$ ativada (McDOWELL, 1992). Dessa forma, caso exista relação do BCAD com a ativação renal da vitamina $\mathrm{D}$, poderia também existir na absorção desse mineral. Entretanto, a absorção aparente não é um bom indicativo do fósforo absorvido. O fósforo excretado nas fezes pode conter grande quantidade de fósforo endógeno oriundo da saliva, o que dificulta a interpretação dos 
resultados. A absorção aparente foi considerada alta nos dois balanços, o que sugere uma alta absorção real. FREDEEN et al. (1988a), estudando o balanço de fósforo em vacas em lactação, observaram diminuição do fósforo fecal para o grupo alimentado com dieta aniônica, fato semelhante foi encontrado no primeiro balanço do presente experimento. Esses mesmos autores, quando trabalharam com vacas no pré-parto, não encontraram diferenças significativas no balanço do fósforo. BEIGHLE et al. (1995), utilizaram como tratamentos BCAD de -11,1; +16,5 e +25,6 $\mu \mathrm{mol} / 100 \mathrm{~g}$ MS e verificaram que as concentrações de $\mathrm{P}$ fecal foram maiores para as dietas aniônicas comparadas ao controle e à catiônica. TAKAGI e BLOCK (1991a), não encontraram diferenças significativas na absorção aparente de fósforo em função do uso de dieta aniônica. Os autores trabalharam com ovinos machos, sendo o presente estudo conduzido de maneira semelhante. GOMIDE (1996), em experimento desenvolvido com carneiros com tratamentos de -12; 30; 76 e $133 \mathrm{mEq} / \mathrm{kg}$ de MS não encontrou variações na absorção aparente desse mineral. TUCKER et al. (1988), GAYNOR et al. (1989) também não encontram efeito do BCAD na absorção aparente de fósforo. BEIGHLE et al. (1997) encontraram uma maior excreção fecal de fósforo em função do uso de dieta aniônica (-11 mEq/100g de MS). Entretanto nesse experimento os níveis dietéticos de fósforo eram de 0,25\% ou menos, o que poderia interferir na absorção. CAMPOS (1998), avaliando o balanço dietético cátion-aniônico na alimentação de vacas leiteiras pré-parto, observaram que a dieta aniônica reduziu a absorção aparente de fósforo. DEL CLARO et al. (2002) em experimento conduzido com bovinos em crescimento, não encontraram alteração na absorção aparente, com o uso de uma dieta aniônica.

Os resultados obtidos no presente experimento e a literatura consultada mostram grande divergência, com uma maior prevalência de experimentos que não encontraram efeito do BCAD na absorção aparente de fósforo. Dessa forma, a relação entre a absorção aparente de fósforo e BCAD não pode ser 
descrita. Isso porque os resultados obtidos podem ser influenciados por variáveis não controladas, como por exemplo, a secreção de fósforo salivar.

Pela análise de contraste observa-se que no segundo balanço as dietas negativas (N1 e N2) em média excretaram maior quantidade de fósforo do que as dietas positivas e a controle.

Os resultados do primeiro balanço concordam com VAN MOSEL et al. (1993), os quais não encontraram diferenças nos níveis de fósforo na urina de vacas secas alimentadas com BCAD de -4 ou $+572,5 \mathrm{mEq} / \mathrm{kg}$ de $\mathrm{MS}$. JACKSON e HEMKEN (1994) também não encontraram diferenças na excreção urinária de fósforo em função da BCAD. GOMIDE (1996) não observou efeito da manipulação do BCAD na excreção de fósforo pela urina. JACKSON et al. (2001) verificaram que diferentes relações entre cátions e ânions não alteraram a excreção urinária de fósforo, os autores trabalharam com bezerros e BCAD de 0 e $200 \mathrm{mEq} / \mathrm{kg}$ de MS. DEL CLARO et al. (2002) não observaram efeitos da dieta aniônica na excreção de fósforo pela urina.

DELAQUIS e BLOCK (1995), observaram para vacas em início de lactação, uma tendência de aumento na excreção urinária de fósforo (de 67,2 para 103,5 mg/dl), em função da diminuição da BCAD (de 258,1 para 55,5 $\mathrm{mEq} / \mathrm{kg}$ de $\mathrm{MS}$ ), entretanto não suficiente para alterar a retenção dessa macromineral. SETTI (2001), encontrou maior excreção urinária de fósforo para as dietas aniônicas (-50,80 $\mathrm{mEq} / \mathrm{kg}$ de $\mathrm{MS})$, quando comparadas com as catiônicas $(+146,80 \mathrm{mEq} / \mathrm{kg}$ de MS ), resultados que concordam apenas com o segundo balanço no presente experimento.

Dentre os ácidos excretados na urina, o $\mathrm{NaH}_{2} \mathrm{PO}_{4}$ corresponde a maior fração da chamada acidez titulável em humanos (DOUGLAS, 2002a) e em suínos (GOLS e CRENSHAW, 1991). Assim, se o mesmo ocorrer em ruminantes, o esperado seria uma excreção de fósforo aumentada nos tratamentos negativos, resultado apenas observado no segundo balanço. VAGNONI e OETZEL (1998) em trabalho desenvolvido com vacas secas afirmaram que a contribuição do íon fosfato na acidez titulável diminuí com o 
aumento da excreção de ácidos provocada por sais aniônicos, provavelmente pelo aumento da excreção de outros íons como por exemplo, o $\mathrm{SO}_{4}{ }^{-2}$. Essa afirmação pode explicar a divergência de resultados encontradas na literatura. Provavelmente o tipo sal aniônico (se cloreto ou sulfato) possa interferir na eliminação de fósforo pela urina. Outro fator que pode interferir na excreção de $P$ pela urina é o grau de acidose e as reservas tamponantes do animal.

Para a retenção de fósforo não foram encontrados efeitos significativos nos dois balanços. Esses resultados concordam com os apresentados por TUCKER et al. (1998), GAYNOR et al. (1989), TAKAGI e BLOCK (1991b), DELAQUIS e BLOCK (1995), GOMIDE (1996), DEL CLARO et al.(2002). Mesmo os autores que encontraram efeito na excreção pela urina, não observaram alteração na retenção absoluta ou relativa de fósforo. 


\subsection{Balanço de cálcio}

Os resultados dos balanços de cálcio estão apresentados nas tabelas $16 \mathrm{e}$ 17. Pela Tabela 16 podemos observar que no primeiro balanço, o único efeito das dietas iônicas sobre o balanço de cálcio foi observado na excreção urinária desse elemento, a qual aumentou de forma linear, tanto nos valores absolutos quanto relativos à quantidade consumida. A Tabela 17 revela que no segundo balanço, após 55 dias de oferecimento das dietas iônicas, o comportamento do balanço de cálcio se alterou. A absorção aparente de cálcio, tanto de forma relativa quanto absoluta, apresentou efeito cúbico significativo, sendo que 0 mesmo comportamento foi observado para a retenção desse macromineral. A excreção urinária apresentou comportamento quadrático, e foi sempre maior para os tratamentos negativos (N1 e N2).

TABELA 16. Balanço de cálcio entre o $25^{\circ}$ e $30^{\circ}$ dia de experimento em ovinos, alimentados com diferentes níveis de BCAD.

\begin{tabular}{cccccccccc}
\hline Variáveis & \multicolumn{1}{c}{ Tratamentos. } & \multicolumn{4}{c}{ Análise de variância } \\
& $\mathbf{- 1 6 0}$ & $\mathbf{- 4 0}$ & $\mathbf{1 4 0}$ & $\mathbf{2 5 0}$ & $\mathbf{5 0 0}$ & $\mathbf{C V} \mathbf{\%}$ & $\mathbf{L}$ & $\mathbf{Q}$ & $\mathbf{C}$ \\
\hline Consumo $^{2}$ & 0,798 & 0,830 & 0,783 & 0,810 & 0,814 & - & - & - & - \\
Fezes $^{2}$ & 0,385 & 0,348 & 0,388 & 0,305 & 0,384 & 16,01 & 0,82 & 0,15 & 0,50 \\
Fezes (\%) $^{*}$ & 48,22 & 41,96 & 50,93 & 37,68 & 47,05 & 13,87 & 0,74 & 0,27 & 0,61 \\
Urina $^{2}$ & 0,002 & 0,003 & $<0,001$ & 0,002 & 0,001 & 60,61 & 0,05 & 0,42 & 0,30 \\
Urina (\%) $^{*}$ & 0,324 & 0,414 & 0,128 & 0,237 & 0,189 & 61,29 & 0,05 & 0,42 & 0,40 \\
Abs. Aparente $^{2}$ & 0,413 & 0,482 & 0,377 & 0,504 & 0,428 & 11,01 & 0,77 & 0,37 & 0,88 \\
Abs. Aparente (\%) $^{*}$ & 51,770 & 58,032 & 49,065 & 61,317 & 52,943 & 11,49 & 0,74 & 0,27 & 0,61 \\
Retenção $^{2}$ & 0,410 & 0,478 & 0,376 & 0,503 & 0,427 & 11,10 & 0,73 & 0,36 & 0,86 \\
Retenção (\%) $^{*}$ & 51,450 & 57,620 & 48,936 & 62,079 & 52,753 & 11,57 & 0,71 & 0,26 & 0,59 \\
\hline
\end{tabular}

$\mathrm{CV}^{1}$ Coeficiente de variação. * Calculados em relação ao consumido.

2 gramas por kg ${ }^{0,75} / \mathrm{dia}$.

L - Efeito Linear Q- Efeito Quadrático C- Efeito Cúbico 
TABELA 17. Balanço de cálcio entre o $55^{\circ}$ e $60^{\circ}$ dia de experimento em ovinos, alimentados com diferentes níveis de BCAD.

\begin{tabular}{|c|c|c|c|c|c|c|c|c|c|}
\hline \multirow[t]{2}{*}{ Variáveis } & \multicolumn{5}{|c|}{ Tratamentos. } & \multicolumn{4}{|c|}{ Análise de variância } \\
\hline & -160 & -40 & 140 & 250 & 500 & CV \% & $\mathbf{L}$ & $\mathbf{Q}$ & C \\
\hline Consumo & 0,846 & 0,882 & 0,829 & 0,878 & 0,891 & - & - & - & - \\
\hline Fezes $^{2}$ & 0,291 & 0,267 & 0,388 & 0,358 & 0,308 & 15,16 & 0,10 & 0,01 & 0,08 \\
\hline Fezes $(\%)^{*}$ & 34,288 & 30,347 & 46,953 & 40,887 & 34,578 & 13,63 & 0,14 & 0,01 & 0,04 \\
\hline Urina $^{2}$ & 0,003 & 0,004 & $<0,001$ & $<0,001$ & $<0,001$ & 60,63 & $<0,01$ & $<0,01$ & 0,11 \\
\hline Urina (\%) ${ }^{*}$ & 0,415 & 0,399 & 0,092 & 0,071 & 0,084 & 63,86 & $<0,01$ & 0,03 & 0,17 \\
\hline Abs. Aparente ${ }^{2}$ & 0,555 & 0,614 & 0,441 & 0,520 & 0,582 & 7,63 & 0,45 & $<0,01$ & $<0,01$ \\
\hline Abs. Aparente (\%) & 65,711 & 69,652 & 54,571 & 59,112 & 65,421 & 8,40 & 0,16 & $<0,01$ & 0,04 \\
\hline Retenção $^{2}$ & 0,551 & 0,610 & 0,440 & 0,519 & 0,582 & 7,62 & 0,53 & $<0,01$ & 0,01 \\
\hline Retenção (\%) & 65,297 & 69,252 & 52,954 & 59,040 & 65,337 & 8,20 & 0,17 & $<0,01$ & $<0,04$ \\
\hline
\end{tabular}

A absorção de cálcio se faz por mecanismos ativo e passivos(por difusão). Existe muita controvérsia na literatura, quanto aos efeitos do BCAD na absorção de cálcio. O presente experimento não encontrou efeito do BCAD na absorção de cálcio no primeiro balanço, porém encontrou efeito cúbico significativo no segundo balanço. LECLERC e BLOCK (1989), TAKAGI e BLOCK (1991a) e DEL CLARO et al. (2002), não encontraram alterações na absorção intestinal com uso de dietas aniônicas ou catiônicas em ruminantes. SCHONEWILL et al. (1994) encontraram maior absorção aparente de cálcio com dietas aniônicas. LOMBA et al. (1978), afirmaram que a maior absorção se dá pela natureza acidogênica dos ânions no intestino, que aumentam a solubilização do cálcio, entretanto o baixo pH intestinal poderia inibir a absorção ativa de cálcio (DOUGLAS, 2002a). Para BLOCK (1994), não existe um mecanismo claro de influência do BCAD na absorção intestinal de cálcio, o que explica a divergência de resultados na literatura. Em geral, os resultados encontrados no primeiro balanço do presente experimento têm uma maior 
prevalência na literatura. Segundo MACKDOWELL (1992), as fezes são a principal via de excreção do cálcio, sendo o cálcio das fezes resultado do cálcio não absorvido da dieta, cálcio endógeno não absorvido e da secreção intestinal desse elemento. O efeito cúbico encontrado no segundo balanço pode ter sido em função de uma secreção intestinal de cálcio, o que dificulta a interpretação desses resultados, a não ser que se utilizasse cálcio marcado na dieta.

Com relação à excreção urinária de cálcio, no primeiro balanço do presente experimento foi encontrado efeito linear significativo, tanto na forma absoluta quanto na relativa. No segundo balanço experimental, o efeito observado foi quadrático, entretanto o comportamento foi similar, ou seja, aumento da excreção urinária de cálcio com a queda do BCAD. A Figura 8 ilustra o efeito do BCAD na excreção urinária de cálcio. Os resultados concordam com os relatados por FREDEEN et al. (1988a), GAYNOR et al. (1989), TUCKER et al. (1991), TAKAGI e BLOCK (1991a), JACKSON et al. (1992), JACKSON e HEMKEN (1994), SCHONEWILLE el al. (1994), JOYCE et al. (1997), WILSON et al. (1998), VAGNONI e OETZEL (1998), TAURIAINEN et al. (1998b), SETTI (2001), JACKSON et al. (2001) e DEL CLARO et al. (2002).

SCHONEWILLIE et al. (1999) afirmaram que a excreção urinária de cálcio foi seis vezes maior nas vacas com tratamento aniônico, do que naquelas com tratamento catiônico. VAN MOSEL et al. (1993) afirmaram que vacas alimentadas com dieta aniônica excretam de 10 a 30 vezes mais cálcio que vacas alimentadas com dieta catiônica.

DELAQUIS e BLOCK (1995) não encontraram diferenças na excreção urinária de cálcio com a diminuição do BCAD provavelmente em função da pouca diferença entre os dois tratamentos ( 258,1 e $55,5 \mathrm{mEq} / \mathrm{kg}$ de MS) GOMIDE (1996) também não encontrou aumento de excreção de cálcio na urina com uso de dieta aniônica, provavelmente por ela ser pouco negativa ($12 \mathrm{mEq} / \mathrm{kg}$ de MS). O aumento da excreção urinária, segundo BLOCK (1984), é uma conseqüência secundária do aumento sanguíneo em função da mobilização óssea. Com esse aumento da excreção de cálcio, ocorreria um 
aumento da formação de $1,25(\mathrm{OH})$ que estimularia a mobilização óssea e aumento sanguíneo de cálcio. Outro mecanismo seria em função da produção renal de $1,25(\mathrm{OH})_{2} \mathrm{D}_{3}$, a qual poderia ser influenciado pelo baixo $\mathrm{pH}$ intracelular (BLOCK , 1994).

Como já abordado, a excreção de cálcio é predominantemente feita pelas fezes, sendo que a excreção urinária é muito baixa. A alteração da excreção urinária do cálcio não foi suficiente para influenciar a retenção desse macromineral. Não houve influência do BCAD na retenção de cálcio no primeiro balanço e foram encontrados efeitos cúbicos significativos do BCAD no segundo balanço, provavelmente em função da secreção intestinal de cálcio.

Os resultados apresentados concordam com TAKAGI e BLOCK (1991a), os quais encontraram absorção aparente similar entre os tratamentos e um aumento de excreção urinária não suficiente para alterar a retenção de cálcio. FREDEEN et al. (1988a), em experimento conduzido com vacas no pré-parto, não observaram alteração na excreção fecal de cálcio em função do decréscimo do BCAD. No entanto, diferenças no balanço de cálcio não foram relatadas pelos autores, tanto para as vacas em produção, como para as em pré-parto. A excreção urinária aumentou de 0,59 para $7,6 \%$ em relação ao cálcio consumido para vacas que não estavam em produção. WILSON et al. (1998), trabalhando com carneiros em crescimento, obtiveram um acréscimo de 0,11 para 0,75 grama por dia, de cálcio excretado na urina, quando compararam tratamentos com dieta aniônica e controle. A absorção aparente desse mineral não se alterou, ou seja, o decréscimo na BCAD foi suficiente para alterar a excreção urinária, sem afetar o balanço de cálcio, assim como no presente experimento.

Dessa forma, o BCAD parece não ter influência direta sobre a absorção intestinal de cálcio, contudo tem efeito sobre a excreção urinária, a qual aumenta com o decréscimo do BCAD. Esse efeito, apesar de efetivo, não é suficiente para influenciar a retenção de cálcio. 


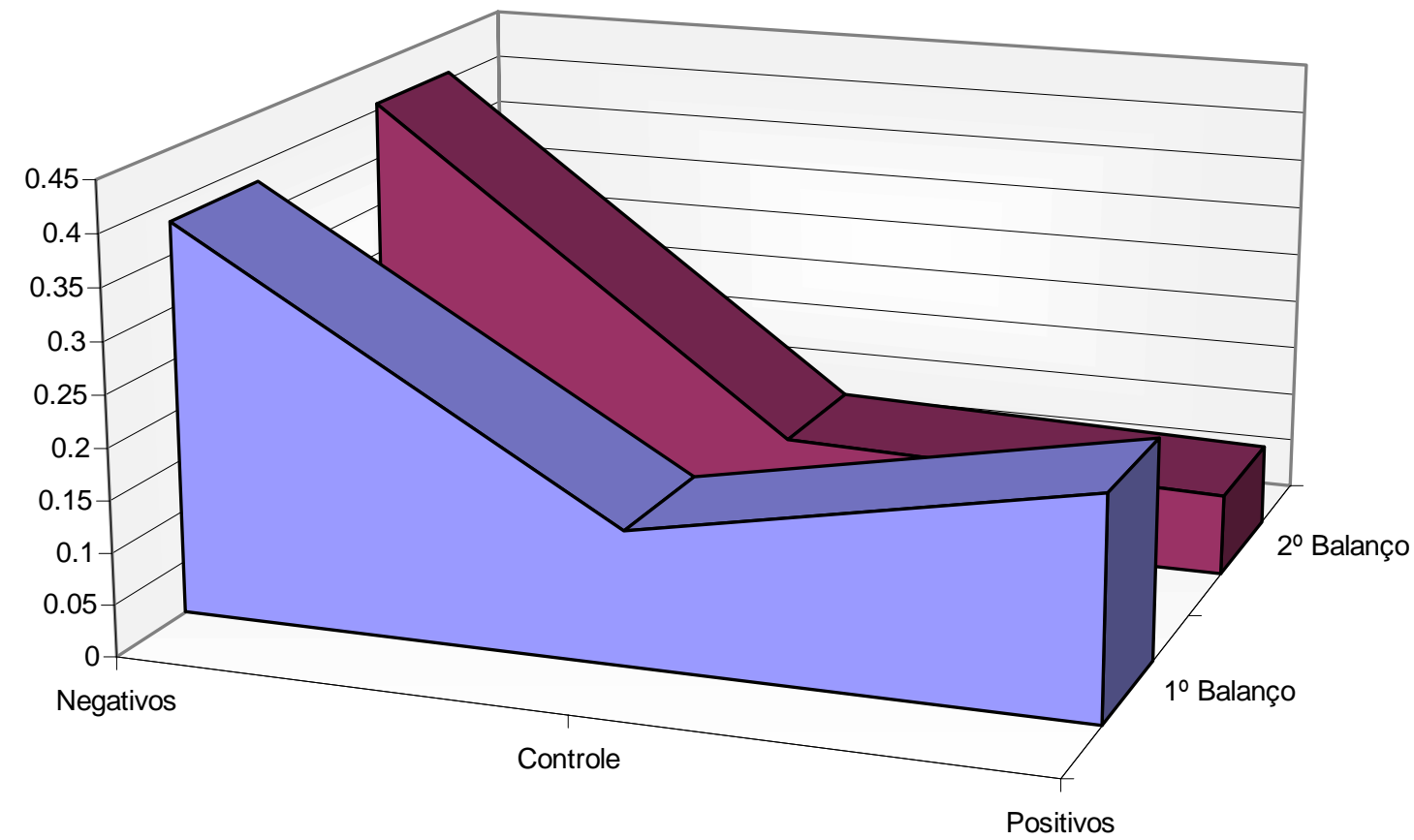

FIGURA 08. Cálcio excretado na urina em \% do cálcio ingerido, nos tratamentos de BCAD negativos (-160 e $-40 \mathrm{mEq} / \mathrm{kg}$ de $\mathrm{MS}$ ), controle (140 $\mathrm{mEq} / \mathrm{kg}$ de MS) e positivos (250 e $500 \mathrm{mEq} / \mathrm{kg}$ de MS). 


\subsection{Cálcio sérico.}

A Tabela 18 e a Figura 9 e 10 apresentam os níveis do cálcio total e ionizado ( $\mathrm{mg}$ por $\mathrm{dL}$ ) durante o experimento. Observa-se que para o cálcio total, no $15^{\circ}$ e $60^{\circ}$ dia houve um efeito linear significativo, ou seja, com o decréscimo do BCAD houve um aumento dos níveis séricos de cálcio total. No $30^{\circ}$ dia, apesar do efeito cúbico, os tratamentos negativos apresentaram maiores concentrações de cálcio que os positivos e o controle. De maneira geral, apesar de não encontrarmos efeito linear do BCAD em todos as colheitas, sempre a concentração foi superior nos tratamentos N1 e N2. Para o cálcio ionizado a análise de contrastes revelou que as dietas negativas (N1 e N2) sempre foram superiores as positivas (P1 e P2) e a controle.

TABELA 18. Níveis de cálcio total e ionizado $(\mathrm{mg} / \mathrm{dL})$ em ovinos alimentados com diferentes níveis de BCAD.

\begin{tabular}{|c|c|c|c|c|c|c|c|c|c|}
\hline \multirow[t]{2}{*}{ Variáveis } & \multicolumn{5}{|c|}{ Tratamentos } & \multicolumn{4}{|c|}{ Análise de variância } \\
\hline & -160 & -40 & 140 & 250 & 500 & CV\% & L & $\mathbf{Q}$ & C \\
\hline $\begin{array}{c}\text { Total } \\
15^{\circ} \text { dia }\end{array}$ & 8,09 & 7,83 & 7,40 & 7,54 & 6,64 & 9,74 & $<0,01$ & 0,66 & 0,48 \\
\hline $30^{\circ}$ dia & 8,91 & 10,48 & 8,90 & 7,97 & 8,56 & 14,09 & 0,09 & 0,89 & 0,02 \\
\hline $45^{\circ} \mathrm{dia}$ & 8,90 & 9,28 & 8,28 & 8,18 & 8,37 & 12,05 & 0,16 & 0,50 & 0,31 \\
\hline $60^{\circ} \mathrm{dia}$ & 10,17 & 9,81 & 8,57 & 8,52 & 8,71 & 8,16 & $<0,01$ & 0,03 & 0,52 \\
\hline Ionizado & & & & & & & & & \\
\hline $15^{\circ} \mathrm{dia}$ & 4,42 & 4,37 & 4,11 & 4,06 & 3,50 & 12,05 & $<0,01$ & 0,30 & 0,76 \\
\hline $30^{\circ} \mathrm{dia}$ & 4,92 & 4,95 & 4,89 & 3,94 & 4,51 & 11,08 & 0,04 & 0,34 & 0,06 \\
\hline $45^{\circ} \mathrm{dia}$ & 4,70 & 4,79 & 4,32 & 3,97 & 4,31 & 13,65 & 0,10 & 0,29 & 0,22 \\
\hline $60^{\circ}$ dia & 5,29 & 5,59 & 4,50 & 4,48 & 4,58 & 12,28 & 0,05 & 0,07 & 0,04 \\
\hline
\end{tabular}


Do cálcio total $(\mathrm{mg} / \mathrm{dL})$ encontrado no sangue dos ovinos, 45 a $50 \%$ estão na forma solúvel,ou seja, ionizada. Cerca de 40 a $45 \%$ estão ligados à proteína, principalmente albumina. Os outros $5 \%$ formam complexos com elementos inorgânicos, de acordo com o pH do sangue. A concentração de cálcio no soro dos ovinos do presente experimento se encontra dentro da normalidade. Os maiores níveis encontrados nos tratamentos com inclusão de sal aniônico concordam com a maior parte dos trabalhos consultados. BLOCK (1984), trabalhando com níveis de $+330,5$ e $-128,5 \mathrm{mEq}$ por $\mathrm{kg}$ de MS, nos tratamentos controle e aniônico respectivamente, observou uma maior concentração plasmática nas vacas, durante o pré-parto quando alimentadas com o BCAD negativo. Provavelmente essa manutenção é resultado de um aumento na mobilização óssea, como pode ser observado pelo aumento da hidroxiprolina. LECLERC e BLOCK (1989), concluíram que a alimentação com balanço cátion-aniônico negativo durante o pré-parto reduz o declínio natural da concentração plasmática de $\mathrm{Ca}$. Esse resultado, segundo os autores ocorre de efeito indireto da acidose metabólica, afetando a reabsorção renal de Ca e a mobilização óssea desse macromineral. TUCKER et al. (1990) observaram um acréscimo no cálcio plasmático nos animais com suplementação aniônica, tanto para a utilização de sais de cloro, quanto de enxofre. Os autores trabalharam com vacas em início de lactação, sendo que os animais receberam a dieta aniônica por três semanas. TAKAGI e BLOCK (1991b) obtiveram aumentos nos teores de cálcio plasmático com a elevação dos níveis do BCAD e concluíram que esse efeito pode ser atribuído ao aumento da absorção de cálcio no intestino e pelo aumento da mobilização de cálcio dos ossos. SCHONEWILLE et al. (1999) verificaram que as concentrações de cálcio ionizado no plasma foram significativamente aumentadas quando oferecidas dietas aniônicas para vacas. DEL CLARO et al. (2002) observaram aumento no nível de cálcio total no soro 19 dias após o oferecimento de dieta aniônica (-150 meq/kg).

VAGNONI e OETZEL (1998) trabalharam com vacas secas e BCAD de 203;-51;-40 e -63 mEq (Na+K) -(Cl+S)/ kg de MS e não encontraram alterações 
nos níveis de cálcio total e ionizado entre os períodos que as vacas foram submetidas ao tratamento de $203(\mathrm{Na}+\mathrm{K})-(\mathrm{Cl}+\mathrm{S}) / \mathrm{kg}$ de $\mathrm{MS}$ em relação aos tratamentos com sais aniônicos. O pouco tempo de oferecimento dos tratamentos aniônicos (7dias) pode ser a explicação para esse resultado.

A adição de bicarbonato de sódio na ração de vacas não promoveu nenhuma variação na concentração sérica do cálcio (TUCKER et al., 1991). FAUCHON et al. (1995), em experimento com ovinos em crescimento, com tratamentos de 4, 175, 390 e $580 \mathrm{mEq}(\mathrm{Na}+\mathrm{K})-(\mathrm{Cl}+\mathrm{S}) / \mathrm{kg}$ de $\mathrm{MS}$ não encontraram diferenças na concentração de cálcio plasmático, entretanto os autores afirmaram que os animais desse experimento não estavam sob condições de acidose, a qual iria propiciar a reabsorção óssea de forma indireta.

Experimentos citados por BLOCK (1994), conduzidos com ratos e cachorros mostraram que os tecidos são refratários ao PTH durante a alcalose metabólica, reduzindo a produção de $1,25(\mathrm{OH})_{2} \mathrm{D}_{3}$. GOFF et al. (1991) mostraram que a redução do BCAD aumentou a produção de $1,25(\mathrm{OH})_{2} \mathrm{D}_{3}$ por unidade de PTH. Então, a acidose metabólica oferecida pelo BCAD negativo estimula a transformação de $25(\mathrm{OH})$ colicalciferol em $1,25(\mathrm{OH})_{2} \mathrm{D}_{3}$, a qual aumenta a reabsorção óssea liberando cálcio para a corrente sangüínea (HORST et al, 1994), o que pode explicar em parte, os resultados do presente estudo. 


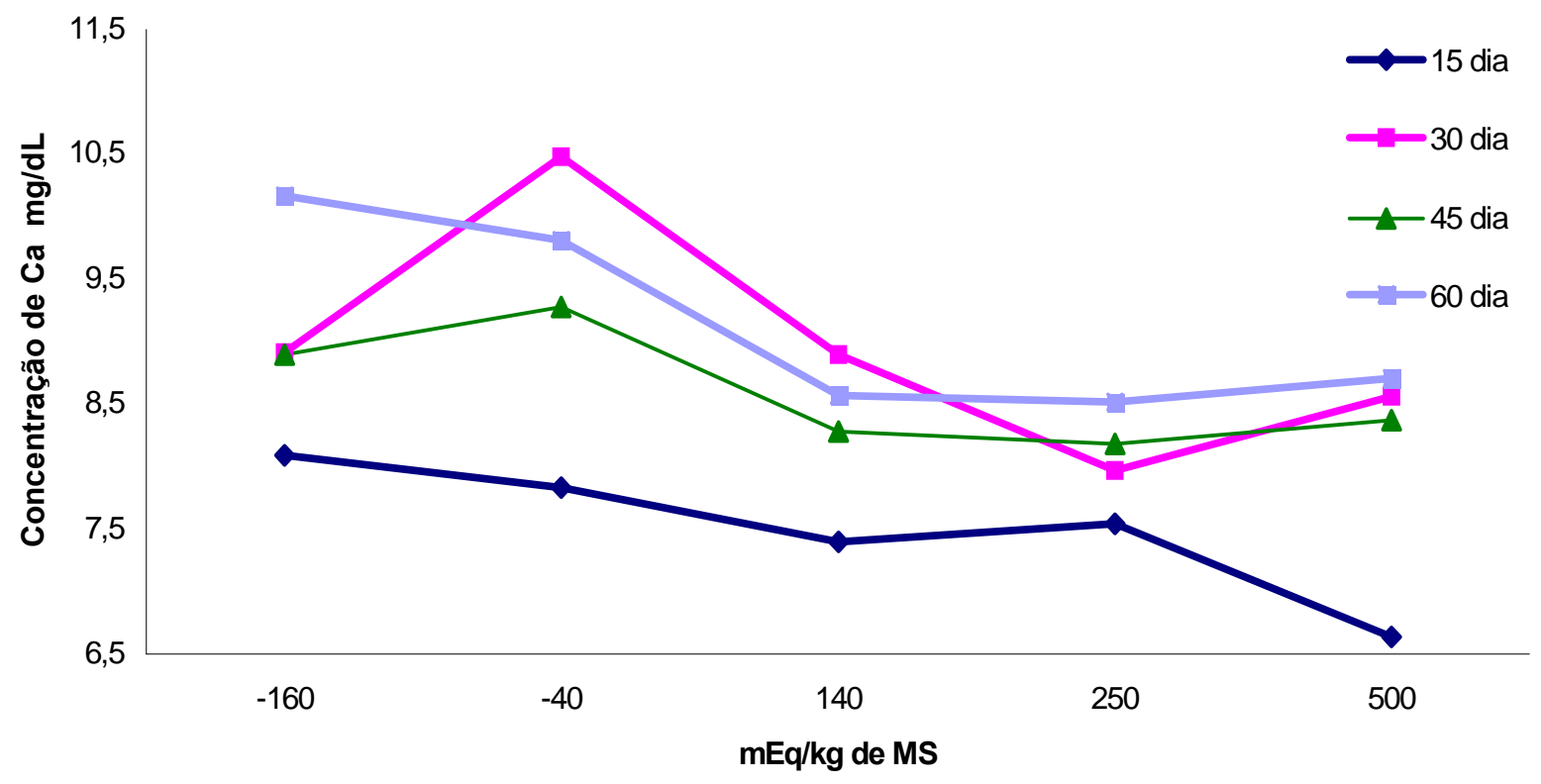

FIGURA 09. Efeito do BCAD no cálcio total ( $\mathrm{mg} / \mathrm{dL})$, nos diferentes dias de colheita do experimento. 


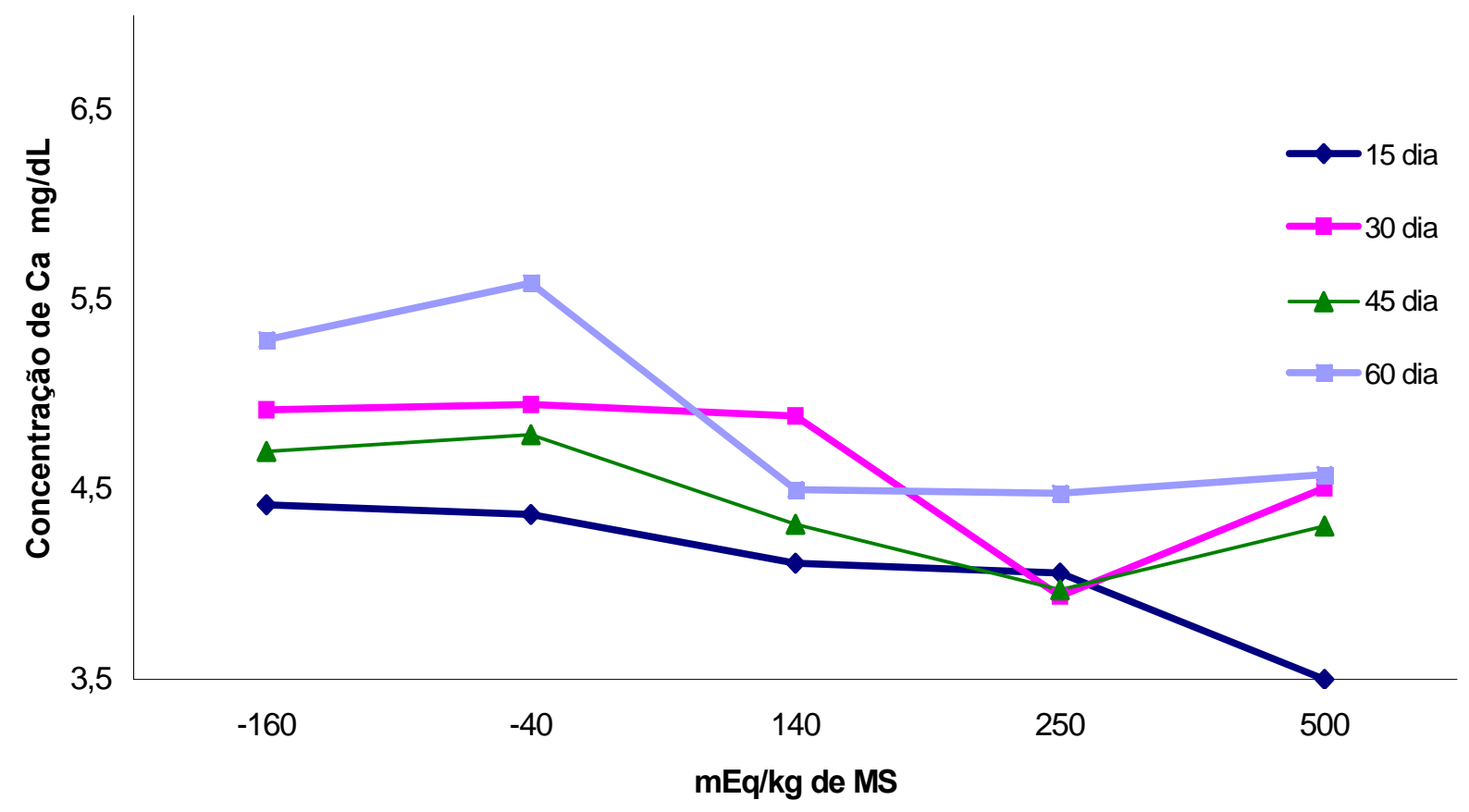

FIGURA 10. Efeito do BCAD no cálcio ionizado ( $\mathrm{mg} / \mathrm{dL})$, nos diferentes dias de colheita do experimento. 


\section{CONCLUSÕES}

Os resultados obtidos nos permitem concluir que a IMS aumentou com o acréscimo do BCAD. O BCAD, para o melhor desempenho em ovinos em crescimento, está entre 250 e $500 \mathrm{mEq}$ de $\{(\mathrm{Na}+\mathrm{K})-(\mathrm{Cl}+\mathrm{S})\}$ por $\mathrm{kg}$ de $\mathrm{MS}$. O aumento do BCAD elevou o $\mathrm{pH}$ do líquido ruminal, porém, teve pouca influência no perfil de ácidos graxos voláteis no rúmen. Entre os níveis de -160 e 500 $\mathrm{mEq} / \mathrm{kg}$ de $\mathrm{MS}$, o pH urinário apresentou relação quadrática com aumento com acréscimo do BCAD. O aumento do BCAD aumentou o volume de urina excretada. O BCAD influenciou o metabolismo macromineral, principalmente o de cálcio. A redução do BCAD resultou em aumento linear na excreção urinária de cálcio, entretanto, não suficiente para mudar a retenção desse macromineral. $A$ concentração de cálcio total e ionizado aumentou com a diminuição do BCAD para níveis de -160 e $-40 \mathrm{mEq} / \mathrm{kg}$ de $\mathrm{MS}$, a partir do $15^{\circ}$ dia. 


\section{REFERÊNCIAS BIBLIOGRÁFICAS}

AROEIRA, L.J.M. Distúrbios metabólicos de vacas de alta produção. In: MINI SIMPÓSIO DO COLÉGIO BRASILEIRO DE NUTRIÇÃO ANIMAL, Valinhos, 1993. Anais. p. 51-70.

ASSOCIATION OF OFFICIAL ANALYTICAL CHEMISTS. Official methods of analysis. 15. ed. Arlington: AOAC, 1990. $1298 \mathrm{p}$.

BEIGHLE, D.E.; BOYAZOGLU, P.A.; HEMKEN, R.W. Acute effects of anionic diet on bone mineral homeostasis in the bovine. Journal of the South African Veterinary Association., v. 68, n. 3, p. 73-77, 1997.

BEIGHLE, D.E.; BOYAZOGLU, P.A.; HEMKEN, R.W..Short-term effects of dietary cation-anion balance on bone mineral homeostasis in the bovine. Journal of the South African Veterinary Association. v.66, n.2, p.5660,1995 .

BLOCK, E. Manipulating dietary anions and cations for prepartum dairy cows to reduce incidence of milk fever. J. Dairy Sci., Champaingn, v. 67, n. 12, p. 2939-2948, 1984.

BLOCK, E. Manipulation of dietary cation-anion difference on nutritionally reted production diseases, productivity, and metabolic responses of dairy cows. J. Dairy Sci., Champaingn, v. 77, n. 5, p. 1437-1450, 1994.

BYERS, D.I. Management considerations for successful use of anionic salts in dry-cow diets. Compend. Contin. Educ. Pract. Vet., v. 16, n. 1-3, p. 237-242, 1994.

CAMPOS, J. M. S. Balanço dietético cátion-ânion na alimentação de vacas leiteiras, no período pré-parto. Belo Horizonte: UFMG, 1998. 103 p.

CUNNINGHAM, J.G. Tratado de fisiologia veterinária. Rio de Janeiro: Guanabara, 1999. 454 p.

DAVENPORT, H. W. ABC da Química Ácido-Basica do Sangue. São Paulo: Ateneu, 1973. $127 \mathrm{p}$.

DEL CLARO, G.R.; ZANETTI M.A.; SALLES, M.S.V. Influência da dieta aniônica no balanço macromineral em novilhos holandeses. Arq. Med. Vet. Zootec, v.74,n.3, p.281-283, 2002. 
DELAQUIS, A.M.; BLOCK, E. Acid-base satatus, renal function, water, and macromineral metabolism of dry cows. J. Dairy Sci., Champaingn, v. 78, n. 4, p. 604-619, 1995.

DEN HARTOG, L. A.; MORS, R. A. .B.; VERSTEGEN, M. W. A.; VAN GILS, G. M. J. Anim. Physiol. Anim. Nutr., v. 63, p. 173-179, 1990.

DOUGLAS, C.R. Tratado de fisiologia aplicada a saúde. São Paulo:Robe editorial, 2002a. $1582 \mathrm{p}$.

DOUGLAS, C.R. Tratado de fisiologia aplicada a nutrição. São Paulo:Robe editorial, 2002b. $1046 \mathrm{p}$.

ERDMAN, R. Dietary buffers and anion-cation balance in relation to acid-base satus, feeed intake milk composition in dairy cow. Acta Vet. Scand. v.89, p.8391, 1993.

ERWIN, E.S.; MARCO, G.J; EMERY, E.M. Volatile fatty acid analyses of blood and rumen fluid by gas chromatography. J. Dairy Sci. Champaingn, v. 44, n. 9, p. 1768-1771, 1961.

FAUCHON, C.; SEOANE, J. R.; BERNIER, J. F. Effects of dietary cation-anion concentrations on performance and acid-base balance in growing lambs. Can. J. Anim. Sci. v.75, p.145-151, 1995.

FISHE, C.M.; SUBBAROW, Y. The colorimetric determination of phosphorus. J. Biol. Chem. Baltimore, v.66, n. 2, p. 375-400, 1925.

FORBES, J. M. Voluntary Food Intake and Diet Selection in Farm Animals. Wallingford: CAB INTERNATIONAL, 1995. $532 \mathrm{p}$.

FRANCE, J.; SIDDONS, R.C.; DHANONA, M.S. Adaptation of compartmental schemes of interpreting isotope dilution data on volatile fatty acid metabolism in the rumen to the non-steady state and for single-dose injection. J. Theor. Biol. v.153, p.247-254, 1991.

FREDEEN, A.; DEPETERS, E.J.; BALDWIN, R.L. Characterization of acid base disturbances and effects on calcium and phosphorus balances of dietary fixed ions in pregnant or lactating does. J. Anim. Sci., Champaign, v. 66, p. 159-173, 1988a. 
FREDEEN, A.; DEPETERS, E.J.; BALDWIN, R.L. Effects of acid-base disturbances caused by differences in dietary fixed ion balance on kinects of calcium metabolism in ruminants with high calcium demand. J. Anim. Sci. Champaign, v. 66, p. 174-184, 1988b.

FULLMER, C.S. Intestinal calcium absorption: calcium entry. J. Nutri. Philadelphia, v. 122, p. 644-650, 1992.

GAYNOR, P.J.; MUELLER, F.J.; MILLER, J.K.; RAMSEY, N.; GOFF, J.P.; HORST, L..R. Parturient Hypocalcemia in Jersey Cows Fed Alfaffa HaylageBased Diets with different Cation to anion Ratios. J. Dairy Sci. Champaingn, v. 72, p. 2525-2531, 1989.

GHORBANI, G.R.; JACKSON, J.A.; HEMKEN, R.W. Effects of sodium bicarbonate and sodium sesquicarbonate on animal performance, ruminal metabolism, and systemic acid-base status. J. Dairy Sci.v.92, n.8, p. 20392045, 1989.

GOFF, J.P.; HORST, R.L . Effects of addition of potassium or sodium, but not calcium, to prepartum rations on milk fever in dairy cows. J. Dairy Sci. Champaingn, v. 80, n.1, p. 176-186, 1997.

GOFF, J.P.; HORST, R.L.; LITTLEDIKE, E. T.; BORIS, A.; USKOKIVIC, M.R. Bone resorption renal function, and mineral status in cows treated with 1,25dihydroxycholecalciferol and its 24-fluoro analogues. J. Nutri. Philadelphia, v. 116, p. 1500-1510, 1986.

GOFF, J.P.; HORST, R.L.; LITTLEDIKE, E.T.; BEITZ, C.D. Use of 24-F-1,25dihydroxyviatmin D3 to prevent parturient paresis in dairy cows. J. Dairy Sci. Champaingn, v. 71, n. 5, p. 1211-1219, 1988.

GOFF, J.P.; HORST, R.L.; MUELLER, F.J.; MILLER, J.K.; KIESS, G.A.; DOWLEN, H.H. Addition of choride to a prepartal diet hight in cations increases 1,25-dihydroxyvitamin d response to hypocalcemia preventing milk fever. J. Dairy Sci. Champaingn, v. 74, n. 11, p. 3863-3871, 1991.

GOLZ, D.I.; CRENSHAW, T.D. The effect of dietary potassium and chloride on cation-anion balance in swine. J. Dairy Sci.v.69, p. 2504-2515, 1991.

GOMIDE, C. A. Influência de diferentes relações cátion-aniônicas sobre o balanço de minerais em ovinos. São Paulo, 1996. 77 p. Tese (Doutorado) Faculdade de Ciências Farmacêuticas, Universidade de São Paulo.

GURTLER, H.; KETZ, A.; KOLB, E.; SCHRODER, L.; SEIDEL, H. Fisiologia Veterinária. 4.ed. Rio de Janeiro: Guanabara Koogan, 1987. 612p. 
GUYTON, A .C. Tratado de fisiologia médica. 6. ed. Rio de Janeiro: Guanabara Koogan, 1988. 799 p.

HORST, L.R., GOFF, J.P., REINHARDT, T.A. et al. Strategies for preventing milk fever in dairy cattle. J. Dairy Sci., v.80: 1269-1280,1997.

HORST, R.L.; GOFF, J. P.; REINHARDT, T.A. Calcium and vitamin D metabolism in the dairy cow. J. Dairy Sci., Champaingn, v. 77, p. 1936-1951, 1994.

JACKSON, J. A., HEMKEN, R.W.. Calcium and cation-anion balance effects on feed intake, body weight gain, and humoral response of dairy calves. J. Dairy Sci. v. 77 p.1430-1436,1994.

JACKSON, J.A., AKAY, V., FRANKLIN, S.T., AARON, D.K. The effect of cation-anion differnce on calcium requeriment, feed intake, body weight gain, and blood gassas and mineral concentration of dairy calves. J. Dairy Sci., Champaingn, v. 84, p.147-153, 2001

JACKSON, J.A., HOPKINS, D.M.; XIN, Z.; HEMKEN, R.W. Influence of cationanion balance on feed intake, body weight gain, and humoral response of dairy calves. J. Dairy Sci., Champaingn, v. 75, n. 5, p. 1281-1286, 1992.

JOYCE, P.W.,SANCHEZ, W.K., GOFF, J.P. Effect of anionic salts in prepartum diets based on alfafa. J. Dairy Sci., Champaingn, v. 80, n.11, p. 2866-2875, 1997.

KAUFMANN, W. Influence of the composition of the ration and the feeding frequency on $\mathrm{pH}$-regulation in the rumen and feed intake in ruminants.

Livestock Production Science. v.3, p.103-114, 1976.

KIM, H.S.; YOON, S.; KWEON, U.; PARK, S.; KIM, J.; JEONG, YH. Effect of dietary ion balance on blood, urinary metabolites DM intake and gain of growing Holstein cattle. J. Dairy Sci., Champaingn, v. 19, n. 2, p. 96-104, 1997a.

KIM, H.S.; YUN, S.K.; KWEON, U.K.; PARK, S.B.; HA, J.K. Effect of dietary ion balance(DIB) on blood and urinary, $\mathrm{Ca}$ and parathyroid hormone concentration in dry cows. J. of Livestock Science. v. 39, n. 2, p. 25-33, 1997b.

LECLERC, H.; BLOCK, E. Effects of reducing dietary cation-anion balance prepartum dairy cows with specific refernce to hypocalm parturient paresis.

Can. J. Anim. Sci., v. 69, p. 411-423, 1989. 
LINCOLN, S.D.; LANE, V.M. Serum ionized calcium concentration in clinically normal dairy cattle, and changes associated with calcium abnormalities. Javma, v. 197, n. 11, p. 1471-1474, 1990.

LITTLEDIKE, E.T.; HORST, R.L. Vitamin $\mathrm{D}_{3}$ toxicity in dairy cows. J. Dairy Sci., 65,p.749-755, 1982.

LOMBA, F.; CHAUVAUX, G.; TELLER, E.; LENGELE, L.; BIENFET, V. Calcium digestibiliy in cows as influenced by ecess of alkaline ions over stable acid in their diets. Br. J. Nutri., v. 39, p. 425-429, 1978.

McDOWELL, L.R. Minerals in Animal and Human Nutrition. Academic Press. New York. 1992.

MILES, R.; BUTCHER, G. Equilíbrio ácido-base I : princípios básicos. Industria avícola, p. 21-24, fev., 1993a.

MILES, R.; BUTCHER, G. Equilibrio ácido-base II: La regulación del equilibrio. Industria Avicola. p.8-12. 1993b.

MONGIN, P. Recent advances in dietary anion-cation balance: applications in poultry. Pro. Nutr. Soc., Cambridge, v. 40, n. 3, p. 285-295, 1981.

MOORE, S.J.; VANDEHAAR, M.J.; SHARMA, B.K.; PILBEAM, T.E. et al. Effects of altering dietary cation-anion difference on calcium and energy metabolism in peripartum cows. J. Dairy Sci. n.83 p.2095-2104, 2000.

NATIONAL RESEARCH COUNCIL. Nutrient Requeriment of Sheep. Washington, D.C., National Academy of Sciences, 1985.

OETZEL, G.R., BARMORE, J.A. Intake of concentrade mixture containing various anionic salts fed to pregnant, nonlactating dairy cows. J. Dairy Sci., Champaingn, v. 76, p. 1617-1623, 1993.

OETZEL, G.R.; FETTMAN, M.J.; HAMAR, D.W.; OLSON, J.D. Screening of anionic salts for palatability, effects on acid-base satatus, ad urinary calcium excretion in dairy cows. J. Dairy Sci., Champaingn, v. 74, n. 3, p. 965-971, 1991.

OETZEL, G.R.; OLSON, J.D.; CURTIS, C.R.; FETTMAN, M.J. Ammonium chloride and ammonium sulfate for prevention of paturient paresis in dairu cows. J. Dairy Sci., Champaingn, v. 71, n. 12, p. 3302-3309, 1988.

OLSON, J. D. Relationship of nutrition to abomasal displacement and parturient paresis. Nutrition Abstract and Reviews, v. 63, p. 277, 1993. 
ORSKOV E.R., RYLE, M. Energy nutrition in ruminants. New York: Elsevier Applied Science 1990. 149 p.

OWENS, F.N.; SECRIST, D.S.; HILL, W.J.; GILL, D.R. Acidosis in cattle: a review. J. Anim. Sci, Champaign, v. 75, n. 3, p. 727-735, 1998.

PATIENCE, J. F. 1991. Acid-base balance in animal nutrition. In: CONTINUING EDUCATION CONFERENCE, Harris Ranch: ARPAS, p. 1-41, 1991.

PATIENCE, J. F.; AUSTIC, R. E.; BOYD, R. D. Effect of dietary electrolyte balance on growth and acid-base status in swine. J. Anim. Sci, Champaign, v. 64, p. 457-466, 1987.

PEHRSON, B.; SVENSSON, C.; GRUVAEUS, I.; VIRKKI, M. J. Dairy Sci. 82:1310-1316, 1999.

RAMBERG JUNIOR, C.J.; JOHNSON, E.K.; FARGO, R.D.; KRONFELD, D.S. Calcium homeostasis in cows, with special refernce to hypocalcemia. Am. J. Physiol., v. 246, p. 698-704, 1984.

ROBY, K. A..W.;CHALUPA, W., ORSINI, J.A, ELSER, A.H., KRONFELD, D. S. Acid-Base and eklectrolyte in dairy heifres fed forage and concentrade rations: effects of sodium bicarbonate. Am. J. Vet Res. 48: p.1012-1016, 1987

ROSS, J. G.; SPEARS, J. W.; GARLICH, J. D. Dietary Electrolyte Balance Effects on Performance and Metabolic Characteristicas in Growing Steers. J. Anim. Sci. Champaign, v. 72, p.1842-1848, 1994a.

ROSS, J. G.; SPEARS, J. W.; GARLICH, J. D. Dietary Electrolyte Balance Effects on Performance and Metabolic Characteristicas in Finisihing Steers. $\mathbf{J}$. Anim. Sci. Champaign, v. 72, p.1600-1607, 1994b.

RUDE, B.J.; RANKINS, D.L. Mineral status in beef cows fed broiler litter diets with cation-anion differnces or suplemented with hay. J. Anim. Sci, Champaign, v. 75, n. 3, p. 727-735, 1997.

RUSSELL, J.B.; CHOW, J.M. Another theory for the action of ruminal buffers salts: decreased fermentation and propionate production. J. Dairy Sci., v. 76, p. 826-830, 1993.

SANCHEZ, J.M. Dietary cation-anion balance in dairy cattle nutrition. Nutricion Animal Tropical, v. 2, p. 3-29, 1995. 
SANCHEZ, W.K., BLAUWIEKEL, R. Prevention of milk fever byappliaction of dietary cation-anion balance concept. Nutrition Abstracts and Reviews, v.65, p.147, 1995.

SAS Institute Inc., SAS Stat Guide, Release 6.03 Edition. Cary, NC: SAS Institute Inc., 1988. 1028p.

SCHONEWILLE, J.T.; KLOOSTER, A.T.; WOUTERSE, H.; BEYNEN, A.C. Hipocalcemia induced by intravenous Administration of disodium ethylenediaminotetraacetate and its effects on excretion of calcium in urine of cows. J. Dairy Sci. v. 82 p.1317-1324 1999.

SCHONEWILLE, J.T.; VAN'T KLOOSTER, A.T.; DIRKZWAGER, A.; BEYNEN, A.C. Stimulatory effect of anion (chloride) rich ration on apparent calcium absorption in dairy cows. Livestock Production Science, v. 40, p. 233-240, 1994.

SETTI, M.C. Influência do balanço cátion-aniônico da dieta no desempenho de vacas Holandesas. Pirassununga, 1996. 74 p. Dissertação (Mestrado) - Faculdade de Zootecnia e Engenharia de Alimentos, USP.

SETTI, M.C. Parâmetros metabólicos e balanço cátion-aniônico da dieta (BCAD) para vacas da raça Holandesa. Jaboticabal, 2001. 209p. Tese(Doutorado) - Faculdade de Ciências Agrárias e Veterinárias. UNESP.

SPANGHERO, M. Urinary $\mathrm{pH}$ and mineral excretion of cows fed four different forages supplemented with increasing levels of anionic compound feed. Animal Feed Science and Technology, v.98, p.153-165, 2002.

STEWART, P.A. modern quantitative acid-base chemistry. An J. Physiol. Pharm., v.61, p.1444-1461, 1983.

SWENSON, M.J. Dukes fisiologia dos animais domésticos. 10. ed. Rio de Janeiro: Guanabara, 1984. 799 p.

TAKAGI, H.; BLOCK, E. Effects of manipulating dietary cation-anion balance on macromineral balance in sheep. J. Dairy Sci., Champaingn, v. 74, n. 12, p. 4202-4214, 1991a.

TAKAGI, H.; BLOCK, E. Effects of various dietary cation-anion balances on response to experimentally induced hypocalcemia in sheep. J. Dairy Sci., Champaingn, v. 74, p. 4215-4224, 1991 b.

TANOR, M.A. Feeding high producing dairy cows during the dry period and hipocalcemia. Veteriner Bilimleri Dergisi, v. 14, n. 2, p. 57-61, 1998. 
TAURIAINEN, S.; SANKARI, S.; PYORALA, S.; QVIST, L. Effect of anionicc salts in concentrate mixture and calcium intake on some blood and urine minerals, acid-base balance and feed intake of dry pregnant cows on grass silage based feeding. Agricultural and food Science in Finland, v. 7,n. 5, p. 523-533, 1998a.

TAURIAINEN, S.; SANKARI, S.; PYORALA, S.; QVIST, L. Effect of anionicc salts in concentrate mixture and magnesium intake on some urine minerals, acid-base balance of dry pregnant cows on grass silage based feeding.

Agricultural and food Science in Finland, v. 7,n. 5, p. 535-543, 1998b.

TAURIAINEN, S.; SANKARI, S.; PYORALA, S.; QVIST, L. Effect of anionicc salts and potassium intake on some blood urine minerals and acid-base balance of dry pregnant cows on grass silage based feeding. Journal of Animal and feed Science, v. 10,n. 1, p.57-71,2001.

THILSING HANSEN, T. JORGENSEN, R.J. OSTERGAARD, S. Milk fever control principles: A review. Acta Veterinaria Scandinavica v. 43,n. 1, p. 1-19, 2002.

TUCKER, W.B.; HOGUE, J.F. ADAMS, G.D. Influence of dietary cation-anion balance during the dry period on the occurrence of paresis in cows fed excess calcium. J. anim. Sci., Champaingn, v. 70, p. 1238-1250, 1992.

TUCKER, W.B.; HOGUE, J.F.; ASLAM, M.; LEMA, M.; RUYET, P.; SHIN, I.S; KOEVERNING, M. T.; VERNON, R.K; ADAMS, G.D. Controlled ruminal infusion of sodium bicarbonate. 3. Influence of infusion dose on systemic acidbase status, minerals, and ruminal milieu. J. Dairy Sci., v.76, p. 2222-2234, 1993.

TUCKER, W.B.; HOGUE, J.F.; WATERMAN, D. F.; SWENSON, T.S.; XIN, Z.; HEMKEN, R.W.; JACKSON, J.A.; ADAMS, G.D.; SPICER, L.J. Role of sulfur and chloride in dietary cation-anion balance equation for lactating dairy cattle. J. Dairy Sci., Champaingn, v. 69, n. 3, p. 1205-1213, 1991.

TUCKER, W.B.; SHIN, I.S; HOGUE, J.F.; ASLAM, M.; ADAMS, G.D.; VAN KOEVERNING, M. T.; VERNON, R.K; CUMMINGS, K.R. Natural sodium sesquicarbonate fed for na entire lactation: influence on performance and acidbase status of dairy cows. J. Dairy Sci., Champaingn, v. 77, n.10, p.531-537, 1994. 
TUCKER, W.B.; XIN, Z.; HEMKEN, R.W. Influence of dietary calcium choride on adaptative changes in acid-base satatus and mineralmetabolism in lactation dairy cows fed a diet hight in sodium bicarbonate. J. Dairy Sci., Champaingn, v. 71, n. 6, p. 1587-1597, 1988.

VAGNONI, D. B.; OETZEL, G.R. Effects of dietary cation-anion differnce on the acid-base status of dry cows. J. Dairy Sci., Champaingn, v.81,p. 16431652, 1998.

VAN SOEST, P.J. Nutricional ecology of the Ruminant. New York: Cornell University Press, 1994. 476p.

VANMOSEL,M., VAN'T KLOOSTER, A., VAN MOUSEL, F. Effectts of reducing dietary cation-anion balance on rate of calcium mobilization by dairy cows at parturition. Research in Veterinary Science, v.54, p.1-9, 1993.

WALKER, R.G.; CARTER, R.R.; MCGUIGAN, K.R.; KNIGHT, R.L.; SILVER, B.A. The effect of altering the cation-anion balance of the pre-calving diet of dairy cows on post-calving milk production and health. BIENNIAL IN CONFERENCE, 22., University of New England, Armidale, New South Wales, Australia, 20-24 April, 1998.

WANG, C.; BEEDE, D.K. Effects of ammonium chloride and sulfate on acid base status and calcium of dry jersey cows. J. Dairy Sci., Champaingn, v. 75, n. 3, p. 820-828, 1992.

WANG, C.; BEEDE, D.K.; DONOVAN, G.A.; ARCHBALD, L.F.; DELORENZO, M.A.; SANCHEZ, W. K. Effects of dietary negative cation-anion difference and hight calcium content prepartum on calcium metabolism, health, lactacional, and reprodutive performance of holstein cows. J. Dairy Sci., Champaingn, v. 74, p. 225, 1991.

WEST, J.W.; COPPOCK, C.E.; NAVE, D.H.; LABORE, J.M.; GRENEE, L.W. Effects of potassium carbonate and sodium bicarbonate on rumen function in lactating Holstein cows. J. Dairy Sci., v.70, p. 81-87, 1987.

WEST, J.W.; HAYDON, K.D.; MULLINIX, B.G.; SANDIFER, T.G. Dietary cation-anion balance and acid-base status of heat-stressed cows. J. Dairy Sci., v.75, p. 2776-2786, 1992.

WHEELER, W.E. Gastrointestinal tract pH environment and the influence of buffering materials on the performance of ruminants. J. anim. Sci., Champaingn, v. 51, n. 1, p. 224-232, 1980. 
WILSON, K. L.; MIN, S.H.; REVELL, D.K.; LEE, J.; MACKENZIE, D.D.S.; COTTAM, Y.H.; DAVIS, S.R. The effects of a cation-anion balanced diet on calcium and phosphorus metabolism in growing lambs. Proceedings of the New Zealand Society of Animal Production, v. 58, p. 192-194, 1998. 